\begin{abstract}
Title of Document:

Planning for Integration of Wind Power Capacity in Power Generation Using Stochastic Optimization

Written By:

Yashar Aliari Kardehdeh, 2013

Directed By:

Professor Ali Haghani

Department of Civil and Environmental Engineering
\end{abstract}

The demand for energy is constantly rising in the world while most of the conventional sources of energy are getting more scarce and expensive. Additionally, environmental issues such as dealing with excessive greenhouse gas emissions (especially $\mathrm{CO} 2$ ) impose further constraints on energy industry all over the globe. Therefore, there is an increasing need for the energy sector to raise the share of clean and renewable sources of energy in power generation. Wind power has specifically attracted large scale investment in recent years since it is ample, widely distributed and has minimal environmental impact.

Wind flow and consequently wind-generated power have a stochastic nature. Therefore, wind power should be used in combination with more reliable and fuelbased power generation methods. As a result, it is important to investigate how much capacity from each source of energy should be installed in order to meet electricity demand at the desired reliability level while considering cost and environmental 
implications. For this purpose, a probabilistic optimization model is proposed where demand and wind power generation are both assumed stochastic.

The stochastic model uses a combination of recourse and chance-constrained approaches and is capable of assigning optimal production levels for different sources of energy while considering the possibility of importation, exportation and storage of electricity in the network. 


\title{
PLANNING FOR INTEGRATION OF WIND POWER CAPACITY IN POWER GENERATION USING STOCHASTIC OPTIMIZATION
}

\author{
By \\ Yashar Aliari Kardehdeh \\ Dissertation submitted to the Faculty of the Graduate School of the \\ University of Maryland, College Park, in partial fulfillment \\ of the requirements for the degree of \\ Doctor of Philosophy \\ 2013
}

Advisory Committee:

Dr. Ali Haghani, Chair

Dr. Michael O. Ball

Dr. Qingbin Cui

Dr. Jeffrey W. Herrmann

Dr. Alireza Khaligh 
(C) Copyright by

Yashar Aliari Kardehdeh

2013 
Table of Contents

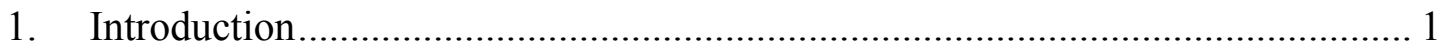

1.1. Demand for Energy in the World .................................................... 1

1.2. Non-fossil Energy Sources ...................................................................... 3

1.3. Renewable Energy ............................................................................. 5

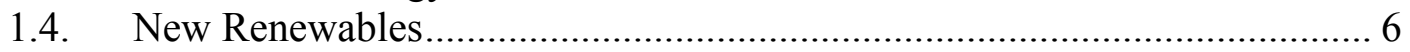

1.5. Wind Power .................................................................................... 8

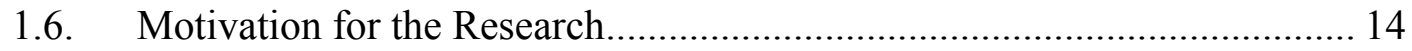

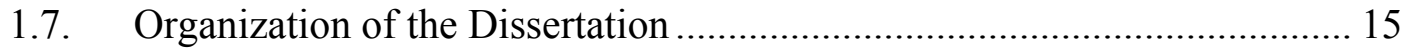

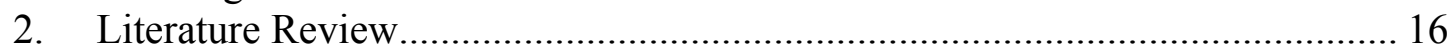

2.1. Review of research on wind power reliability and capacity credit ............ 16

2.2. Potential Contribution Area ................................................................... 29

3. Model Assumptions and Theoretical Background........................................... 31

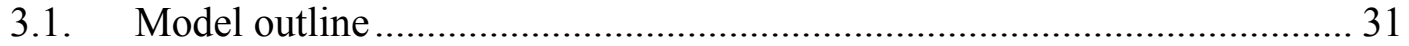

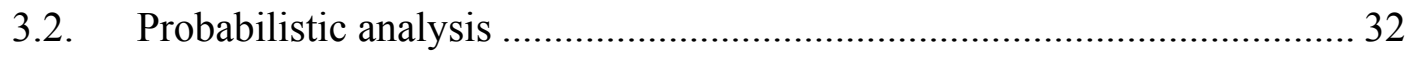

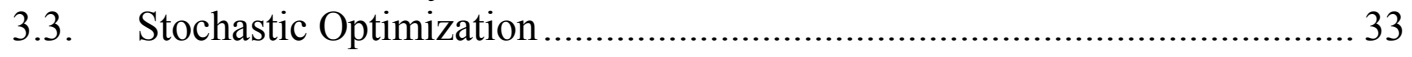

3.3.1. The Recourse Method ................................................................. 33

3.3.2. The Chance Constrained Programming Method............................... 35

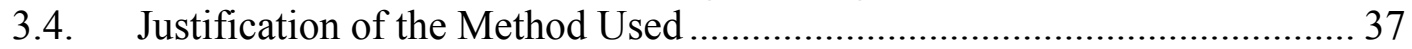

3.5. Wind Energy and Wind Generated Power............................................. 38

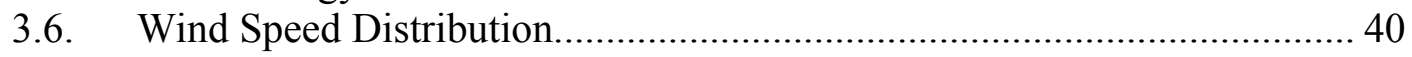

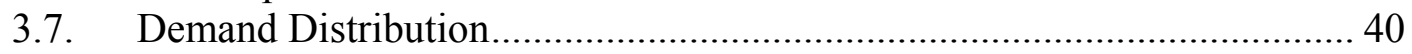

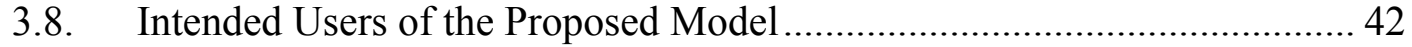

3.8.1. Regulated Market........................................................................... 42

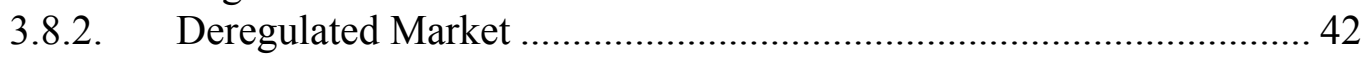

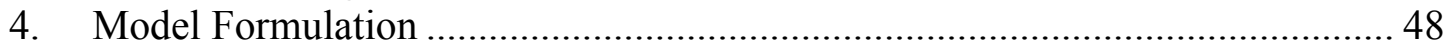

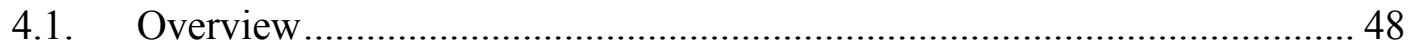

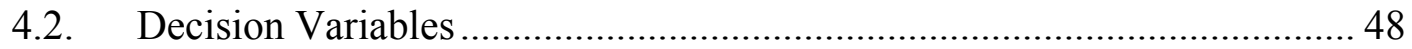

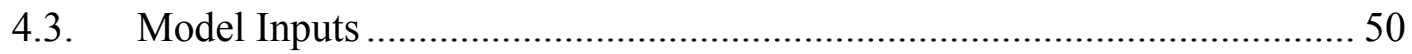

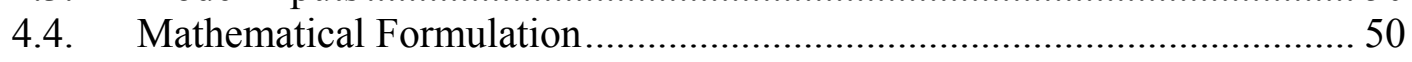

4.4.1. Objective Function.................................................................... 51

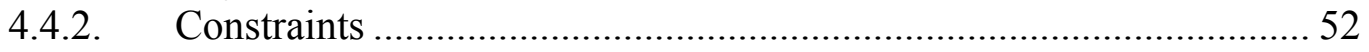

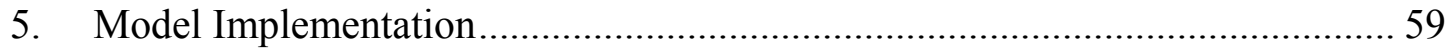

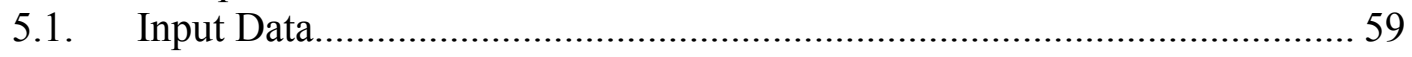

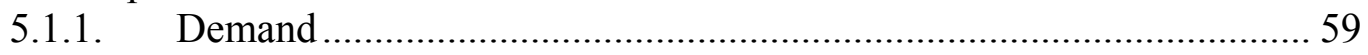

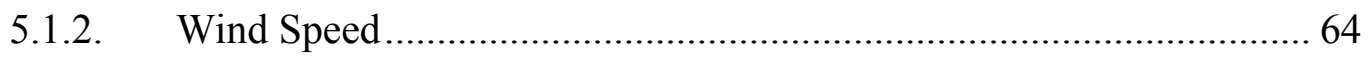

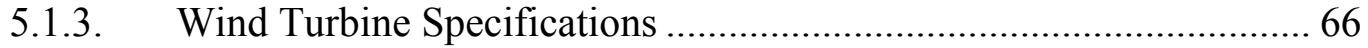

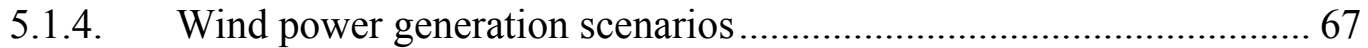

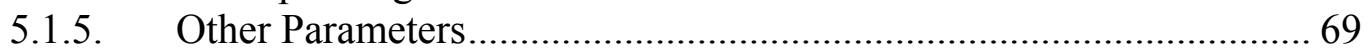

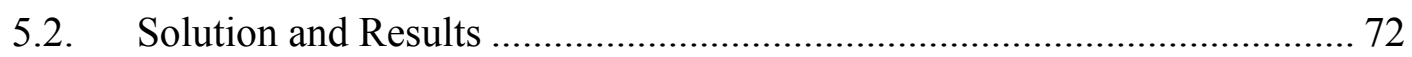

5.2.1. Transforming the Chance Constraint ........................................... 72

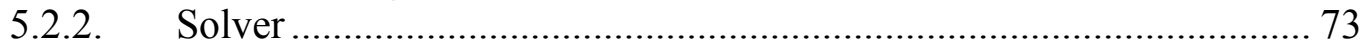

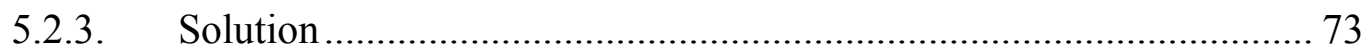




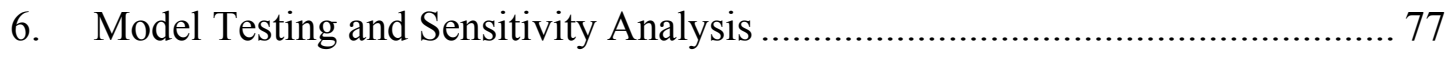

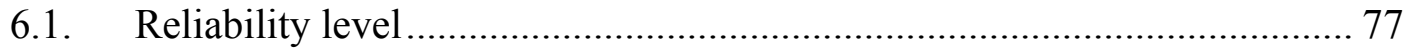

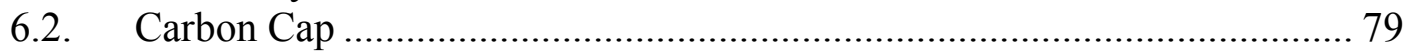

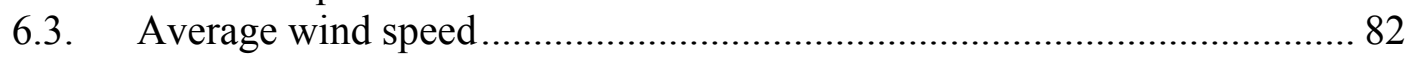

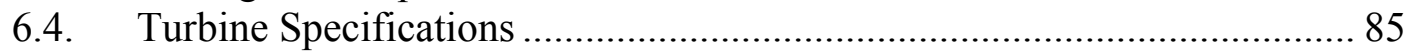

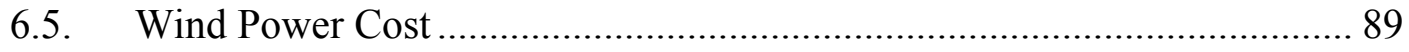

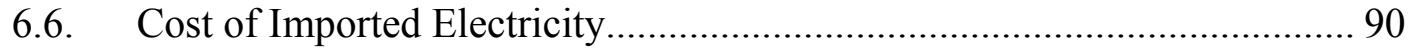

6.7. Price of Exported Electricity........................................................... 92

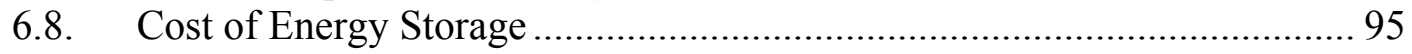

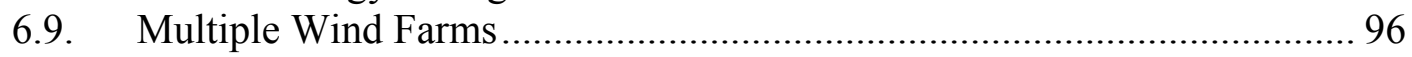

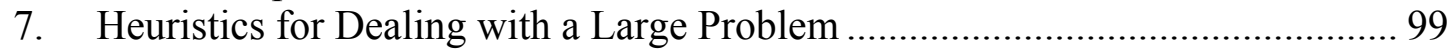

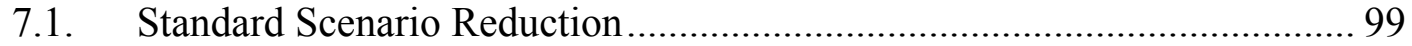

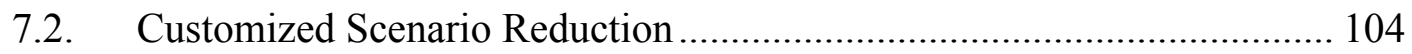

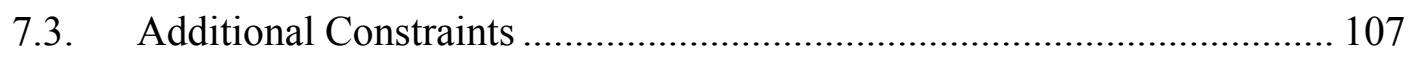

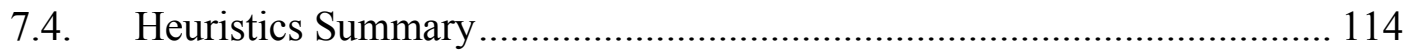

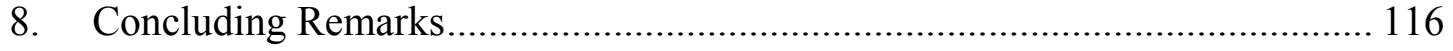

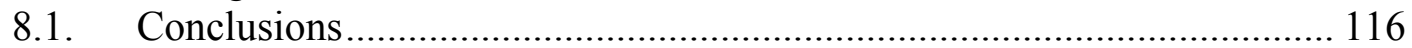

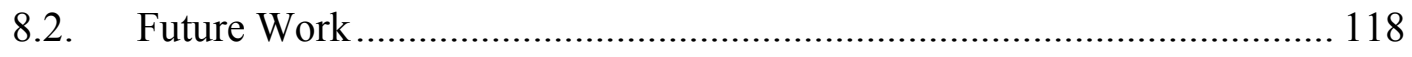

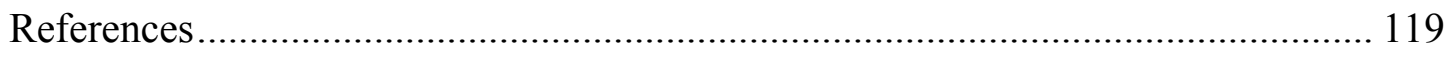


List of Tables

Table 1- U.S. average levelized costs (2010 \$/MWh) for Plants Entering Service in

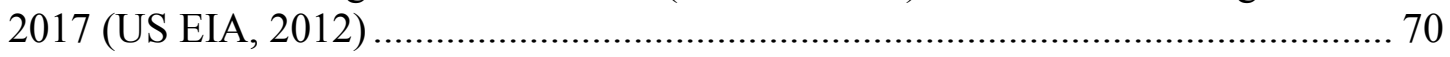

Table 2- Basic case solution considering varying number of scenarios .................... 74

Table 3- Solution for the base case without wind power........................................ 76

Table 4- Sensitivity analysis with respect to reliability level ................................ 77

Table 5- Sensitivity analysis with respect to carbon cap limit................................. 79

Table 6- Sensitivity analysis on carbon emission limit with wind power capacity

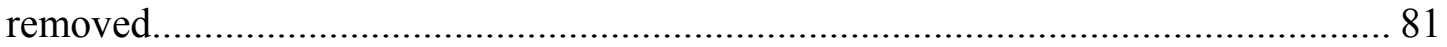

Table 7- Solutions for varied values of average wind speed ................................ 83

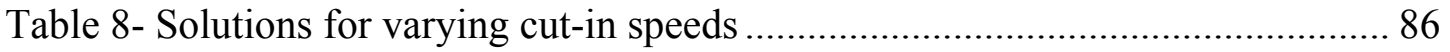

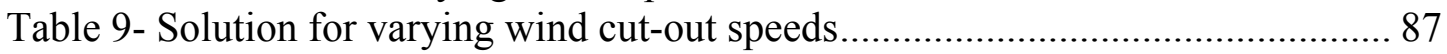

Table 10- Model solution for varying rated wind speed........................................ 88

Table 11- Sensitivity analysis with respect to the unit cost of wind power............... 89

Table 12- Sensitivity analysis with respect to imported energy cost....................... 92

Table 13- Model solution for varying prices of exported power .............................. 93

Table 14- Model solution for varying energy storage costs .................................... 95

Table 15- Model solution for multiple wind farms............................................... 97

Table 16- Multiple wind farm impact with recourse ............................................... 98

Table 17- Power production rate and probabilities considering ten scenarios ......... 100

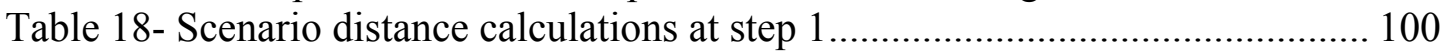

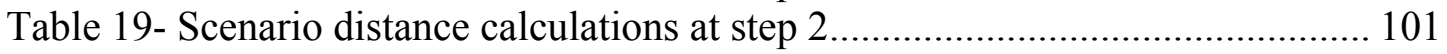

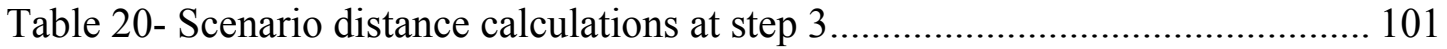

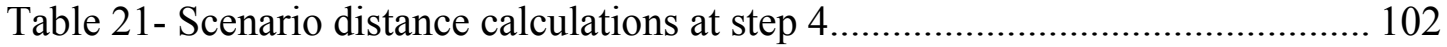

Table 22- Probability redistribution for three selected scenarios ............................ 102

Table 23- Probability redistribution for four selected scenarios.............................. 103

Table 24- Model solution for three and four selected scenarios ............................. 103

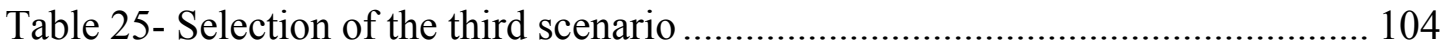

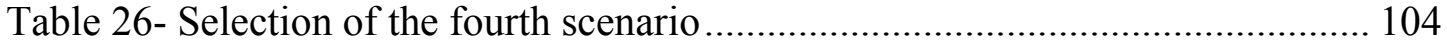

Table 27- Reduced set for three scenarios using standard redistribution (set 3-1) ... 105

Table 28- Reduced set for three scenarios using modified redistribution (set 3-2).. 105

Table 29- Reduced set for four scenarios using standard redistribution (set 4-1) .... 105

Table 30- Reduced set for four scenarios using modified redistribution (set 4-2) ... 105

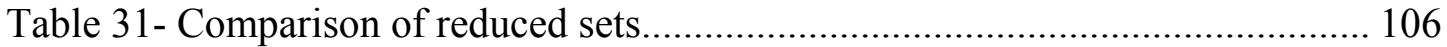

Table 32- Solution for ten wind farms with no recourse ....................................... 106

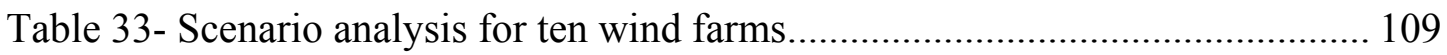

Table 34- Solution for different threshold values ................................................ 113

Table 35- Comparison of original solution with heuristics for four wind farms ...... 114 
List of Figures

Figure 1- World energy consumption in terawatts for 1965-2005 (Graph by Frank

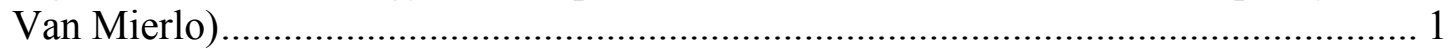

Figure 2- US energy consumption by source and sector (USEIA, 2011) ..................... 2

Figure 3- Global fossil carbon emissions (Marland, 2007) ........................................ 3

Figure 4- Sources of energy production in the world in 2005 (Omegatron, 2007) ...... 4

Figure 5- Schematic layout of a hydroelectric dam (Bonsor, 2001) ............................ 6

Figure 6- Schematic view of a geothermal power plant (U.S. DOE, 2012) ................. 7

Figure 7- A concentrated solar thermal system (U.S. DOE, 2011) ............................ 7

Figure 8- Wind power generator layout (California Energy Commission, 2012) ........ 8

Figure 9- Schematic of a pumped storage hydroelectric power plant (BBC, 2013)... 11

Figure 10- Annual average wind speed at $80 \mathrm{~m}$ across the North America (Archer \&

Jacobson, Evaluation of global wind power, 2005)...

Figure 11- Monthly power generation for a 10kW wind turbine (Lu, Yang, \& Burnett, 2002) 16

Figure 12- LOLE graphs for the system before and after addition of WPGs (Giorsetto \& Utsurogi, 1983) 18 Figure 13- LOLE vs. load curve for different wind power penetration levels (Dialynas \& Machias, Dialynas, E. N., and A. V. Machias. "Reliability modelling interactive techniques of power systems including wind generating units." Electrical Engineering (Archiv fur Elektrotechnik) 72, no. 1 (1989): 33-41., 1989).

Figure 14- LOLE \& LOHE forecast over a ten year period (Billinton \& Karki, 2001)

20

Figure 15- LOLE variation with increased wind power capacity (Karki, Wind power in power generation planning, 2004) ...................................................................... 21 Figure 16- Effect of integration of multiple independent wind farms in the system (Karki, Wind power in power generation planning, 2004). 22

Figure 17- Early saturation of reliability benefits with increased WPG capacity (Billinton \& Bai, 2004).... 22

Figure 18- Positive effect of multiple independent wind farms on reliability (Billinton \& Bai, 2004). 23

Figure 19- WUE declining with increased number of turbines (Karki \& Billinton, Cost-Effective Wind Energy Utilization for Reliable Power Supply, 2004)............. 24 Figure 20- Parametric wind speed model (Karki, Hu, \& Billinton, A Simplified Wind Power Generation Model for Reliability Evaluation, 2006) ...................................... 25 Figure 21- Power generation curve for a wind turbine (Karki, Hu, \& Billinton, A Simplified Wind Power Generation Model for Reliability Evaluation, 2006) ........... 26 Figure 22- The simplified six step wind speed model (Karki, Hu, \& Billinton, A Simplified Wind Power Generation Model for Reliability Evaluation, 2006) ........... 26 Figure 23- Comparison of different wind speed models (Karki, Hu, \& Billinton, A Simplified Wind Power Generation Model for Reliability Evaluation, 2006) ........... 27 Figure 24- Effect of distribution of wind turbines in multiple sites (American Solar Energy Society, 2007). 28 
Figure 25- Power curve for a practical turbine (PelaFlow Consulting)..................... 39

Figure 26- Electricity market (Conejo, Carrion, \& Morales, 2010) .......................... 45

Figure 27- U.S. electricity production by source (U.S. Energy Information

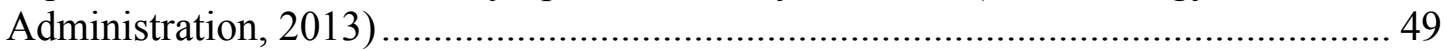

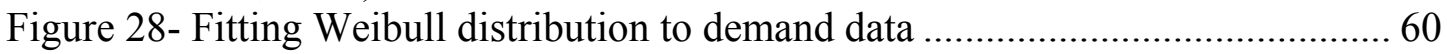

Figure 29- Cumulative distribution function for fitted curve and input data............. 61

Figure 30- Annual average wind speeds at $80 \mathrm{~m}$ across the US (NREL, 2012)........ 64

Figure 31- Annual average offshore wind speeds at 90m for US (NREL, 2012)...... 65

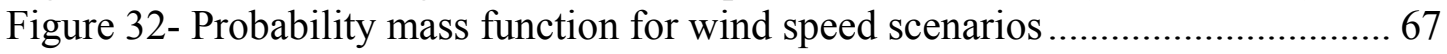

Figure 33- Cost increase at higher reliability levels ......................................... 78

Figure $34-$ Wind power capacity variations as a function of reliability .................... 78

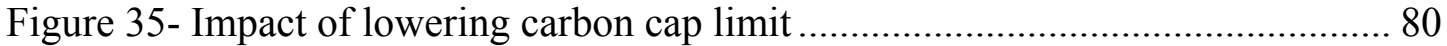

Figure 36- Extended observation of carbon cap impact on wind power capacity and

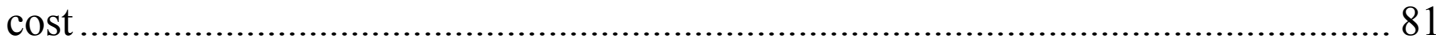

Figure 37- Variation of wind power capacity utilization with average wind speed ... 83

Figure 38- Wind power capacity variation with respect to cut-in speed ................... 86

Figure 39- Impact of rated wind speed on wind power capacity ............................. 88

Figure 40- Variation of total cost and wind power utilization with unit cost of wind

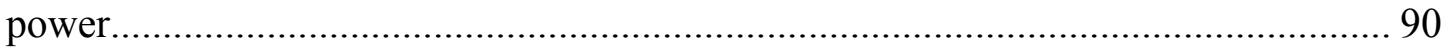

Figure 41- Effect of variations in imported power price ...................................... 92

Figure 42- Impact of exported energy price on wind power capacity ....................... 93

Figure 43- Impact of power storage costs on wind power capacity ...........................96

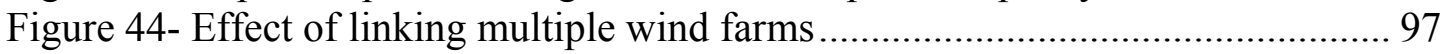

Figure 45- Impact of multiple wind farms with recourse ..................................... 98

Figure 46- Cumulative distribution function for wind generated power .................. 111 


\section{Introduction}

\section{1. $\quad$ Demand for Energy in the World}

According to recent studies, population of the world has more than tripled in the past century (UN, 2009). The consequent rapid development of the infrastructure required for sustaining the enormous metropolitan societies coupled with the industrial revolution has led to an ever-increasing demand for energy. Figure 1 demonstrates the rate of energy consumption in the world from 1965 to 2005 divided by source (BP, 2006). This ascending trend has been present so far with the exception of year 2009 , when a $1 \%$ decrease was seen in energy consumption as a result of the economic crisis. In 2010, however, the demand recovered firmly with a 5\% growth (Enerdata, 2011)

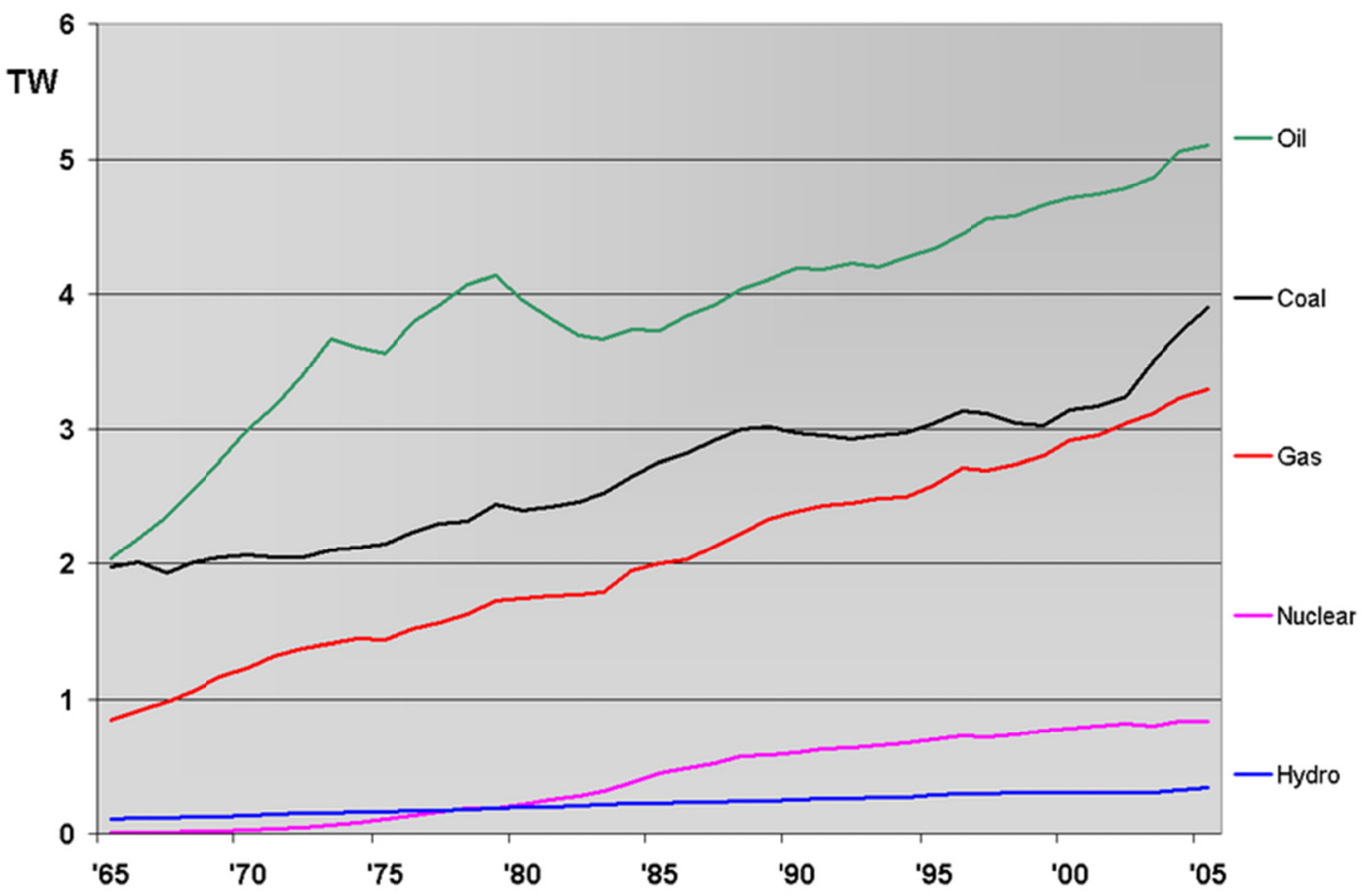

Figure 1- World energy consumption in terawatts for 1965-2005 (Graph by Frank Van Mierlo) 
Electric power generation sector is the largest consumer of primary sources of energy in the US followed by transportation, industrial and residential/commercial sectors (USEIA, 2012). Figure 2 shows US energy consumption (in quadrillion Btu) by source and sector. As it can be seen, the majority of this huge energy demand is met by combustion of different types of fossil fuel. In 2008, approximately $81 \%$ of the energy consumed in the world was originated by burning oil (33.5\%), coal (26.8\%) and gas (20.9\%) (Swedish Energy Agency, 2010). As a result, the available reserves of fossil fuel are depleting quickly while the unit prices are rising steadily. Therefore, there is a necessity to gradually decrease the share of fossil fuel in energy production and replace it with other alternatives.

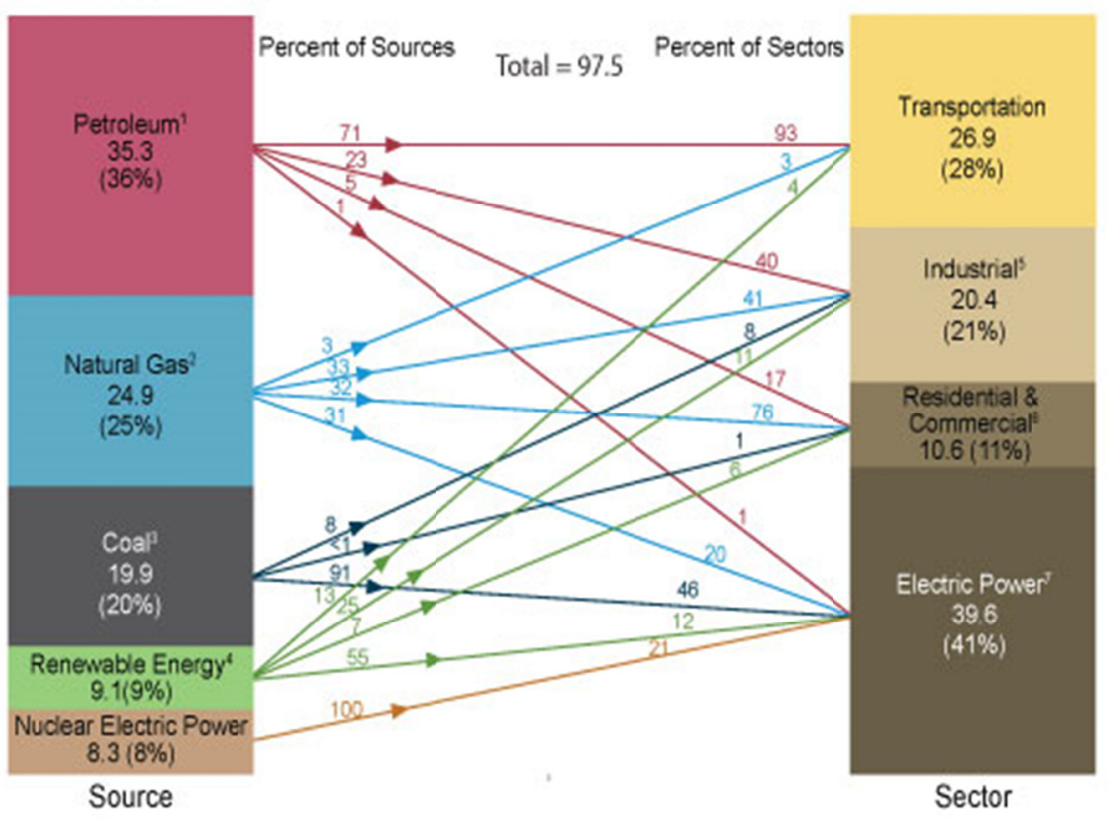

Figure 2- US energy consumption by source and sector (USEIA, 2011)

Additionally, political considerations as well as environmental issues such as global warming in the recent years have further emphasized the urgency of switching to 
other (and preferably cleaner) sources of energy. Global warming is believed to be closely related to greenhouse gas emissions, especially $\mathrm{CO} 2$. Figure 3 demonstrates the abrupt increase in carbon emissions in recent years due to fossil fuel combustion.

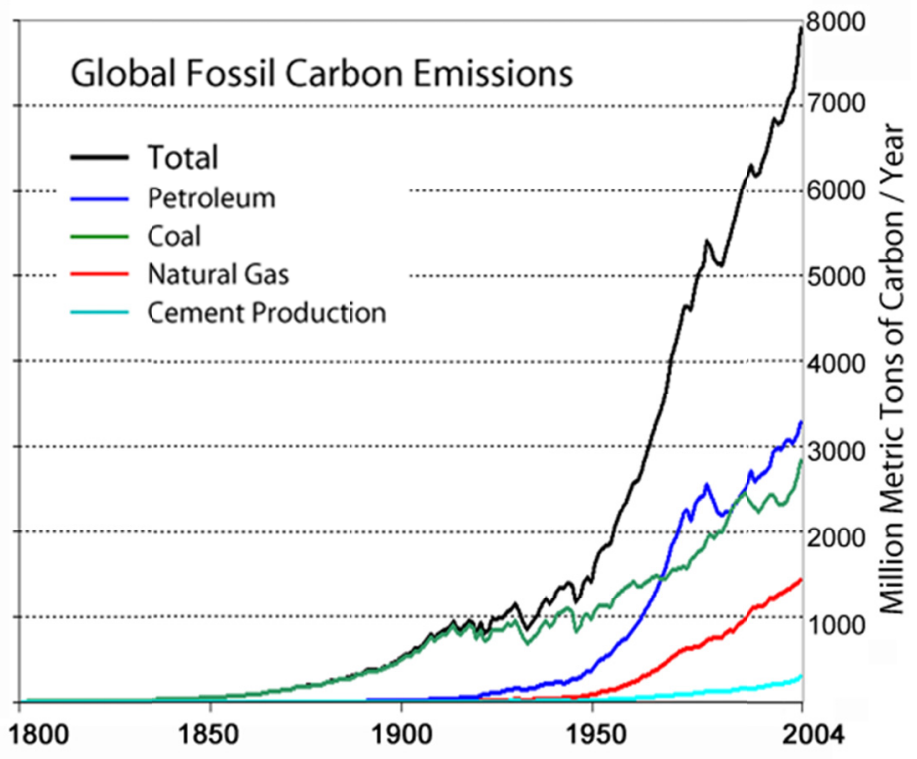

Figure 3- Global fossil carbon emissions (Marland, 2007)

\section{2. $\quad$ Non-fossil Energy Sources}

As discussed in the previous section, scientists have been constantly working on discovering efficient and eco-friendly methods to extract and harness other forms of energy in order to diversify the energy production portfolio. As a result of this effort, a variety of power generation methods are readily available. Figure 4 shows the major sources of energy production in 2005 (BP, 2006). 


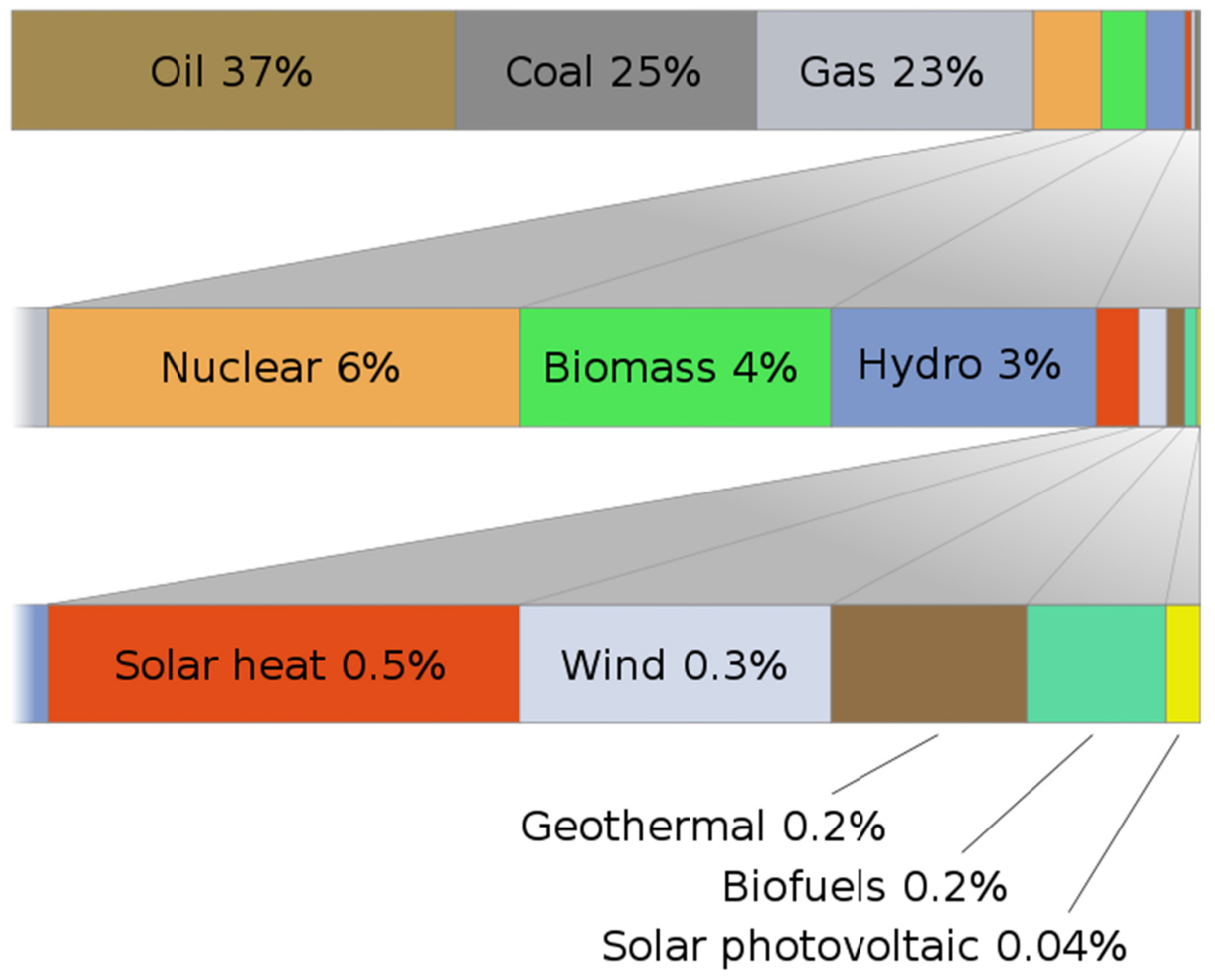

Figure 4- Sources of energy production in the world in 2005 (Omegatron, 2007)

As it can be seen, nuclear power is leading the chart in non-fossil fuel categories. Although this method has been used quite reliably for a few decades, there are still many environmental, safety and security concerns regarding nuclear fuel usage. Incidents such as Chernobyl disaster and more recently the 2011 Tohoku earthquake and tsunami which damaged Fukushima reactors and caused radioactive material leakage are some examples revealing the costly, life-threatening and extensive impact of failure in these systems. Therefore, renewable energy sources are by far better candidates to replace fossil fuel or even nuclear energy. 


\subsection{Renewable Energy}

According to the International Energy Agency, "Renewable energy is derived from natural processes that are replenished constantly. In its various forms, it derives directly from the sun, or from heat generated deep within the earth. Included in the definition is electricity and heat generated from solar, wind, ocean, hydropower, biomass, geothermal resources, and biofuels and hydrogen derived from renewable resources. “(IEA Renewable Energy Working Party, 2002)

One of the oldest forms of renewable energy utilized by mankind is the traditional biomass. Woods and dry plants have been used for heating for thousands of years. Modern biomass renewables mainly include biofuels such as bioethanol, biodiesel, etc. used as transport fuel. Combustible gasses generated in landfills are also in this category.

Hydropower is another form of renewable energy with a usage history dating back to thousands of years ago. Ancient water irrigation systems and watermills indicate that early civilizations knew how to harness and benefit from the water power. With the advent of the modern technology, water power has been extensively used for electricity generation. Figure 5 shows a schematic view of a hydroelectric dam. A large number of dams have been constructed for this purpose in the past century. In recent years, however, this technique has somewhat lost its popularity due to environmental issues since large-scale flooding and disturbance of the local hydrological regime can have substantial negative impacts on the eco-system. Tidal power is another source of hydroelectric energy which is unencumbered by this setback. 


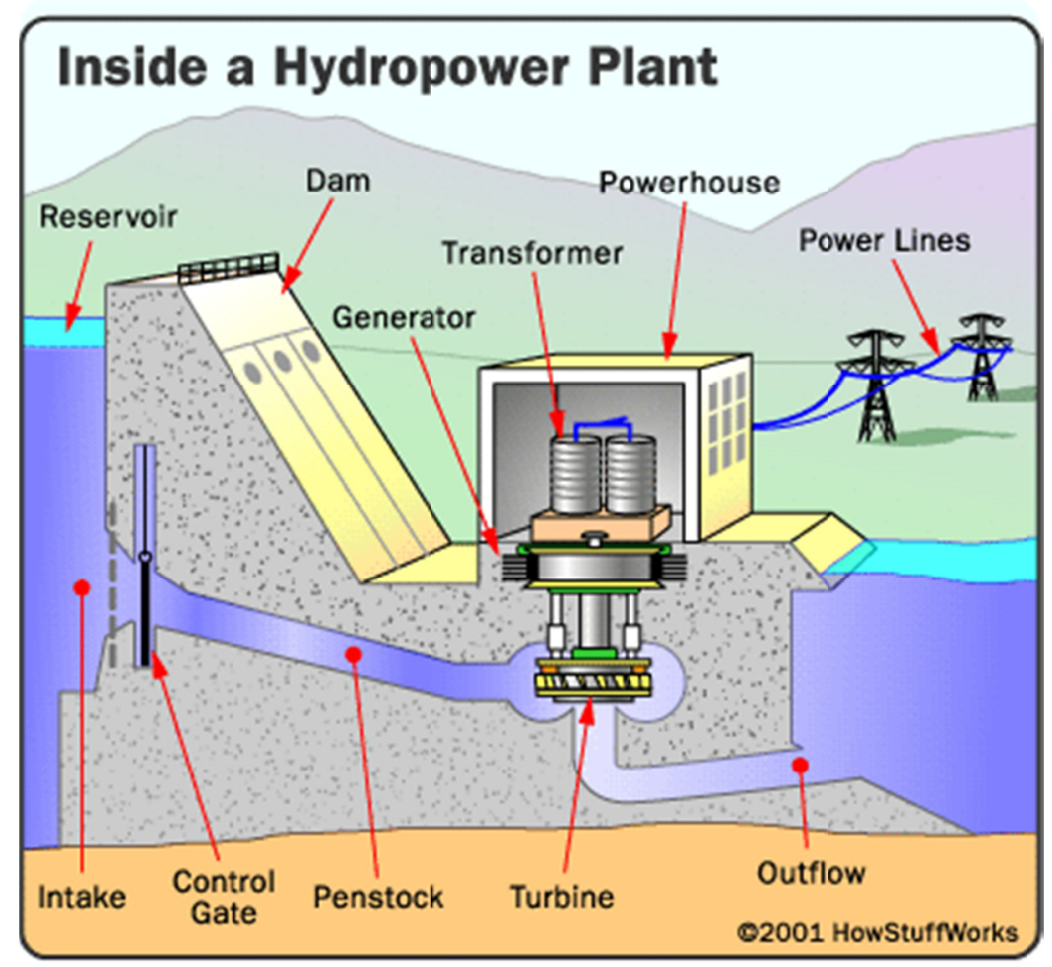

Figure 5- Schematic layout of a hydroelectric dam (Bonsor, 2001)

\subsection{New Renewables}

Besides the huge progresses achieved in techniques and technologies of utilizing the traditional sources of power, novel sources of energy have been successfully harnessed and exploited in recent years. Geothermal energy is one of the new renewables which is favorable in those regions of the earth with a thin crust layer. In this technology, the heat from the depth of the earth is used either directly for heating purposes or for powering the steam generators used in electricity generation. Figure 6 shows a schematic layout of a geothermal power plant. 


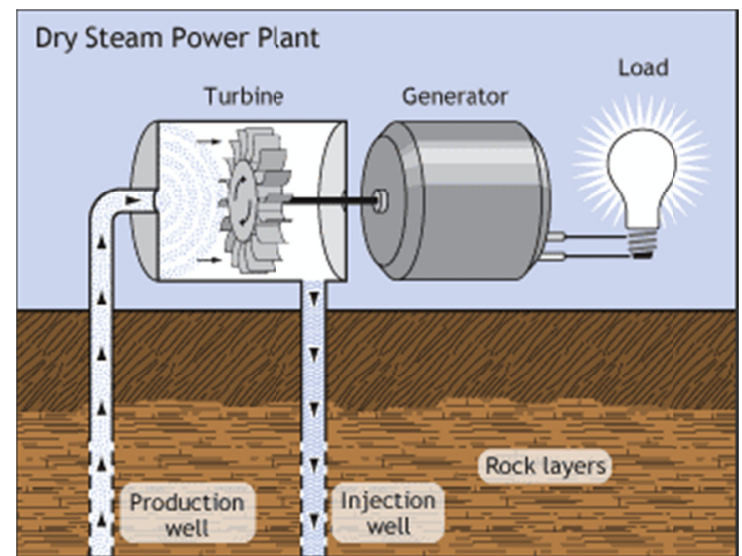

Figure 6- Schematic view of a geothermal power plant (U.S. DOE, 2012)

Solar energy is another example of the new renewables which is growing rapidly in applications. It consists of two sub-categories; one is the solar thermal energy where the heat from sunlight is utilized as the energy source. It includes a range of applications from direct heating (for hot water for instance) to power generation with heat engines. Figure 7 shows the layout of a solar thermal power generation facility.

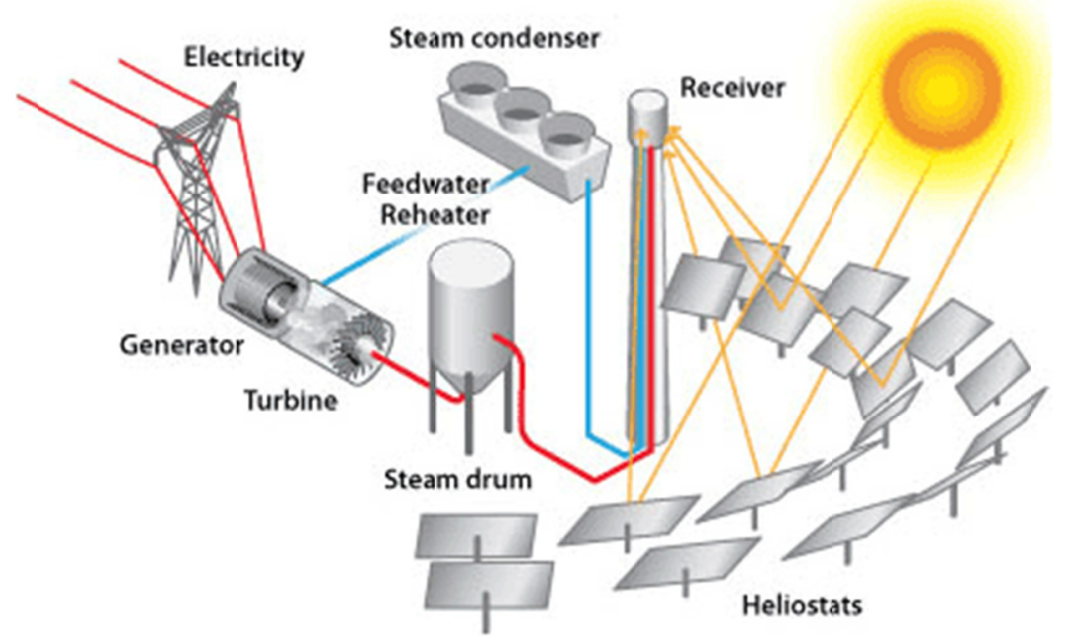

Figure 7- A concentrated solar thermal system (U.S. DOE, 2011)

The other sub-category is called Photovoltaics (PV) where electricity is directly generated from the sunlight by exposing semiconductors with photovoltaic effect to 
sun radiation. Although at the present solar energy covers a small fraction of the energy demand of the world, new achievements in this technology are very promising. Scientists have expressed hope that in fifty years, solar energy could meet most of our energy needs while the other renewables cover the rest.

Wind power is another source of renewable energy which has attracted a great deal of attention and investment in recent years. Wind power is discussed in more detail in the next section.

\section{5. $\quad$ Wind Power}

Although wind energy is considered one of the new renewable technologies, mankind has benefitted from wind energy for thousands of years. Wind propelled ships and sailboats have been around as a means of transportation throughout the recorded history. Moreover, windmills were used in Middle East, Holland and some other regions of the world for grinding grains or pumping water in early ages. The modern techniques of electricity generation from wind power, however, are no more than a few decades old. A wind power generator has been depicted in Figure 8.

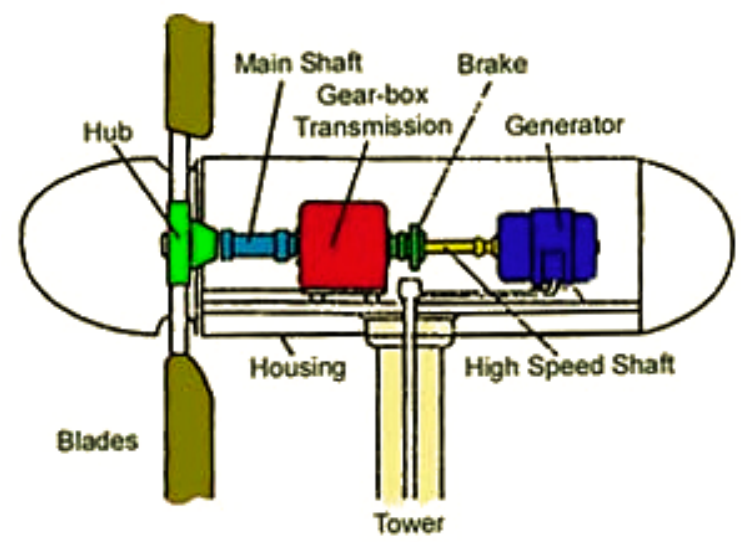

Figure 8- Wind power generator layout (California Energy Commission, 2012) 
Wind power generation is one of the most promising technologies among the new methods of energy generation and it has grown faster than any other type of renewable technology in recent years. A study by Stanford University shows that the total potential for wind generated power on earth is several times greater than the total energy consumption of the world (Archer \& Jacobson, Evaluation of global wind power, 2005).

Generation of electricity from wind power has several advantages over conventional methods. The main advantage is its cleanliness; there is no greenhouse gas emission during operation of wind turbines (the emissions during the construction and installation processes are negligible) and also no other contaminating byproduct is produced.

Furthermore, wind is ample and widely distributed. Unlike fossil fuel resources, high speed winds gust across many countries, at least locally or seasonally. Another specific advantage of wind power is that the periods of peak electricity demand often coincide with the periods of high wind speeds. In other words, wind generally blows stronger during the daylight hours when the businesses and industries are running. As a result, it would be easier to adjust to demand fluctuations in the network. Moreover, wind and solar energy can complement one another since normally windy days are cloudy and sunny days are calm.

Nevertheless, there are some disadvantages associated with wind power generation as well. For example, wind farms occupy extensive lots of land. The rotors usually make a lot of noise and can be a life hazard for the avian population in the region. 
Therefore, some critics have raised aesthetic and environmental concerns over construction of large wind farms.

Apart from the problems mentioned above, utilization of wind generated electricity is limited by some other technical and operational shortcomings as well. For instance, wind power is not a reliable source of energy. As formerly discussed, wind is a stochastic phenomenon. Therefore, short-term prediction of wind speed and estimation of the quantity of the resulting power cannot be made with sufficient accuracy. Another setback of this technology is that wind power is not dispatchable either. In other words, when there is an increase in demand, there is no way to intentionally increase the production.

In spite of these shortcomings, several methods are available to mitigate their impact. Energy demand management is an efficient method to reduce fluctuations in demand profile in order to make it more predictable. Furthermore, some spare generation capacity of dispatchable type could be made available in order to handle the residual demand (or supply) variations. This additional generation capacity can supplement the electricity production upon demand. Operating reserve, which is specified as the extra capacity available through connecting spare generators to the grid or increasing the output of underutilized generators is a common method of maintaining reliability in grids. Some other approaches to deal with this problem are grid energy storage and system interconnection.

Pumped-storage hydroelectricity is an effective technique for creating grid power storage and load leveling capability. As illustrated in Figure 9, this system roughly consists of two nearby reservoirs with considerable elevation difference, a dam at the 
higher elevation, a pump station to refill the higher reservoir and also the power generators. When there is a supply surplus in the grid, the pump station is switched on in order to pump the water from the downstream lake to the upstream reservoir behind the dam, creating gravitational potential energy. When demand increases beyond the normal generation capacity in the grid, water is released from the upstream reservoir to generate extra electricity at the power station embedded in the dam.

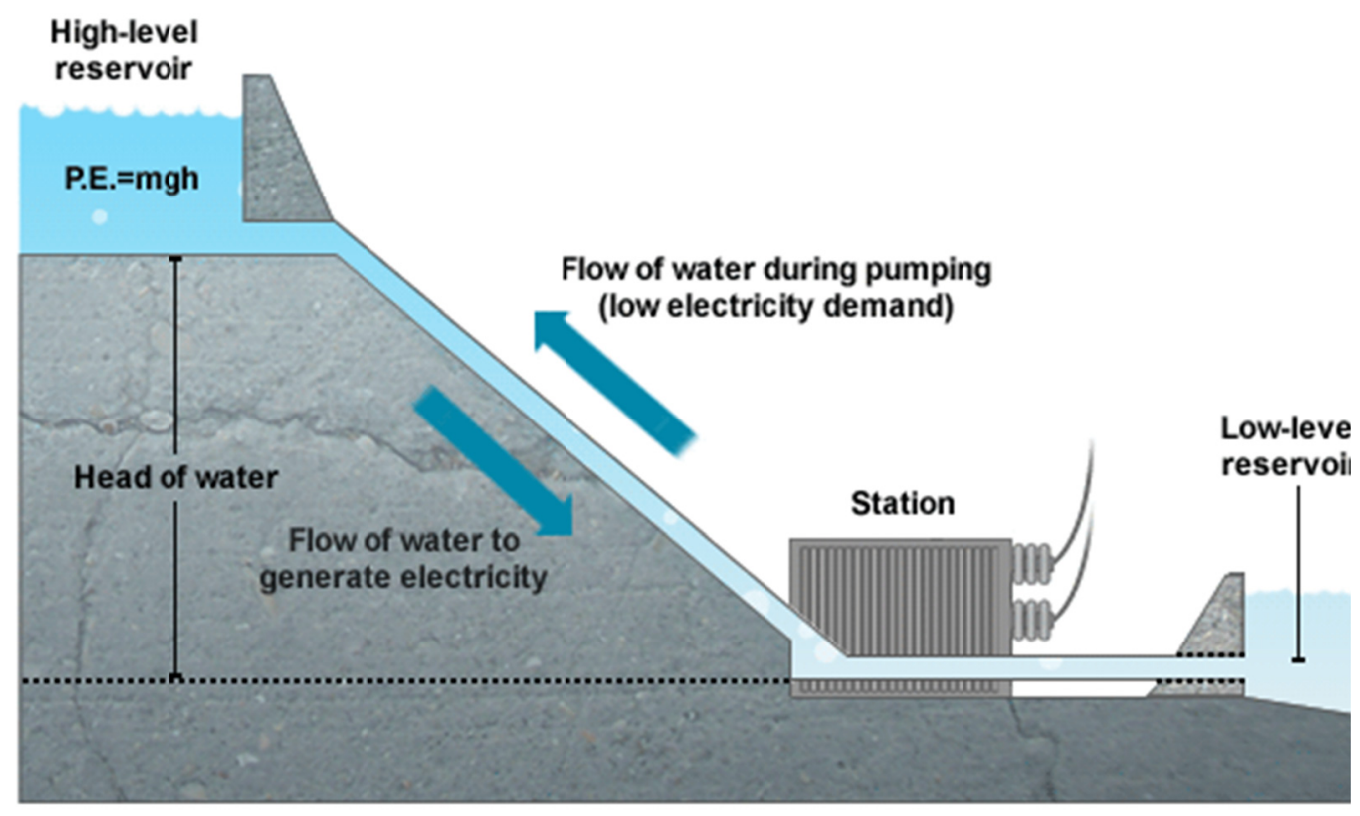

Figure 9- Schematic of a pumped storage hydroelectric power plant (BBC, 2013)

Large-scale batteries can also be used for grid storage. Flow batteries with capacities as much as $12 \mathrm{MW}$.hr have been manufactured for this purpose (Wachter, 2006).

Mass production of electric vehicles (EV) provides another great opportunity for large-scale energy storage. In a smart grid network, in the event of a deficit in electricity production, power can be drawn back to the grid from the batteries of the 
cars which are plugged in. This system is called Vehicle-to-Grid (V2G). Although this idea seems somewhat far from reality right now, it is quite possible in the near future for some communities to rely significantly on storage capacity of electric vehicles (Levitan, 2010).

System interconnection is another method which takes advantage of available surplus supply in other linked network grids. HVDC (High Voltage Direct Current) cables are usually used for long distance electricity transmission since their energy loss is less than AC (Alternating Current) lines. A special application of this technique would involve interconnection of several wind farms located in different regions. Although operating reserve would still be required, studies indicate that the reliability of wind farm systems would increase as more wind farms are linked together. A Study by Stanford University has reported that under specific circumstances, interconnecting more than ten wind farms can increase reliability up to $33 \%$ on average (Archer \& Jacobson, Supplying Baseload Power and Reducing Transmission Requirements by Interconnecting Wind Farms, 2007). The capacity credit generally reported for a single wind turbine is in $20 \%$ range.

Obviously, all of these methods for creating operating reserve increase the unit cost of wind generated power. However, continuous progresses in research and technology as well as commercial and large scale production of wind power generation equipment have resulted in descending unit prices for wind power technology in recent years. Some other contributing factors to the economies of wind generated power are governmental incentives and imposition of carbon taxes. 
A few countries have already developed strong infrastructure for wind technology. Denmark, Spain, China, Portugal, United States, Ireland and Germany are among the countries with the highest installed capacities for wind power generation. Denmark is producing more than $20 \%$ of its power demand from wind energy (WWEA, 2011). Although United States of America has been one of the leading countries in terms of installed capacity, the total wind generated power in the US is only about $2 \%$ of the electricity demand. It is interesting to know that based on a study sponsored by the Department of Energy, the wind power potential in the Great Plain States is more than sufficient to supply the entire nation (Lu, McElroy, \& Kiviluoma, 2009). Figure 10 demonstrates the distribution of annual average wind speeds at $80 \mathrm{~m}$ elevation across the North America.

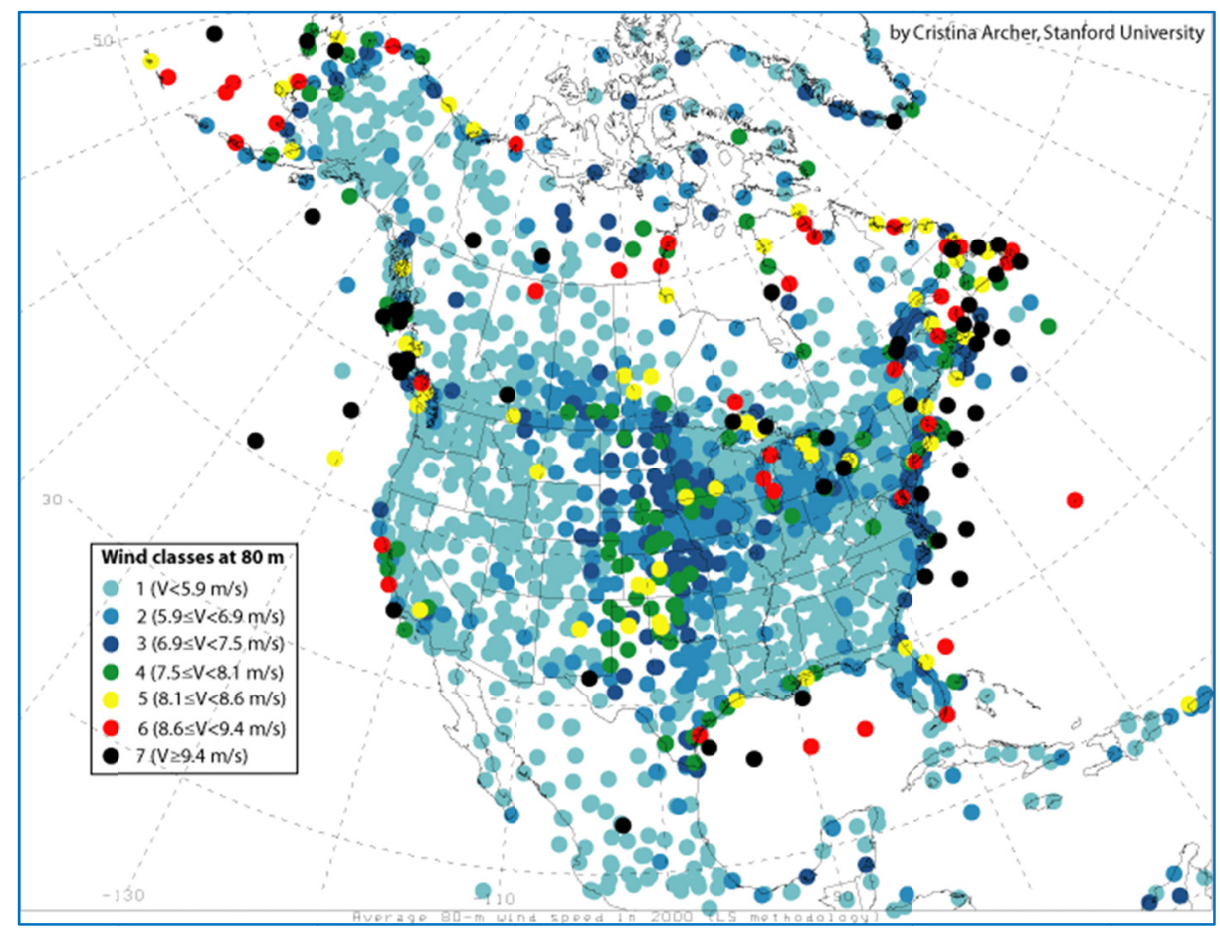

Figure 10- Annual average wind speed at $80 \mathrm{~m}$ across the North America (Archer \& Jacobson, Evaluation of global wind power, 2005) 
Furthermore, studies show that up to $20 \%$ of the total electricity demand in the network can be supplied from wind power with minimal complications (American Solar Energy Society, 2007). Therefore, a huge progress over the current status is easily achievable.

\section{6. $\quad$ Motivation for the Research}

As discussed in the previous sections, wind speed has a stochastic nature and consequently, the power generated from wind is intermittent. Most of the power is generated from high speed winds which occur for short periods of time. Therefore, wind power is mainly regarded as fuel-saver rather than capacity-saver. In other words, it is treated as an auxiliary source in most power supply systems and full standby capacity is available for backup when wind flow subsides. Accordingly, it appears that more research and deliberation is required to further demonstrate the capacity adequacy of wind technology.

In order to take advantage of the potential capacity credit of wind power generators, capacity planners should be provided with a modeling tool capable of simulating demand and anticipating power production from different available sources of energy with reasonable accuracy. In this study, we will first review the literature to investigate how this subject has been addressed by other researchers and identify areas for improvement. Then, we will try to implement some of these improvements and develop a new mathematical model for optimal allocation of capacities for each type of available energy source in the network. Capacities should be assigned such that the electricity demand is met at the desired reliability level while minimizing cost and environmental impacts. 


\section{7. $\quad$ Organization of the Dissertation}

In the following chapters, a literature review on the capacity adequacy of wind power generators and their reliability is presented and then a brief theoretical background is provided for popular methods of dealing with these types of problems. Subsequently, the problem under investigation is specified and a mathematical formulation is introduced for modeling the problem. In the next stage, a numerical example is constructed and solved in order to evaluate the validity of the formulation. Sensitivity analysis is carried out to verify reasonable behavior of the model in a variety of circumstances.

Furthermore, since the size of the model can become too large for certain instances of the problem, a heuristic method will be developed in order to enable the model to deal with a reasonably large problem. And finally, a conclusive summary is presented and some ideas for extension of this work are discussed. 


\section{Literature Review}

\subsection{Review of research on wind power reliability and capacity credit}

Power generation from wind energy has been a very popular field of study in multiple disciplines in recent decades. Planning and reliability issues have always been among the important topics investigated by several researchers. Although a couple of decades ago only a handful of countries were active in wind power generation field, many countries have studied potentials of the wind technology in their territory nowadays. One such study has been done in early 2000s in Hong Kong. In this work, based on the local climate analysis, an optimum wind speed for power generation is calculated and used for selection of a suitable and efficient wind turbine. The results of a case study simulation show that a capacity factor (The ratio of average actual power generated to the rated power) of $35 \%$ is achievable by using these guidelines.

Figure 11 shows the expected quantity of generated power from a $10 \mathrm{~kW}$ wind turbine in different months of the year in Waglan Island (Lu, Yang, \& Burnett, 2002).

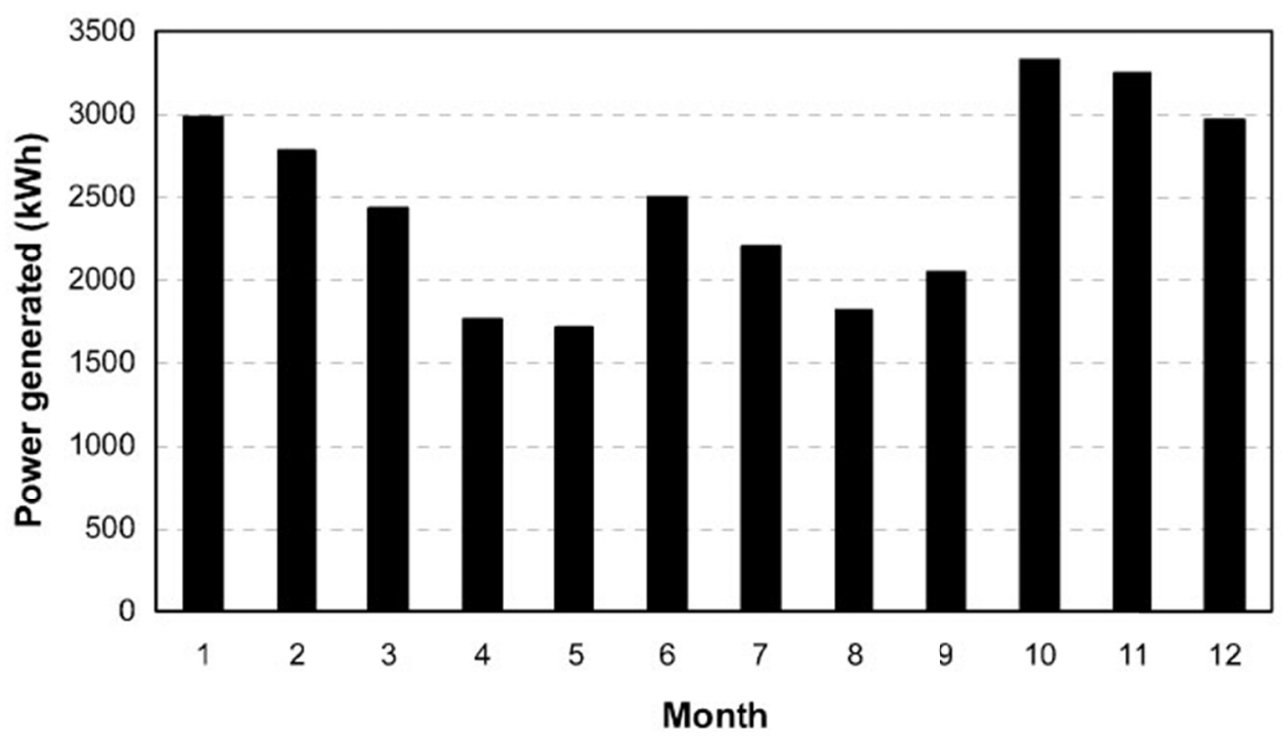

Figure 11- Monthly power generation for a $10 \mathrm{~kW}$ wind turbine (Lu, Yang, \& Burnett, 2002) 
One of the early studies on reliability of wind technology pertains to wind power generation in Oahu Island in Hawaii. Before construction of wind farms, nearly all of the consumed electricity in the island was generated by oil fueled power plants. Evidently, such systems are both expensive and detrimental to the environment. As a result, a contract was awarded for construction of a wind farm in multiple stages. The ultimate planned capacity of the wind farm was 80 MW to be reached by 1985 .

Obviously, reliability of the new system was in question. In order to investigate this issue, statistical data was collected on seasonal wind speeds at the wind farm location. Then, considering the production curve for a single wind turbine and Forced Outage Rates (the probability of wind turbines not operating due to mechanical or electrical failure), the aggregate cumulative distribution function for the production of the wind farm is derived. In the next step, this aggregate function is incorporated into the reliability model of the utility system using simple convolution. Finally, reliability of the utility system including the wind farm is calculated in terms of Loss of Load Expectation (the annual expected duration of outages in hours) using a computer code. In addition, LOLE values have been used to calculate Equivalent Conventional Unit (ECU) and Equivalent Load Carrying Capacity (ELCC) values in order to provide a better baseline for comparison of wind power generators and conventional units. ECU is equal to the capacity of a conventional unit which could maintain the same reliability level as the wind farm. ELCC is the amount of increase in demand that the system can handle without violating the reliability requirements. In other words, ELCC is equal to the capacity of an equivalent perfect conventional unit (i.e. ECU with zero outages) capable of supplying the increased demand. Figure 12 shows 
LOLE versus peak load graphs for the system before and after addition of wind power generators (WPG). The ELCC value is visually illustrated as the horizontal distance between the two curves (Giorsetto \& Utsurogi, 1983).

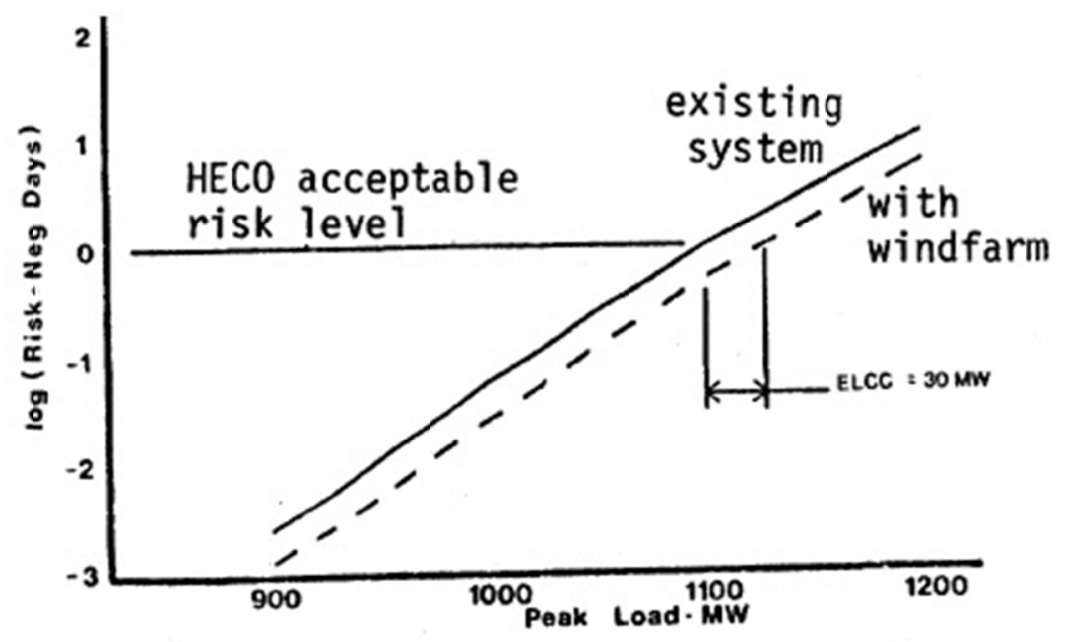

Figure 12- LOLE graphs for the system before and after addition of WPGs (Giorsetto \& Utsurogi, 1983)

A few years later, researchers at the National Technical University of Athens developed a similar approach for reliability modeling of utilities systems incorporating intermittent supplies. In this method, each generating unit is represented by a (two-state or multi-state) Markov model. The system is divided into conventional generation subsystem and intermittent generation subsystems. Using Forced Outage Rates, the capacity availability model for each subsystem is built by adding up the generator unit models sequentially until every generator in the subsystem is added. Finally, treating each subsystem as a multi-state Markovian model, the overall generation availability model for the whole system is constructed. Rounding is used to reduce the number of states and computational burden. Finally, the aggregated model is used to calculate Loss of Load Expectation. The application of this technique has also been illustrated by calculating LOLE in a test system based on a utility network in a Greek island. Figure 13 shows the results of this case study 
for three wind/conventional generation capacity ratios $(0.427,0.4$, and 0.347$)$. It is observed that increasing this ratio (moving from curve 3 towards 1 ) leads to higher LOLE values (Dialynas \& Machias, Reliability modelling interactive techniques of power systems including wind generating units, 1989).

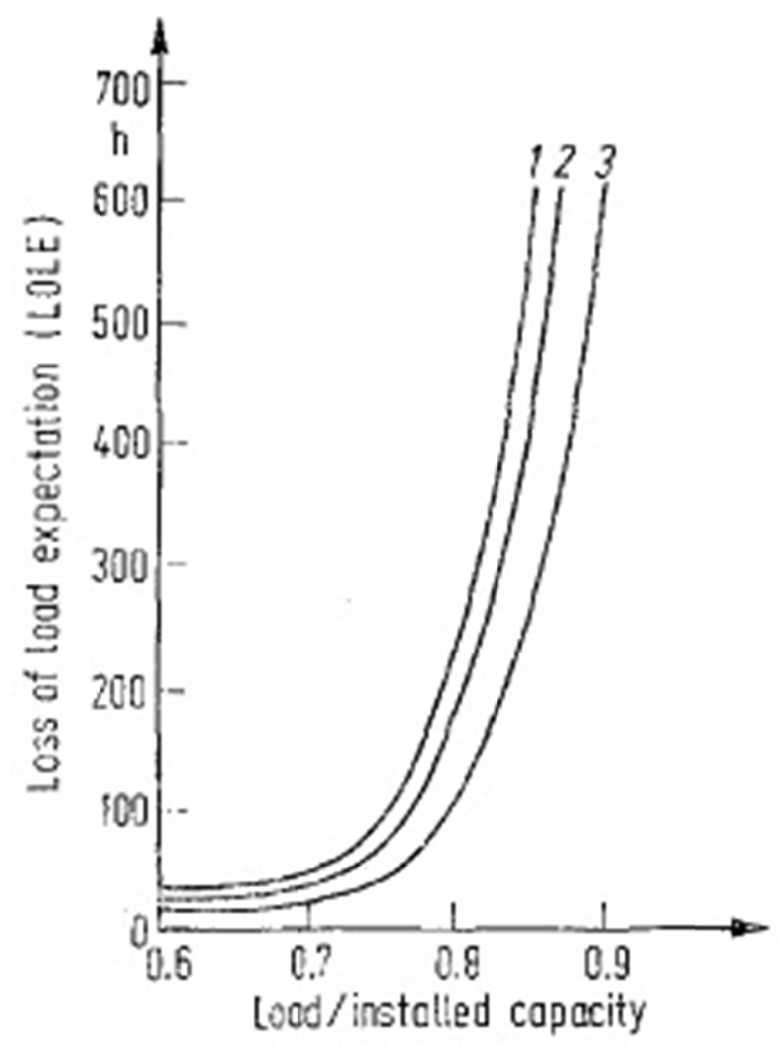

Figure 13- LOLE vs. load curve for different wind power penetration levels (Dialynas \& Machias, Dialynas, E. N., and A. V. Machias. "Reliability modelling interactive techniques of power systems including wind generating units." Electrical Engineering (Archiv fur Elektrotechnik) 72, no. 1 (1989): 33-41., 1989)

In the same field of research, scientists at University of Saskatchewan have published several papers on wind power reliability. In one of their earlier works, reliability of small isolated power systems (SIPS) including wind power generators has been addressed. These systems conventionally run on diesel fuel. Wind power generators and photovoltaic systems have also become very popular recently since they have lower operational costs. 
For the purpose of reliability analysis, a basic system consisting of diesel generators has been considered in the first step. Subsequently, historical data on weather conditions including wind speeds and solar radiation is collected. This data is used to generate hourly average values for electricity production rates. Finally, considering an increasing demand within a ten year time horizon, reliability of the system is assessed for different combinations of power generation systems. Monte Carlo simulation has been used to model energy production for wind power generators and photovoltaic systems. Loss of Health Expectation (the expected number of hours in a year when the reserve capacity requirements of the system cannot be met) and Loss of Load Expectation (the annual expected duration of outages in hours) values are used as measures of reliability. It has been concluded that wind and solar power generation systems are not capable of maintaining reliability requirements beyond a certain rise in demand. This conclusion has been illustrated in Figure 14. More diesel generator units are needed to be installed in order to maintain reliability beyond this limit (Billinton \& Karki, 2001).

Annual peak load forecast for example system

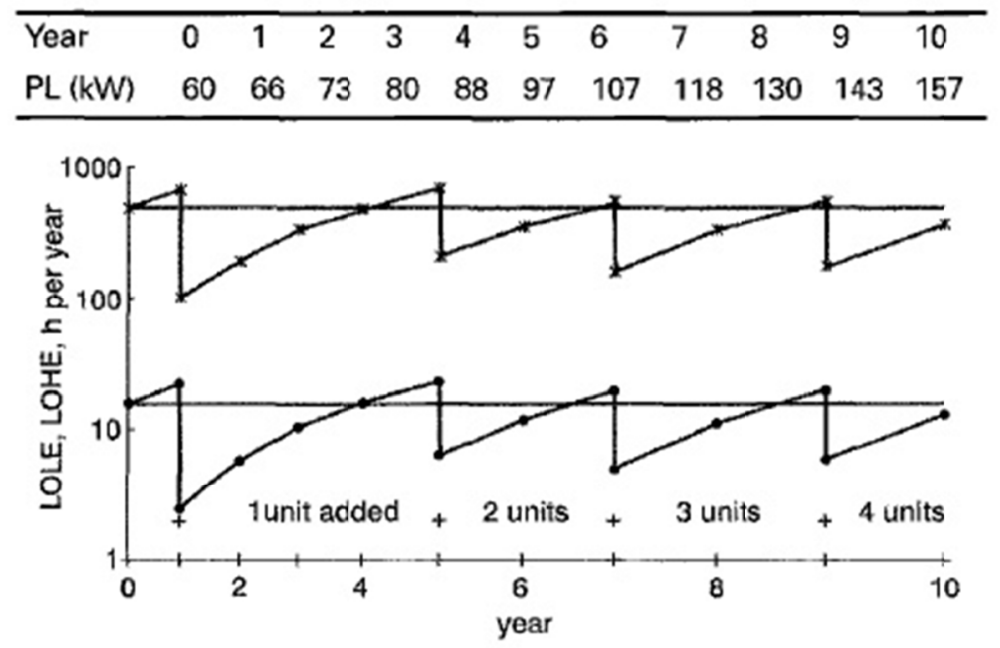

Figure 14- LOLE \& LOHE forecast over a ten year period (Billinton \& Karki, 2001) 
Same authors have also separately studied capacity credit and reliability issues of wind generated power for planning purposes. The approach they have utilized is similar to the method used for the analysis of small isolated power systems (previous work). Karki has used an ARMA (Auto Regressive Moving Average) time series to model the chronological variation of wind speeds. Based on this model, the power produced by wind turbines is calculated for the duration of the analysis. Subsequently, these results are aggregated with the energy production from other sources of electricity generation to obtain the total amount of energy produced. Finally, the total production values are compared to demand magnitude chronologically through a Monte Carlo simulation in order to calculate the Loss of Load Expectation. For validation purposes, the IEEE (Institute of Electrical and Electronics Engineers) reliability test system is analyzed with this model and up to $350 \mathrm{MW}$ of electricity production capacity is replaced by wind power generators. It is demonstrated that under such circumstances, the reliability level would deteriorate and it would not be possible to restore the system reliability by using merely wind power generators (Figure 15).

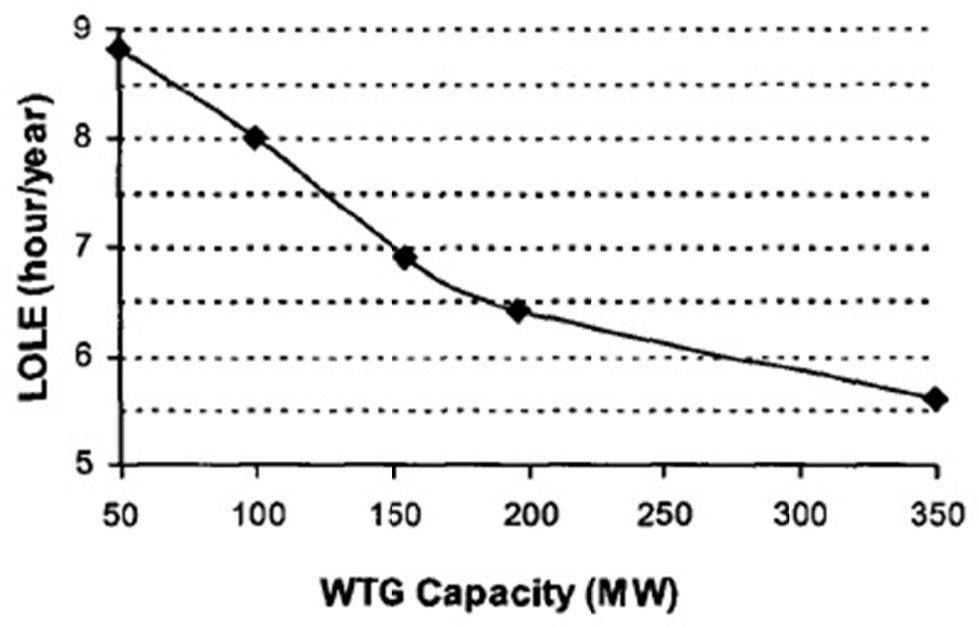

Figure 15- LOLE variation with increased wind power capacity (Karki, Wind power in power generation planning, 2004) 
Furthermore, it is shown that distribution of wind turbines in two or three sites with independent wind conditions would lead to an improved reliability state compared to installation in a single site. Results of this analysis are depicted in Figure 16 (Karki, Wind power in power generation planning, 2004).

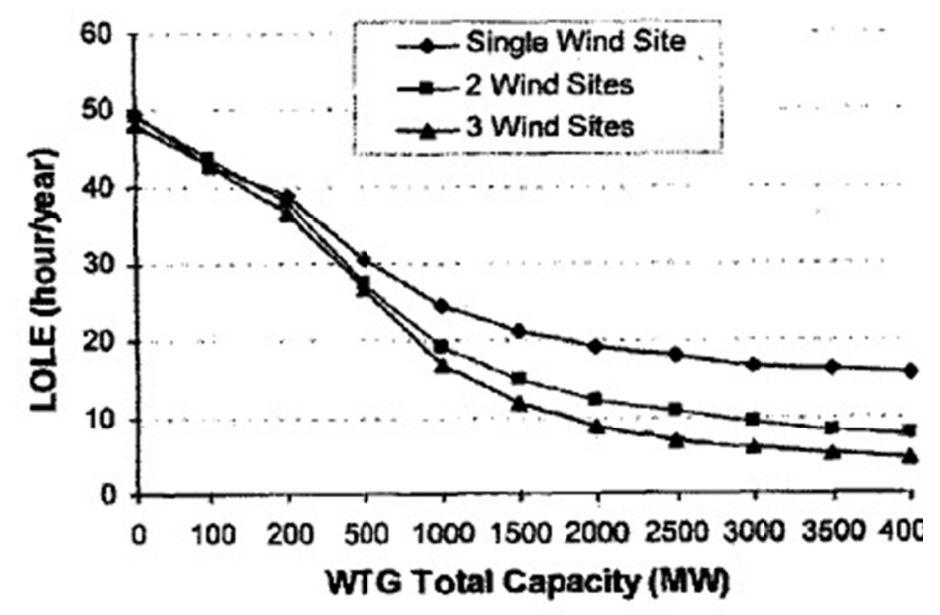

Figure 16- Effect of integration of multiple independent wind farms in the system (Karki, Wind power in power generation planning, 2004)

Billinton and Bai have presented a similar method for assessing the capacity adequacy gained from introducing wind power generators to existing power production systems. Identical results are observed regarding early saturation of improvements in reliability levels as wind generation capacity increases (Figure 17).

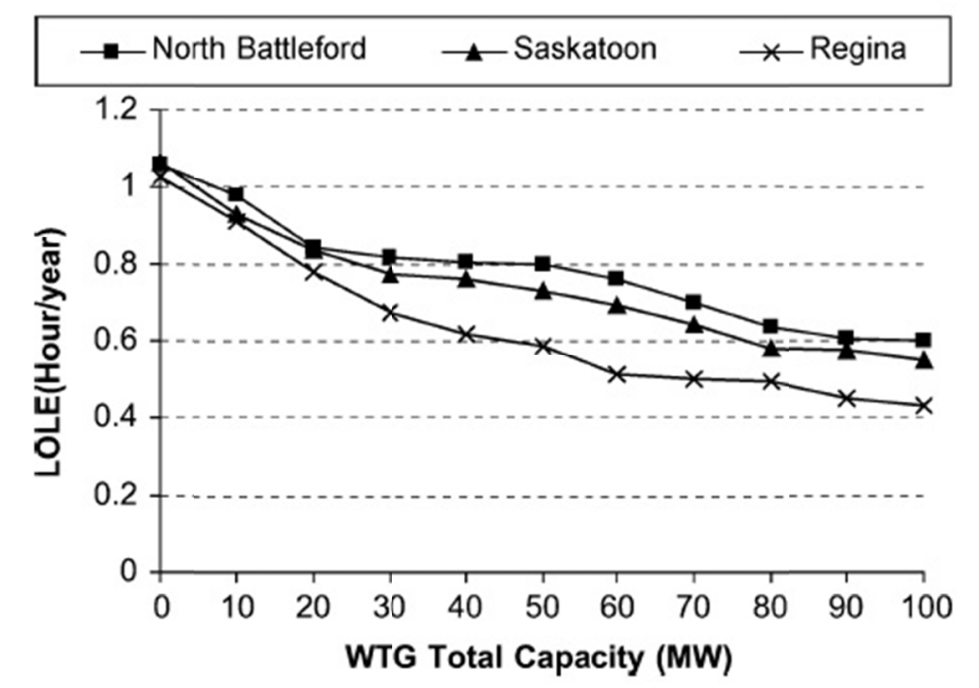

Figure 17- Early saturation of reliability benefits with increased WPG capacity (Billinton \& Bai, 2004) 
Furthermore, the reliability benefits of wind power generation from multiple independent wind farm sites are verified as demonstrated in Figure 18 (Billinton \& Bai, 2004).

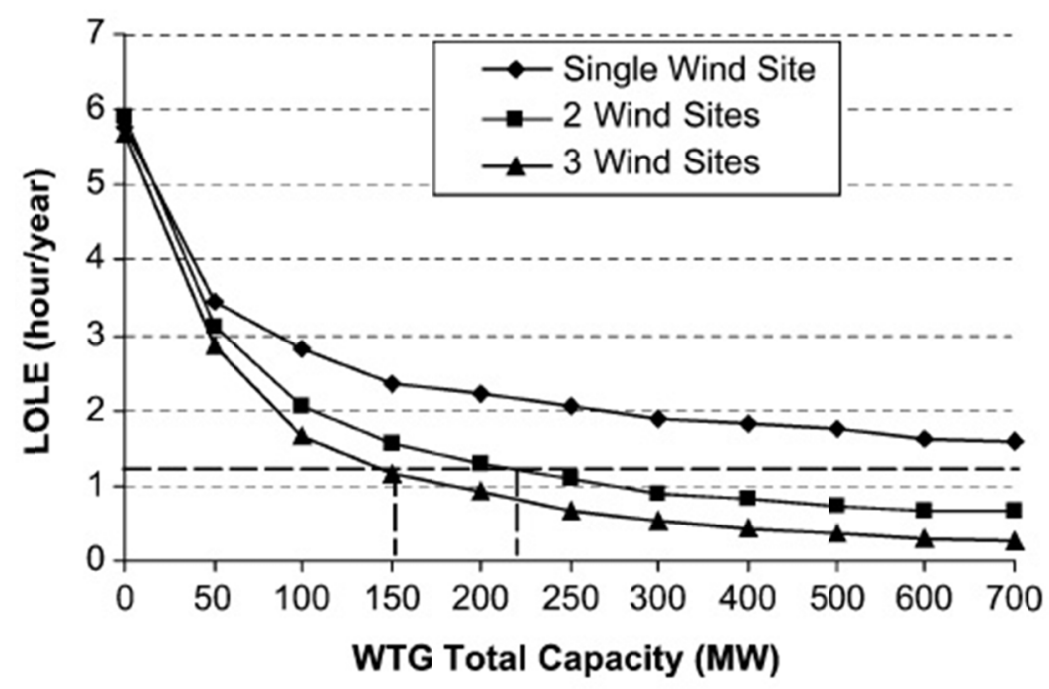

Figure 18- Positive effect of multiple independent wind farms on reliability (Billinton \& Bai, 2004)

In another joint paper, Billinton and Karki have taken a similar approach for studying reliability issues along with budget concerns in large-scale power generation planning. While they have applied an analogous simulation procedure, new indices have been introduced to represent efficiency and cost implications. Expected Surplus Wind Energy (ESWE) is defined as the amount of wind generated power in excess of demand which would not be utilized. Also, Wind Utilization Factor (WUF) is defined as the ratio of the Expected Wind Energy Supplied (EWES) to the total generated energy, or EWES/ (EWES+ESWE). Finally, the Wind Utilization Efficiency (WUE) is introduced as the product of Wind Utilization Factor and Capacity Factor (Capacity Factor for a wind turbine is defined as the ratio of average actual generated power to the nominal power of the turbine) or WUE $=$ WUF $x$ CF. Healthy state probability 
(i.e. operation with adequate reserve capacity) has been used as the reliability measure.

It is observed that increasing the number of installed wind turbines decreases the Wind Utilization Efficiency (WUE) index (Figure 19). So, the efficiency of the wind generation system drops as more units are installed (i.e. wind turbines become increasingly underutilized). The authors suggested imposing a lower bound on WUE to limit excessive investment on wind power and supply the additional required capacity through conventional generators. They have also demonstrated through a numerical example that adding wind power generators to an already adequate energy network can lead to cost savings resulting from less fuel consumption and less contamination (Karki \& Billinton, Cost-Effective Wind Energy Utilization for Reliable Power Supply, 2004).

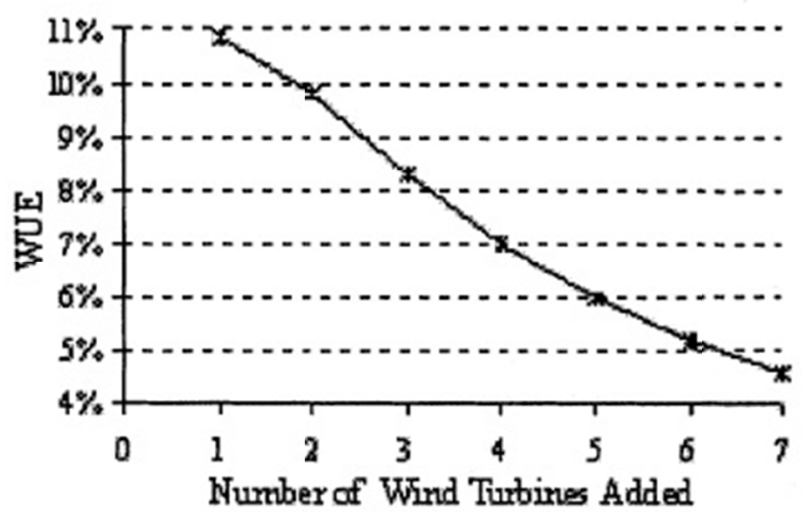

Figure 19- WUE declining with increased number of turbines (Karki \& Billinton, Cost-Effective Wind Energy Utilization for Reliable Power Supply, 2004)

It should be noted, however, that the possibility of energy storage or trade has not been considered in this model. While the availability of large-scale grid storage is very limited at the present, development of technologies for economical storage of electricity in larger capacities can highly impact these results. 
In another collaborative effort at the University of Saskatchewan, a simplified model has been introduced for evaluation of reliability in wind generation systems. This model is based on a parametric probability distribution function for local wind speeds. The initial model encompassing 100 points is presented in Figure 20.

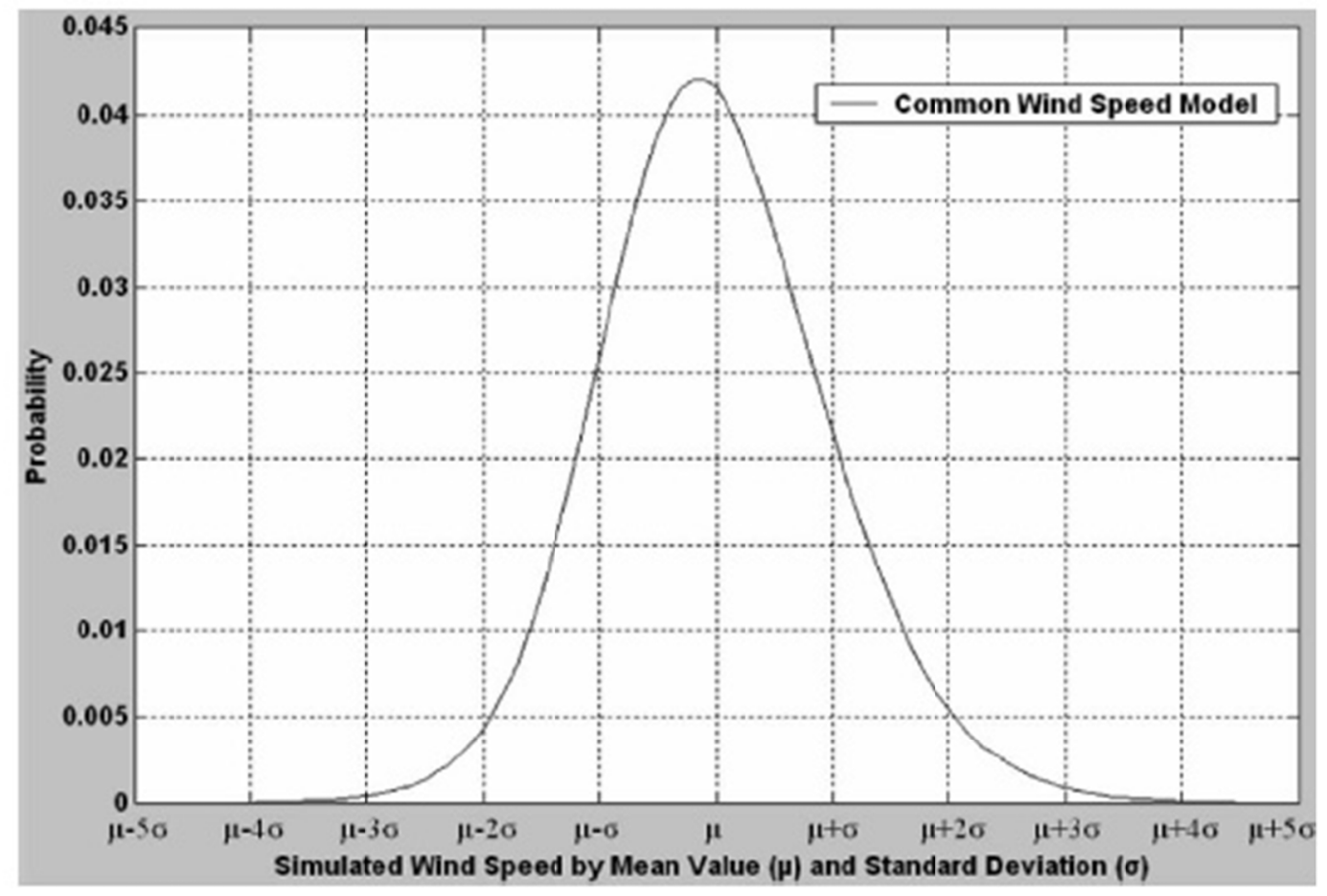

Figure 20- Parametric wind speed model (Karki, Hu, \& Billinton, A Simplified Wind Power Generation Model for Reliability Evaluation, 2006)

The wind model is derived from historical data collected over several wind farm sites in Canada. The input parameters in this model are mean and standard deviation of wind speed. Once these parameters are obtained for a site, the probability distribution function for wind power production can be generated using respective power curves for the specified wind turbines. A typical wind turbine power curve is illustrated in Figure 21. 


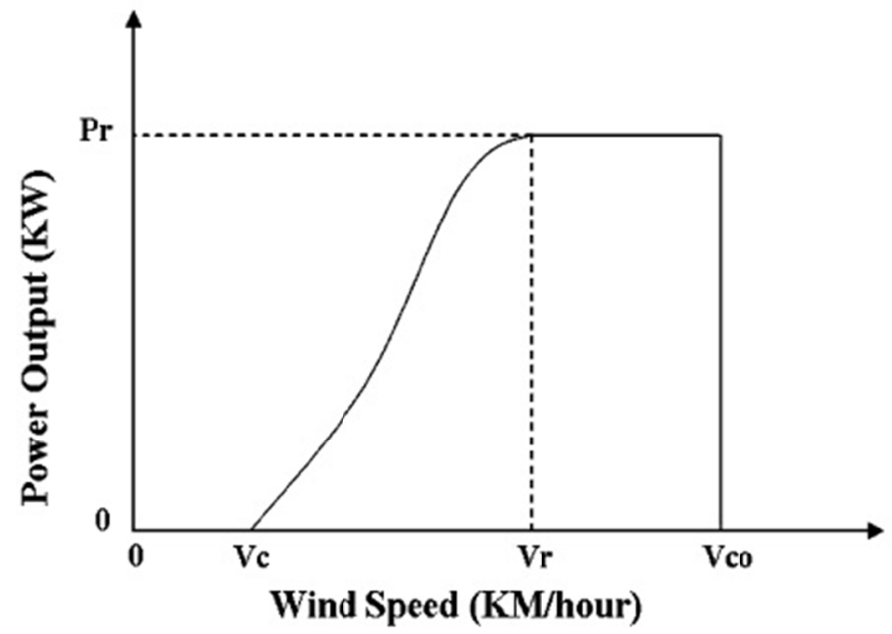

Figure 21- Power generation curve for a wind turbine (Karki, Hu, \& Billinton, A Simplified Wind Power Generation Model for Reliability Evaluation, 2006)

In order to demonstrate the applicability of this approach, reliability of a test system is evaluated using both the proposed wind model and also the common ARMA model and the results are compared. Eventually, in an attempt to further simplify the model, a six-step model is proposed to replace the original 100 point curve. This model is depicted in Figure 22.

\begin{tabular}{cc}
\hline \hline Wind Speed $($ By $\mu$ and $\sigma)$ & Probability \\
\hline$\mu-2^{*}(5 \sigma / 3)$ & 0.0051 \\
$\mu-(5 \sigma / 3)$ & 0.1920 \\
$\mu$ & 0.6120 \\
$\mu+(5 \sigma / 3)$ & 0.1796 \\
$\mu+2^{*}(5 \sigma / 3)$ & 0.0109 \\
$\mu+3^{*}(5 \sigma / 3)$ & 0.0003 \\
\hline \hline
\end{tabular}

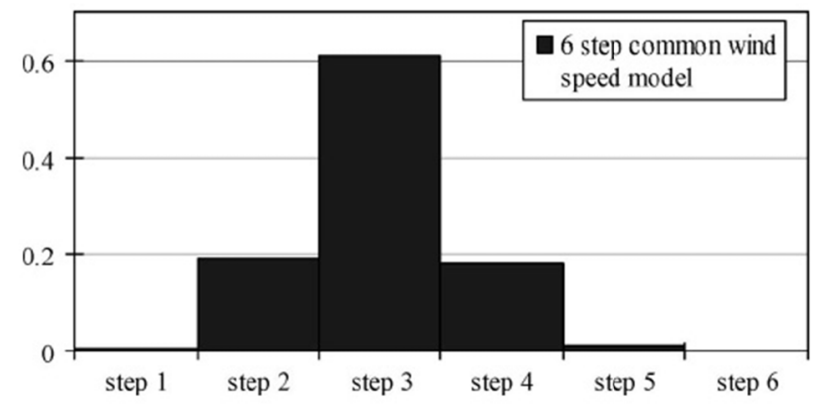

Figure 22- The simplified six step wind speed model (Karki, Hu, \& Billinton, A Simplified Wind Power Generation Model for Reliability Evaluation, 2006)

Another example problem is analyzed in the paper to validate the accuracy of the sixstep model (Figure 23). The results show that this model is adequate for accurate calculation of the Loss of Load Expectation for a given power generation system 
including wind farms (Karki, Hu, \& Billinton, A Simplified Wind Power Generation Model for Reliability Evaluation, 2006).

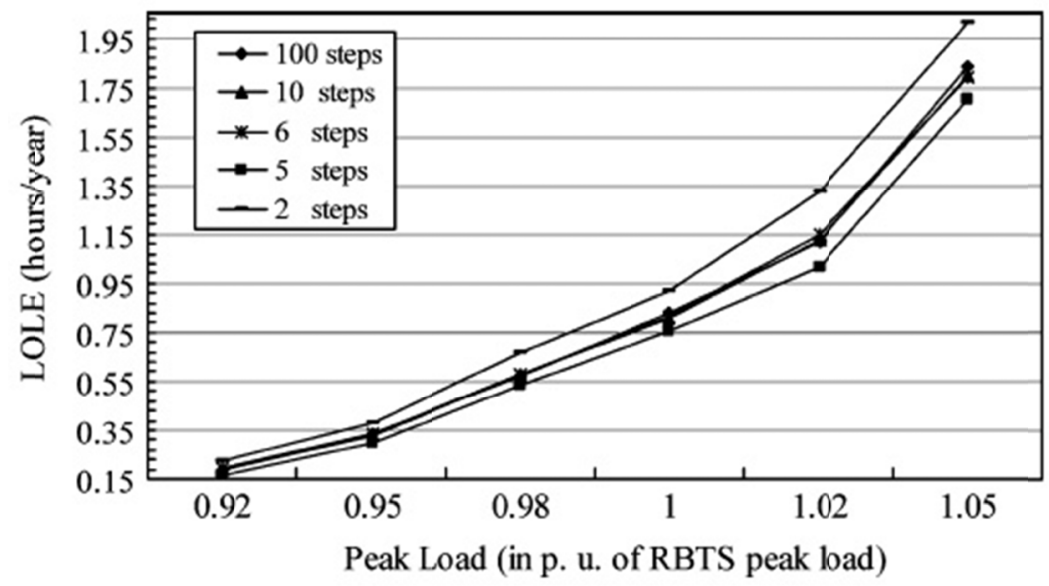

Figure 23-Comparison of different wind speed models (Karki, Hu, \& Billinton, A Simplified Wind Power Generation Model for Reliability Evaluation, 2006)

Wind farm interconnection advantages have also been noticed by several authors in the literature as mentioned earlier. For instance, Archer and Jacobson have investigated the hypothetical reliability gains achievable by interconnecting up to 19 wind farms. Figure 24 shows the complementary cumulative distribution function of wind generated power for arrangement of wind turbines in one, seven and nineteen wind farm locations. As it can be seen, although the probability of power generation at peak rates decreases with increased number of wind farm sites, the likelihood of power generation at very low rates drops as well. Results of this analysis demonstrate that an average of $33 \%$ capacity credit could be achieved by interconnecting multiple wind farms in Mid-Western United States. It is also concluded that the capacity ratio could be further increased by interconnecting more wind farms (Archer \& Jacobson, Supplying Baseload Power and Reducing Transmission Requirements by Interconnecting Wind Farms, 2007). 


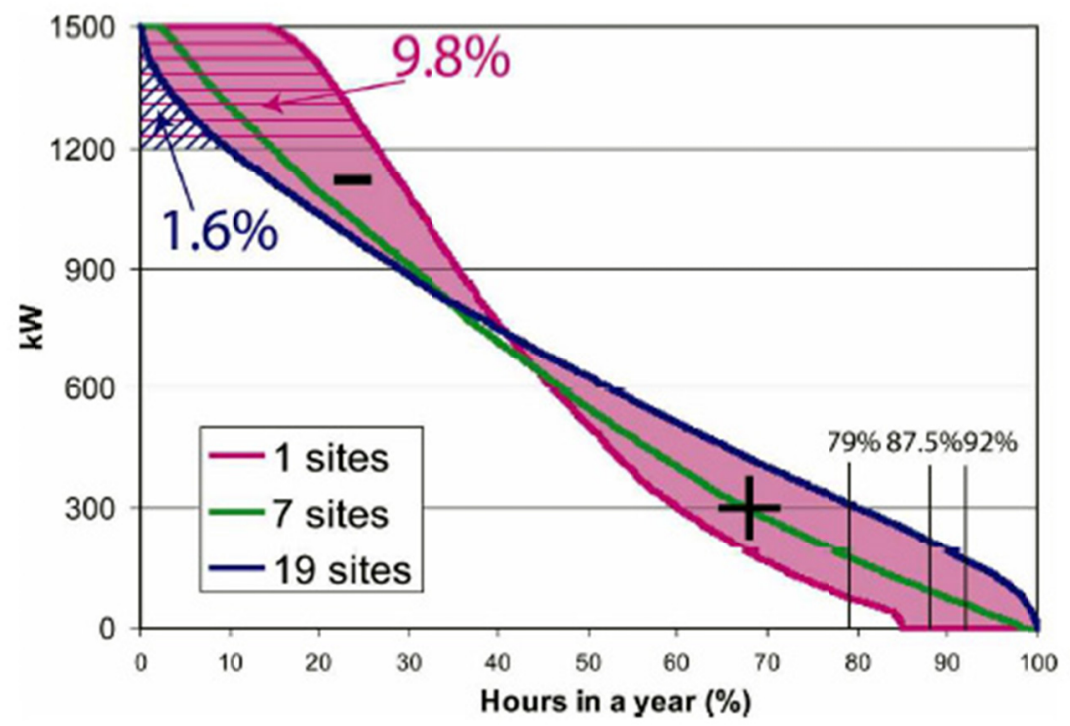

Figure 24- Effect of distribution of wind turbines in multiple sites (American Solar Energy Society, 2007)

There has also been several works in the literature dedicated to exploring the limitations on wind farm sizes resulting from technical constraints. Wiik et al have proposed a simulation-based method for calculation of the maximum allowable number of wind turbines in a wind farm without violating thermal and voltage constraints (Wiik, Gjerde, Gjengedal, \& Gustafsson, 2002). While they have based their calculations on maximum power output from the wind turbines, Zhao et al have utilized a probabilistic model to account for wind speed variations and also tolerance margins of grid constraints. They have confirmed that the probabilistic approach allows for better utilization of wind power generators and larger wind farms compared to the more conservative deterministic approaches (Zhao, Chen, \& Blaabjerg, 2006). Ju et al have addressed the same problem with a different probabilistic approach. They have used a combination of simulation and genetic algorithm to come up with the maximum allowable capacity for wind farms $(\mathrm{Wu}, \mathrm{Li}$, Cheng, \& Sun, 2006). 
Maximizing wind farm capacity subject to probabilistic reliability constraints has also been considered in the literature. Xiaoqing and Yong have developed a model in MATLAB which uses a combination of simulation and genetic algorithm approaches to calculate the maximum installed wind power capacity with respect to load reliability requirements. These probabilistic constraints are defined in terms of LOLE (Loss of Load Expectation) and EENS (Expectation of Energy Not Supplied). No other system configuration constraints are considered in this model (Xiaoqing \& Yong, 2009).

As briefly demonstrated in this section, power generation from wind has been investigated in various senses in the literature. Nevertheless, there still remain lots of possibilities for improvements.

\section{2. $\quad$ Potential Contribution Area}

As discussed earlier, several mathematical methods have been developed for modeling different characteristics of wind power generation. Most of them, however, focus on a specific element. For instance, some researches have concentrated on reliability whereas financial implications are not discussed. In some other cases, the objective has been to maximize wind power utilization although it might not result in the best power source combination with respect to cost and other considerations.

Moreover, most of the models are based on Monte Carlo simulation. While simulation is a very good approach for modeling stochastic processes, it generally involves a huge computational effort. In addition, since simulation is a descriptive method, it is usually not the most efficient way for dealing with optimization problems compared to prescriptive methods. The reason is that finding the best 
solution generally involves some sort of trial and error which translates into several simulation runs. And in the end, optimality of the obtained solution is not guaranteed. Genetic Algorithm and other meta-heuristic approaches are normally more efficient than simulation for optimization purposes. However, they suffer from the same shortcoming (i.e. sub-optimality is highly probable).

Finally, effective use of wind power in electricity generation is greatly dependent on energy storage and power transferring capabilities. Wind power generators cannot achieve a high capacity credit if there is no use for wind generated power surplus. Hence, any plan for effective and substantial utilization of wind power in electricity generation must include provisions for grid storage and out-of-network electricity transfer. This is an area of the subject matter which has not been explored quite as thoroughly.

These observations have provided the incentive for this research project. In the next chapters, a model has been introduced in response to some of the issues mentioned above. While every model has its own limitations, we have tried to incorporate some of the most important details in power generation planning in our formulation. 


\section{Model Assumptions and Theoretical Background}

\section{1. $\quad$ Model outline}

As discussed earlier, the purpose of this research project is to develop a mathematical model which is capable of obtaining the best combination of capacities for each type of energy source in the network. The capacities should be assigned such that the designed network would meet the electricity demand at the desired reliability level while cost is minimized and environmental impact is kept under control. As mentioned before, a prescriptive method will work the best in this case. Also, since there are stochastic parameters involved in the problem, a probabilistic approach is favored. Accordingly, a stochastic optimization model is proposed for this purpose where both demand and wind power are assumed probabilistic.

The stochastic model uses a combination of recourse and chance-constrained approaches for assigning optimal installed capacities for each type of power source while considering energy storage, import and export possibilities within the network. These two approaches are explained in detail in the next section. More specifically, the chance-constrained method is used to model the stochastic nature of electricity demand while recourse action is incorporated in the formulation to accommodate electricity exchanges based on the actual realization of wind speed scenarios.

Some other factors which can be considered in the model include carbon emission cap and carbon tax. Bounds are also imposed on the capacities for each type of power generation source to address a variety of restrictions such as technical, geographical, financial and regulatory constraints. 


\section{2. $\quad$ Probabilistic analysis}

Probabilistic analysis is used in various fields of science. There exist a variety of approaches to deal with such problems in every discipline. Nonetheless, some of the most frequently used methods belong to one of the two broad families of techniques: simulation and analytical approaches.

In simulation, we need to study the characteristics of input parameters and their distributions first. Then, a model is developed to replicate the process under investigation. The more realistic the model, the more precise the results would be. In the next step, using the results from the input analysis, several instances of input parameters are generated and fed to the model. Consequently, we would have a distribution for each output variable which could be used to extract the unknown parameters or performance measures. As mentioned earlier, if the model and the sampling process are sufficiently realistic, simulation can be a straightforward and powerful tool to study probabilistic phenomena. Simulation is specifically useful when the complexity of the problem makes using a direct analytical method cumbersome or impossible.

Analytical approaches involve calculation or estimation of output parameters by manipulating input parameters using probability laws. For example, we might be able to analytically calculate the mean and standard deviation of the output variables based on the functional relationship and statistical measures of the input data. In many instances, the expected value is used for representing a scenario case and making comparisons. The decision making process involved in selecting an investment option among different alternatives based on the expected profit is an example of this 
application. While an analytical solution is generally preferred to simulation, it is not always possible to easily solve a problem analytically without making simplifications. That is when simulation comes in handy. Therefore, it is quite common to use a combination of these methods for probabilistic analysis purposes.

\section{3. $\quad$ Stochastic Optimization}

The general approaches discussed earlier have also been used in optimization studies as well. Starting from the last years of the previous century, simulation has been increasingly used to improve user-defined configurations in order to enhance performance measures of a stochastic discrete-event system (Fu, 2002). Similarly, several stochastic programming approaches are available for modeling uncertainty in optimization problems. In this category, "Two-Stage Stochastic Programming with Fixed Recourse" and "Chance Constrained programming" are two powerful probabilistic programming techniques which have been used in this research. These methods are briefly introduced in the following sections.

\subsubsection{The Recourse Method}

This approach is suitable for those types of problems involving two-stage (or multistage) decision making. In this family of problems, a set of variables represents the decisions made before the stochastic event turnout is revealed (here and now) while a second set of variables denotes the recourse action available after the realization of the stochastic event (wait and see). For example, in a production problem with stochastic demand, the first stage variables can be the assigned production capacities while the second stage variables could be the surplus or the deficit in production 
amounts after the realization of the stochastic demand, which could translate into commodity exchange at the market. So, the second stage variables are used to further optimize the objective function given a specific realization of the stochastic event.

As it can be inferred from the discussion above, the objective function in these problems consists of the first stage costs plus the expected value of the second stage costs. The first stage costs are deterministic; however, since the second stage costs involve uncertainty, their expected value is used as their deterministic equivalent. The general extensive form of formulation for this type of problem is as follows (Birge \& Louveaux, 1997):

$\min c^{T} x+E_{\xi}\left[\min q(\omega)^{T} y(\omega)\right]$

s.t.

$\mathrm{Ax}=\mathrm{b}$

$T(\omega) x+W y(\omega)=h(\omega)$

$\mathrm{x} \geq 0, \mathrm{y}(\omega) \geq 0$

Where $\mathrm{x}$ is the first stage decision variable vector and $\mathrm{c}$ is the corresponding cost matrix $\left(\mathrm{c}^{\mathrm{T}}\right.$ is the transpose matrix). Equation 3.2 is the constraint set for the first stage problem with $\mathrm{A}$ and $\mathrm{b}$ as coefficients and right hand side matrices respectively.

Equation 3.3 is the constraint set for the second stage problem. $y(\omega)$ is the second stage decision variable vector and $\mathrm{W}$ is the fixed recourse matrix. $\omega \in \Omega$ is a specific realization of the random phenomenon $\xi$. The values of the coefficient matrix $\mathrm{T}(\omega)$ and the right hand side $h(\omega)$ as well as the second stage decision variable $y(\omega)$ depend on the particular realization of the stochastic event, $\omega$. Once $\omega$ is specified, $\mathrm{T}(\omega)$ and $\mathrm{h}(\omega)$ are determined and $\mathrm{y}(\omega)$ can be calculated. 
The second term in the objective function is the expected value of the second stage cost which is taken over all possible realizations of the random occurrence, $\xi$. The cost matrix in this term, $q(\omega)$, can also be scenario dependent.

The problem can be formulated in the following implicit form as well:

$\min c^{T} x+E_{\xi} Q(x, \xi)$

s.t.

$\mathrm{Ax}=\mathrm{b}$

$\mathrm{x} \geq 0$

With the second stage problem being:

$\mathrm{Q}(\mathrm{x}, \xi)=\min \mathrm{q}^{\mathrm{T}} \mathrm{y}$

s.t.

$\mathrm{Wy}=\mathrm{h}-\mathrm{Tx}$

$\mathrm{y} \geq 0$

As it could be inferred from the above discussion, using this method involves assigning a number of scenario cases to the random phenomenon and defining the values of input parameters for every scenario, which can sometimes be a cumbersome and time-consuming process. With respect to its scenario based approach, the recourse method is similar to simulation and it can be regarded as a hybrid between analytical and simulation approaches.

\subsubsection{The Chance Constrained Programming Method}

A conventional optimization programming is comprised of an objective function and a set of deterministic constraints. Obviously, every point in the feasible region must satisfy these constraints at all times. In chance constrained programming, however, 
one or more of the constraints are stated using probabilistic terms. This means that a point in feasible region may not necessarily satisfy all the constraints at all times. Nevertheless, the relationship must hold at a prescribed frequency or probability. The general form of a probabilistic constraint is demonstrated below (Birge \& Louveaux, 1997):

$\mathrm{P}\{\mathrm{A}(\omega) \mathrm{x} \geq \mathrm{h}(\omega)\} \geq \alpha$

Which basically asserts that the probability of satisfying constraint $A(\omega) x \geq h(\omega)$ should be equal to or greater than $\alpha$ where $0 \leq \alpha \leq 1$.

One effective approach for solving such problems is to replace each probabilistic constraint with its deterministic equivalent. This process involves deriving the cumulative distribution function (CDF) of the random parameter and sometimes obtaining its inverse function. For example, assume that $\mathrm{A}$ is a constant matrix and $\mathrm{h}$ is a random parameter with a known $\mathrm{CDF}, \mathrm{F}$. That is:

$\mathrm{F}(\mathrm{Z})=\mathrm{P}(\mathrm{h} \leq \mathrm{Z})$

Then we have:

$\mathrm{P}\{\mathrm{A}(\omega) \mathrm{x} \geq \mathrm{h}(\omega)\}=\mathrm{F}\{\mathrm{A}(\omega) \mathrm{x}\}$

So, 3.11 can be rewritten as:

$\mathrm{F}\{\mathrm{A}(\omega) \mathrm{x}\} \geq \alpha$

And inverting both sides of the inequality yields:

$\mathrm{A}(\omega) \mathrm{x} \geq \mathrm{F}^{-1}(\alpha)$

Equation 3.15 is the deterministic equivalent of Equation 3.11.

Thus, application of this technique is most convenient when the random parameter has a closed form cumulative distribution function (CDF). It should also be noted that 
even if this condition is met, the deterministic equivalent constraint is most probably non-linear and possibly non-convex. So, solving the problem might still be quite complicated and labor-intensive.

\section{4. $\quad$ Justification of the Method Used}

As discussed earlier, prescriptive methods are the better options for solving optimization problems. So, a stochastic optimization model is used for this problem. In addition, since energy exchange and storage are to be included in the formulation, a scenario-based method is deemed necessary. Moreover, as two stochastic phenomena (wind and demand) are considered, scenarios would typically represent different realizations of these random parameters. The reliability requirements, however, can be incorporated in the formulation using chance constraints. Under such circumstances, demand scenarios would no longer be necessary.

This approach has two main advantages. Firstly, there is always some inaccuracy in scenario-based analysis when a finite number of realizations are used to model a continuous random parameter. Using chance constrained method avoids dealing with this type of error. Yet, it should be noted that some inaccuracy may also be involved in chance constrained method, especially in fitting distribution function to demand. However, there is more control over this kind of error and it can generally be kept within a reasonable margin.

The other obvious advantage is the smaller number of scenarios since we do not have to deal with demand values explicitly. It should be noted that in this manner, we also manage to keep the problem homogenous. The importance of homogeneity is that it makes scenario reduction techniques much easier to apply. For example, if we 
consider multiple wind farm sites and generate scenarios for each location, since the identifier of the scenarios is power production, they can easily be combined and aggregated. This could not as easily and effectively be done if the identifier of a scenario is a two dimensional vector (production and demand).

\subsection{Wind Energy and Wind Generated Power}

The total amount of kinetic energy available in the wind can easily be calculated using basic physics laws. The kinetic energy in a moving object is equal to the product of half of its mass $(\mathrm{m})$ and square of its velocity $(\mathrm{V})$. So, the energy passing through a specific area (A) during a time interval ( $\mathrm{t}$ ) is equal to:

Wind energy $=0.5 \mathrm{~m} \mathrm{~V}^{2}=0.5(\rho . A . V . t) \mathrm{V}^{2}$

Where $\rho$ is the air density. Dividing by time (t) to obtain the power, we have:

$\mathrm{P}_{\mathrm{w}}=0.5 \rho \cdot \mathrm{AV}^{3}$

However, not all of this power can be harnessed with a turbine. Albert Betz has proven that only about $\% 59$ of this energy can theoretically be captured with a turbine (Betz, 1966). Considering mechanical, friction and other types of losses, the amount that actually can be converted is even less.

The actual power curve of a practical wind turbine is shown in Figure 25. This curve is characterized by four regions which are defined by three wind speeds. At very low speeds, the kinetic energy of the wind is not enough to overcome friction and other losses and thus no power will be generated (Region 1). At Cut-In wind speed (equal to $3.5 \mathrm{~m} / \mathrm{s}$ in the figure), power generation begins (Region 2) and rises with increased wind speed up to the Rated Power of the turbine at the Rated Speed $(14 \mathrm{~m} / \mathrm{s}$ in the figure). From this point on (Region 3), the power production remains constant up to 
Cut-Out wind speed $(25 \mathrm{~m} / \mathrm{s}$ in the figure $)$. At wind velocities beyond this limit, the turbine is shut down to avoid mechanical damage (Region 4).

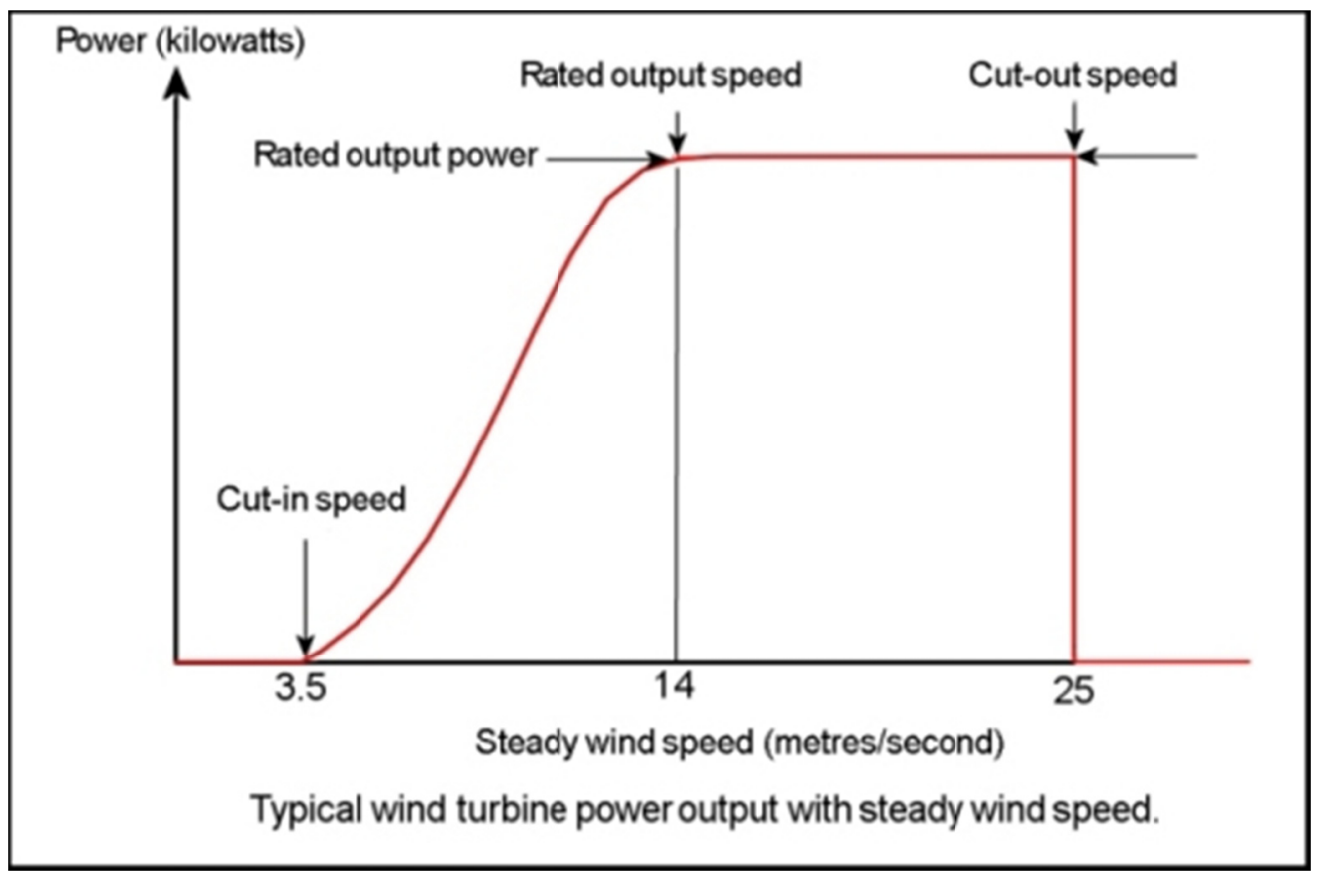

Figure 25- Power curve for a practical turbine (PelaFlow Consulting)

So, we have:

$P_{w}(V)=\left\{\begin{array}{lr}0 & V \leq V_{c i} \text { or } V \geq V_{c o} \\ P_{a s c}(V) & V_{c i} \leq V \leq V_{r} \\ \mathrm{P}_{r} & V_{r} \leq V \leq V_{c o}\end{array}\right.$

Where $\mathrm{V}$ is the wind velocity, $\mathrm{V}_{\mathrm{ci}}$ is cut-in wind speed, $\mathrm{V}_{\text {co }}$ is the cut-out wind speed and $\mathrm{V}_{\mathrm{r}}$ and $\mathrm{P}_{\mathrm{r}}$ are the rated wind speed and power respectively. Several models have been proposed for the ascending segment $\left(\mathrm{P}_{\text {asc }}\right)$ of the power curve (Region 2) including linear, quadratic and cubic formulations (Albadi \& El-Saadany, 2010). Some of these models are more flexible since they possess regression coefficients to fit specific power curves better. However, our preference is to use more generic models defined only by cut-in and rated wind speeds so that the input process of the model is simplified. Among these generic models, linear and quadratic formulations 
have been reported to have a closer fit on average (Akdağ \& Güler, 2010). For our model, we have picked the quadratic formulation since it has a smaller absolute error according to the same report. So, we use the following equation for Region 2 of the curve:

$P_{a s c}(V)=P_{r}\left(\frac{V^{2}-V_{c i}^{2}}{V_{r}^{2}-V_{c i}^{2}}\right)$

\section{6. $\quad$ Wind Speed Distribution}

Another issue that we have to address in the model is the variability of wind speed. Since wind is modeled as a stochastic parameter, a distribution has to be assigned to it. Based on many instances of reported data, Weibull distribution is generally accepted as a good fit for wind speed variability over time (EWEA, 2009). The shape factor is usually taken equal to 2 (Rayleigh distribution). We will use the same approach in our model. So we have:

$f(V)=\frac{2 V}{\lambda^{2}} e^{-\left(\frac{V}{\lambda}\right)^{2}}$

$F(V)=1-e^{-\left(\frac{V}{\lambda}\right)^{2}}$

Where $\mathrm{f}$ is the probability density function, $\mathrm{F}$ is the cumulative distribution function and $\lambda$ is the scale factor. $\lambda$ and mean wind speed $\left(\mathrm{V}_{\text {mean }}\right)$ are linearly related:

$V_{\text {mean }}=\frac{\lambda \sqrt{\pi}}{2}$

\subsection{Demand Distribution}

Electricity demand is the other stochastic parameter in the model. We need to assign a distribution to this parameter as well. Once we have the historical or forecasted data, fitting a distribution is straightforward. However, it should be noted that since we 
intend to solve the problem analytically, it will be greatly helpful to pick a less mathematically complex distribution. Specifically, those distributions with closed form cumulative probability function are preferable.

The electricity demand pattern for small communities or specific isolated systems can be significantly variable in time and space (different from a location to another). However, for large communities consisting of industries, commercial centers and households, like towns and cities, a common trend can be found.

Considering a typical day, demand starts to grow from a minimum level during early hours of morning to a peak value as the industries start up and then gradually fall as businesses shut down. Therefore, the probability density function (PDF) curve is expected to have two peaks, one corresponding to low demand periods and one for high demand periods. The high demand peak is expected to be greater in frequency since high consumption period lasts longer in a typical day. As a result, bell shaped or triangular distributions are often a good fit for the electricity demand histogram, especially in the vicinity of the high demand peak. Some examples of triangular shaped demand functions used in the literature are Normal distribution (Davies \& Paterson, 1962), Beta distribution (Herman \& Kritzinger, 1993), and Gamma distribution (McQueen, Hyland, \& Watson, 2004).

While the shape of the fitted distribution does not impose a limitation on our model, it is always helpful to know what to expect in advance. Based on the above discussion, we know that a closed form triangular distribution function serves our model best. A suitable distribution for this purpose is the Weibull distribution since it is very flexible and capable of taking a triangular form and also it possesses a closed form 
cumulative distribution function (CDF). Some other distributions with similar characteristics include Dagum distribution, Fréchet distribution, Logistic distribution and Erlang distribution. It is worthwhile noting that Erlang distribution is a special case of Gamma distribution, which has already been used in the literature for modeling demand.

\section{8. $\quad$ Intended Users of the Proposed Model}

The main task of the model is to allocate optimal capacities for power generation. Therefore, in a small scale, the model is directly applicable for designing an isolated power system using multiple types of generators or evaluating the reliability of such a system. In a larger scale, almost all of the parties concerned with capacity planning or grid reliability can benefit from this model. It can include several agents and institutions based on the market structure.

\subsubsection{Regulated Market}

In a regulated system, there are typically several governmental agencies in charge of managing electricity supply. One of the most important functions of these agencies is to plan and invest on new generation capacity based on the forecasted future demand. The proposed model provides a suitable instrument for such analyses for individuals with monopolistic privileges.

\subsubsection{Deregulated Market}

A deregulated market, on the other hand, is more complex and involves interactions among numerous players. The participants trade power in energy pools and futures markets. Pool is used for short term electricity trade and comprises of "day-ahead", 
"adjustment" and "balancing" markets. Most of power delivery transactions and exchanges are consolidated at the day-ahead market. Several adjustment markets may follow the day-ahead market later in order to modify the initial transactions. Eventually, the balancing market provides a final opportunity to bridge the gap between supply and demand. It is cleared in real-time and deals with the production surplus or deficit which may result from unforeseen conditions such as sudden demand fluctuations or failures. The final result of market clearing in the pool is the assignment of accepted energy blocks from specific producers and hourly electricity prices. These values are defined such that the total cost of meeting demand is minimized.

Futures markets, on the other hand, are designed for mid-term and long-term transaction. Options and derivatives on electricity prices are offered in this marketplace. The purpose of futures market is to provide opportunities for market participants to hedge against price volatility. It also helps to somewhat stabilize energy prices in a longer time horizon.

Additionally, in order to ensure reliable delivery of electricity, other types of markets are also necessary. Stand-by power is acquired through "reserve market" to provide a safety net against demand fluctuations and facility outages. Load following capability and real-time leveling of supply and demand balance is accommodated within the "regulation market". Arrangements are made in this market such that the system frequency is preserved.

A typical electricity market includes the following agents and institutions (Conejo, Carrion, \& Morales, 2010): 
- Producers: Producers are the owners of power generation units and they can sell electricity through bilateral contracts or in the pool. They can also sell reserve and regulation power in the market.

- Consumers: They are the end users of electricity and they can purchase energy in the market, through bilateral contracts or from retailers.

- Retailers: Generally speaking, retailers do not produce power. They buy electricity in the market or through bilateral contracting and sell it to their customers.

- Non-Dispatchable Producers: These producers operate non-dispatchable sources of energy such as wind turbines and solar power systems. They need to participate in balancing market to cover the deviations from their commitments.

- Market Operator (MO): It runs the market and determines the quantities and rates in power transactions using market clearing procedures.

- Independent System Operator (ISO): ISO is a non-profit entity which is responsible for technical management of the grid. It should provide all of the market agents with equal access to the grid and promote smooth and efficient trade in the market. ISO is generally in charge of clearing the reserve and regulation markets and supports $\mathrm{MO}$ in clearing the balancing market.

- Market Regulator: It is an authority supervising the adequacy and competitiveness of the market. It can enact and enforce rules and regulations in order to fulfill this purpose. 
A schematic diagram of the electricity market and its players are depicted in Figure 26. As stated earlier, the objective of all of the interactions in this marketplace is to supply the demand for electricity and also to determine the price. The targeted time span for these transactions mainly covers short-term and mid-term energy supply.

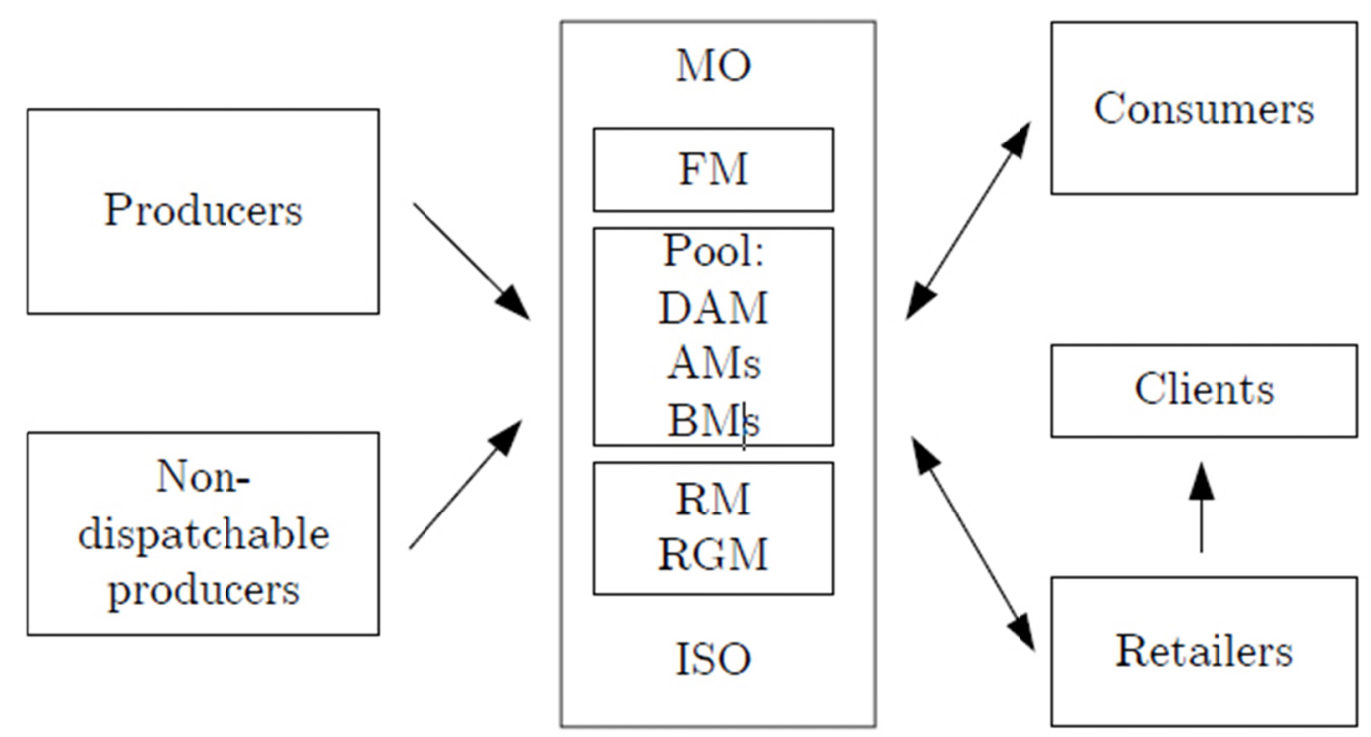

FM: futures market, DAM: day-ahead market, AMs: adjustment markets, BMs: balancing markets, RM: reserve market, RGM: regulation market.

Figure 26- Electricity market (Conejo, Carrion, \& Morales, 2010)

For long-term functionality of energy trade in the market, another type of market is required. These markets are called capacity markets and they serve the purpose of long-term system reliability. Market mechanism is not capable of ensuring resource adequacy in energy market due to several reasons. One of the main reasons for this failure is demand inelasticity (Cramton \& Ockenfels, 2011). So, in most markets, Load Serving Entities (LSE) such as retailers who deliver electricity to end-users are required to contract capacity in excess of their monthly expected peak load to provide a reserve margin. This can be done through bilateral agreements or capacity markets (Creti \& Fabra, 2003). 
The brief outline of a fully-fledged energy market described in previous paragraphs indicates that the developed model can also be used by entities engaging in such markets. This model can best be used by large consumers (such as large industrial plants, etc.) who should fulfill their demand through a combination of bilateral contracts, forward contracts, pool trading and self-production (Conejo, Carrion, \& Morales, 2010).

Furthermore, retailers can use this model to plan for their medium-term electricity trading. The reason is that unlike the pool, prices of medium-term transactions are fixed through forward contracting. So, the retailer can evaluate several available forward contract offers and sign the most profitable agreements.

Producers can also be among the potential users of this model. Similar to any other business entity, producers should invest in their future by planning for reconstruction and expansion. While they can capitalize on the same technology they have used traditionally, it is always a good idea to diversify the investment portfolio. Especially, considering the fact that environmental restrictions on carbon emission and other contaminating refuses of power plants are getting more stringent while sustainable energy production is incentivized, investing in renewable energy seems like a smart move by producers. This model can help a producer plan for capacity expansion while evaluating the potential for saving on fuel consumption and reducing carbon emissions by incorporating wind power generation.

Finally, the model can be used to check the reliability of existing systems (feasibility check). So, entities responsible for ensuring system reliability such as Independent 
System Operator (ISO) or Market Regulator can use the model for that purpose. It can also serve as a simulation tool to evaluate the impacts of new regulations. 


\section{Model Formulation}

\section{1. $\quad \underline{\text { Overview }}$}

In this chapter, the mathematical formulation of the proposed model will be presented. The objective is to assign optimal production capacities for wind power generators and other power production resources subject to meeting demand at a predefined reliability level with the provision of different types of recourse action for dealing with deviations. The electricity demand and wind power are both assumed stochastic.

\subsection{Decision Variables}

As the above explanation indicates, the solution should determine the amounts of electricity to be produced, traded, stored and released. As Figure 27 shows, the major sources of electricity generation in U.S. are coal, natural gas and nuclear energy. Therefore, a separate decision variable has been considered for each one of these main sources in the model. We have also included an additional variable to cover all of the remaining sources of power generation which are not represented explicitly (such as hydropower, petroleum, etc.). A weighted average cost should be calculated for this variable.

For wind power generation, while it is possible to assign a variable for the amount of electricity produced, the number of wind turbines appears to be a better representative. The reason is that there is no fuel cost associated with wind power generation and most of the expense is incurred during construction. So, using the number of installed wind turbines (which is equivalent to the total nameplate 
capacity) is straightforward especially with respect to cost considerations. In addition, while integer variables are naturally expected to denote the wind turbine counts in the model, real valued variables are used to avoid the extra complexity of solving a mixed-integer program and the solution will be rounded up. The rounding error is so small compared to the objective function that it can easily be ignored as demonstrated in the numerical example solution in the next chapter.

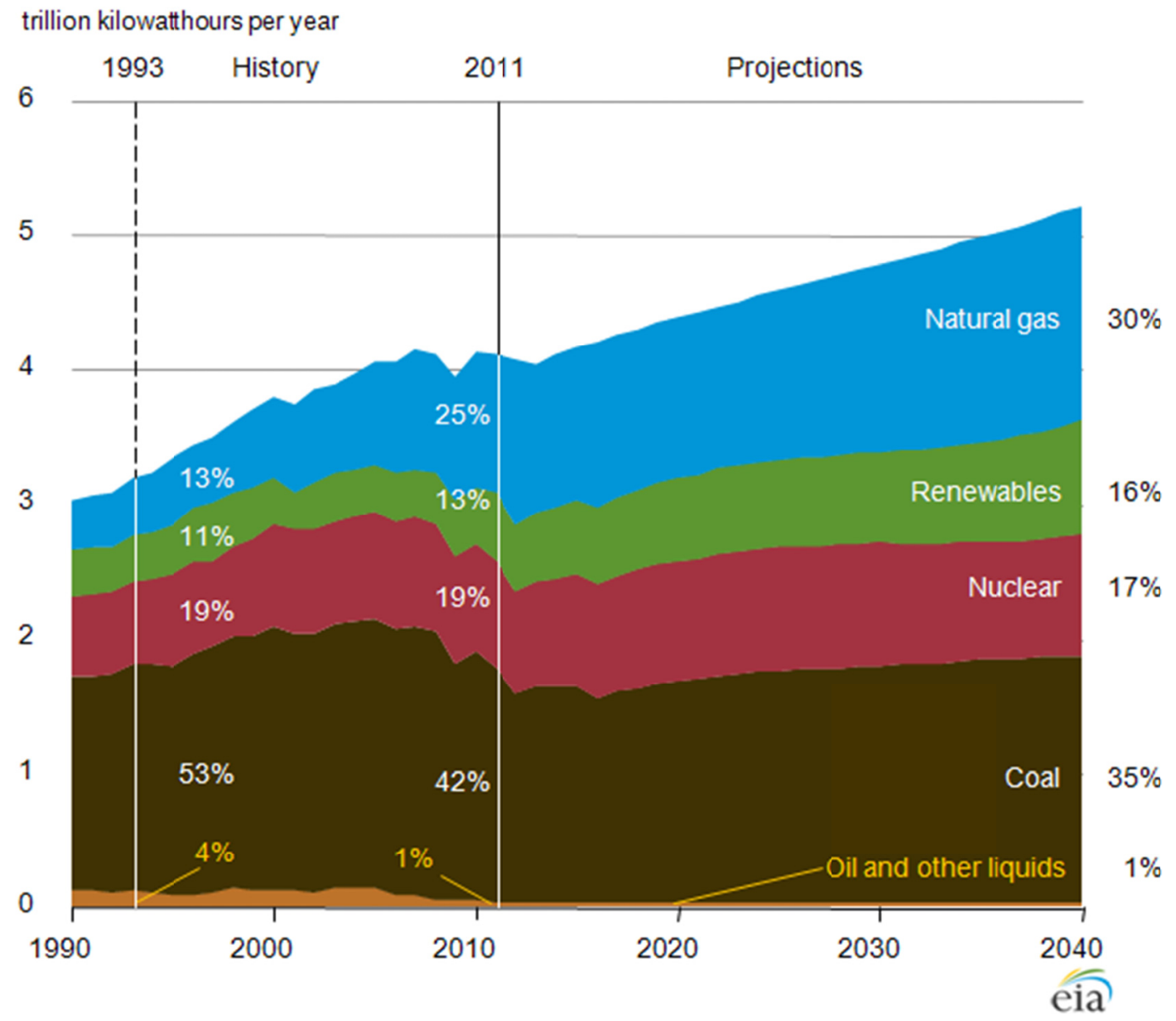

Figure 27- U.S. electricity production by source (U.S. Energy Information Administration, 2013)

The remaining groups of decision variables are scenario dependent and include the amounts of electricity being imported, exported, stored and released in each realization of the random phenomenon. They are all second stage (wait-and-see) 
variables and represent the recourse actions available after first stage decisions are made (After electricity production levels are determined).

\section{3. $\quad$ Model Inputs}

Several scalar parameters and a function must be defined prior to running the model. Scalar parameters include unit cost and capacity factor for each energy source, total cost of wind power generators (construction, setup and maintenance), specifications of wind turbines (cut-in, cut-out and rated speed and rated power), average wind speed in wind farm site, carbon emission per unit of electricity production from fossil fuel plants, carbon emission cap, upper bounds and lower bounds for electricity production units and finally the reliability level.

The input function is the electricity demand distribution which is based on historical or forecasted demand data. This data is generally traced and reported on an hourly basis over several days. So, a distribution function can easily be fitted to this hourly demand data. As discussed in the assumptions (previous chapter), a function with closed form cumulative distribution function (CDF) such as Weibull distribution is favorable. A list of useful functions for this purpose has been presented in the previous chapter.

\subsection{Mathematical Formulation}

As explained earlier, the objective of this optimization model is to minimize electricity procurement cost subject to certain physical, environmental and reliability constraints. The mathematical formulation of the objective function and the 
constraints which collectively constitute the optimization model are presented in following sections.

\subsubsection{Objective Function}

Everything needs to be expressed in the same dimension in the objective function. As mentioned earlier, electricity demand is usually recorded on an hourly basis. Likewise, it is more convenient to scale power production amounts and costs to hourly values. Subsequently, the objective function would yield the expense of meeting demand in one hour.

Furthermore, it should be noted that since we are using the recourse method, several wind speed scenarios must be defined. The cost incurred by scenario-dependent decision variables is the stochastic component of the objective function and it should be expressed in terms of expected value. Thus, the objective function can be written in the following form:

$$
\begin{aligned}
\operatorname{Min} Z & =\left\{C_{c} \cdot X_{c}+C_{g} \cdot X_{g}+C_{n} \cdot X_{n}+C_{r} \cdot X_{r}+C_{w} \cdot X_{w}\right. \\
& \left.+\sum_{I} P_{i} \cdot C_{i m} \cdot \text { Xim }_{i}-\sum_{I} P_{i} \cdot P_{e x} \cdot \text { Xex }_{i}+\sum_{I} P_{i} \cdot C_{s t} \cdot X s t_{i}\right\}
\end{aligned}
$$

The first four terms of the formulation represent cost of power generation using coal, natural gas, nuclear energy and other available sources (except wind) respectively. The terms on the second line of equation 4.1 stand for the expected cost of imported energy, the expected revenue from energy export and the expected cost of energy storage respectively. The problem shall be solved for any reasonable time span, e.g. hour, day, week, month, etc. However, solving for an hour is straightforward as explained earlier. The decision variables are:

$\mathrm{X}_{\mathrm{c}}$ : The amount of energy produced from coal 
$\mathrm{X}_{\mathrm{g}}$ : The amount of energy produced from natural gas

$\mathrm{X}_{\mathrm{n}}$ : The amount of energy produced by nuclear power stations

$\mathrm{X}_{\mathrm{r}}$ : The amount of energy produced by total residual capacity from all other sources

$\mathrm{X}_{\mathrm{w}}$ : Total number of wind turbine units of the designated type in the wind farm

$\mathrm{Xim}_{\mathrm{i}}$ : Amount of imported energy in scenario $\mathrm{i}$

$\mathrm{Xex}_{\mathrm{i}}$ : Amount of exported energy in scenario $\mathrm{i}$

Xst $\mathrm{i}_{\mathrm{i}}$ : Amount of stored energy in scenario i

Xrel $_{\mathrm{i}}$ : Amount of energy released from storage in scenario $\mathrm{i}$

The last decision variable (amount of released energy) will be used in constraints. The parameters are:

$\mathrm{C}_{\mathrm{c}}$ : Cost of power generation from coal (\$/unit energy)

$\mathrm{C}_{\mathrm{g}}$ : Cost of power generation from natural gas (\$/unit energy)

$\mathrm{C}_{\mathrm{n}}$ : Cost of power generation from nuclear energy (\$/unit energy)

$\mathrm{C}_{\mathrm{r}}$ : Weighted average cost of power generation using residual capacity (\$/unit energy)

$\mathrm{C}_{\mathrm{w}}$ : Cost of power generation from wind energy (\$/unit time)

$\mathrm{C}_{\mathrm{im}}$ : Cost of imported energy ( $\$$ /unit energy)

$P_{\text {ex }}$ : Price of exported energy ( $\$$ unit energy)

$\mathrm{C}_{\mathrm{st}}$ : Cost of energy storage (\$/unit energy)

I: Set of all scenarios

$\mathrm{P}_{\mathrm{i}}$ : Probability of scenario i

\subsubsection{Constraints}

The problem should be solved subject to the following constraints:

$P($ Production $\geq$ Demand $) \geq \alpha$ 
$\sum_{I} P_{i} \cdot \mathrm{Xrel}_{i}=E_{s t} \sum_{I} P_{i} \cdot X s t_{i}$

$X_{c} \cdot \operatorname{Co} 2 c+X_{g} \cdot \operatorname{Co} 2 g \leq$ CCap

$L_{C} \leq X_{c} \leq U_{c}$

$L_{g} \leq X_{g} \leq U_{g}$

$L_{n} \leq X_{n} \leq U_{n}$

$L_{r} \leq X_{r} \leq U_{r}$

$L_{w} \leq X_{w} \leq U_{w}$

$X s t_{i} \leq U_{s t}$

$\mathrm{Xrel}_{i} \leq U_{s t}$

$X_{i m} \leq U_{i m}$

$X_{e x} \leq U_{e x}$

$X_{c}, X_{g}, X_{n}, X_{r}, X_{w}$, Xim $_{i}$, Xex $_{i}, X s t_{i} \geq 0$

The parameters used in these constraints are:

$\alpha$ : System reliability

$E_{s t}:$ Efficiency factor for energy storage

$E_{c}$ : Capacity factor for fossil fuel power stations running on coal

Eg: Capacity factor for fossil fuel power stations running on natural gas

$\mathrm{E}_{\mathrm{n}}$ : Capacity factor for nuclear power stations

$E_{r}$ : Weighted average capacity factor for other types of available power stations

$E_{\mathrm{w}}$ : Healthy state probability for wind turbines (i.e. when they are not shut down for repair or maintenance)

Co2c: Amount of carbon emission per unit of power generated from coal (weight/unit energy) 
Co2g: Amount of carbon emission per unit of power generated from natural gas (weight/unit energy)

CCap: Carbon cap (weight)

$L_{c} \& U_{c}$ : Lower and upper bound on energy generated from coal

$\mathrm{L}_{\mathrm{g}} \& \mathrm{U}_{\mathrm{g}}$ : Lower and upper bound on energy generated from natural gas

$L_{n} \& U_{n}$ : Lower and upper bound on energy generated from nuclear plants

$L_{r} \& U_{r}$ : Lower and upper bound on energy generated from other sources

$\mathrm{L}_{\mathrm{w}} \& \mathrm{U}_{\mathrm{w}}$ : Lower and upper bound on number of wind turbines installed

Ust : Upper bound on energy storage

Uim : Upper bound on energy import

Uex : Upper bound on energy export

The first constraint is the reliability requirement. It states that the total energy production should be greater than demand with probability $\alpha$. This includes all the energy generated by deterministic sources, as well as stochastic ones. For wind power, however, the actual amount of production is a random variable. So, the model calculates the amount of wind generated power for each scenario based on installed wind power capacity and wind speed. The installed capacity is incorporated in the model in terms of the number of designated wind turbines in the wind farm.

Since we are considering a scenario-based approach, the probability of production exceeding demand can be obtained by calculating the product of probability of each scenario and probability of production exceeding demand in that scenario and then summing these products up over all possible realizations. Therefore, we can rewrite equation 4.2 as: 
$\sum_{I} P_{i} \cdot P\left(E_{c} X_{c}+E_{g} X_{g}+E_{n} X_{n}+E_{r} X_{r}+E_{w} R_{i} X_{w}+\right.$ Xim $_{i}-$ Xex $_{i}+$ Xrel $_{i}-$ Xst $_{i} \geq$

Demand) $\geq \alpha$

Where $R_{i}$ is the amount of energy generated from a single wind turbine in the wind farm for scenario i over the selected time span, which can be calculated by power curve formulations in equation 3.18. The time span used here should correspond to the time span assigned to demand function. As the equation shows, the net amount of electricity counterbalancing demand should be calculated on the left hand side of the first inequality. This includes all the power generated from available sources including wind plus imported energy and the amount of stored energy released minus exported energy and the amount being stored in current scenario.

Assuming F as the cumulative distribution function (CDF) of Demand, we have:

$\sum_{I} P_{i} \cdot F\left(E_{c} X_{c}+E_{g} X_{g}+E_{n} X_{n}+E_{r} X_{r}+E_{w} R_{i} X_{w}+X_{i m}-X_{i} x_{i}+X_{r e l}-\right.$

$\left.X s t_{i}\right) \geq \alpha$

Equation 4.16 is the deterministic equivalent of equation 4.2. This constraint will almost always be non-linear for all practical demand distributions. So, as discussed earlier, F should be defined carefully to avoid unnecessary complications. Several suitable distribution functions were introduced in the previous chapter for fitting to demand data.

On the other hand, the good news is that this constraint is a convex constraint for sufficiently large reliability values $(\alpha)$. The reason is that for all continuous cumulative distribution functions, beyond a threshold probability, the curve should monotonically increase and asymptotically approach unit probability. Therefore, the left hand side of equation 4.16 constitutes a concave function for any $\alpha$ larger than 
the threshold value and since the inequality is of "greater than or equal" type, this constraint specifies a convex region. As other constraints and the objective function are also convex, the problem will become a convex program for sufficiently large $\alpha$. Generally, $\alpha$ values used in the model are greater than $90 \%$ since systems are designed with high reliabilities for almost all practical purposes. Fortunately, the concavity threshold for fit distributions is well below this limit. For instance, the farthest (rightmost) inflection point possible for the cumulative distribution function of Weibull distribution falls approximately at $63 \%$ probability. Therefore, presumption of sufficiently high reliability is not really a restricting assumption for the model and the problem will be convex for most applications.

Convexity of the formulation has a great significance with respect to computational effort. In a convex program, any locally optimal solution will also be globally optimal. So, the solution process is over once a local optimum is found. Otherwise, the program should be solved with several initial points to find the global extremums. So, this attribute saves us a lot of time and effort.

The next equation (4.3) is the energy conservation constraint. It basically ensures that there is a balance between the amount of stored energy and the released quantities. Loss has also been considered in this equation since regardless of the technology utilized, there will always be some loss and a fraction of the stored energy would not be recovered. Additionally, the amounts of energy exchanged between scenarios have been normalized by probability weights to account for how frequent each scenario is realized. This modification would not be needed if the scenarios had equal probabilities of occurrence. 
Equation 4.4 imposes a restriction on carbon emissions. There are two major sources of carbon emission in our model: coal and natural gas. The average amount of carbon dioxide released in the air from power generation in the US is $1135 \mathrm{lb} / \mathrm{MWh}$ and $2249 \mathrm{lb} / \mathrm{MWh}$ for gas and coal combustion respectively (US EPA, 2012). That is equal to approximately 1 metric ton for coal and half a ton for gas per megawatt-hour of power generation. This constraint allows for incorporation of environmental policies in the model.

The next five constraints (4.5-4.9) impose upper and lower limits on capacities of different types of power generation facilities. Lower limits can represent existing capacities, or minimum production levels which must be fulfilled as a result of policies, strategies or other commitments. Likewise, upper bounds could replicate policy, logistic and budget limitations or other types of restrictions.

The next constraint (4.10) limits the maximum amount of energy storage in each scenario. As discussed earlier, grid storage is quite expensive at the present and regardless of the technology used, provision of storage capacity is confined by several technical and practical restrictions.

Equation 4.11 is also needed to limit the amount of energy released in each scenario. Without this constraint, the electricity accumulated from several scenarios could be released in a single scenario which might exceed the total storage capacity. This would virtually violate the storage constraint. So, equations 4-10 \& 4-11 collectively enforce the storage constraint.

The next two equations (4.12-4.13) restrict the amount of electricity exchange in each scenario. The capacity of transmission lines connecting the grid to external networks 
has a limitation too. These constraints are used to reflect such restrictions on energy importation and exportation.

Finally, equation 4.14 introduces non-negativity constraints to the formulation.

Now that the model is mathematically defined, we can proceed to solve a numerical example in the next chapter in order to validate and verify the model. 


\section{Model Implementation}

In this chapter, we will solve a numerical example in order to evaluate the performance of the model. In the first step, we should define the problem by assigning values and functions to input variables. In other words, we should construct a case study and specify the demand values, available energy generation facilities, wind speeds, costs, etc. in a coherent fashion.

\section{1. $\quad$ Input Data}

In order to obtain realistic results, it is necessary to feed realistic data to the model. Therefore, we have attempted to use actual numbers or historical records for input parameters wherever possible.

\subsubsection{Demand}

One of the core inputs of the model is the demand function. In order to build this function, we need to fit a distribution to demand values. Actual demand data can be obtained from electricity retailers and distributors. PJM Interconnection (PJM) is a Regional Transmission Organization (RTO) which mainly serves North East USA. This company has made valuable hourly load data available to general public through its website (PJM, 2013). We have used 2012 historical data from the southern region of this market for our case study. The company in charge of power distribution for this region is Dominion Virginia.

Now, we have to fit a distribution to this data so that we can replace its cumulative distribution function in equation 4.15. There are several application packages available for distribution fitting. In this study, we have used @ arisk. Statistical 
analysis of the data shows that several distributions are suitable for our problem such as Lognormal, Weibull and even Triangular. As discussed earlier, Weibull distribution is preferred for its closed and differentiable form (Triangular distribution also has a closed form, but it needs to be defined piecewise. So Weibull distribution is more convenient in this sense. In addition, it is a closer fit). Figure 28 shows the fitted distribution.

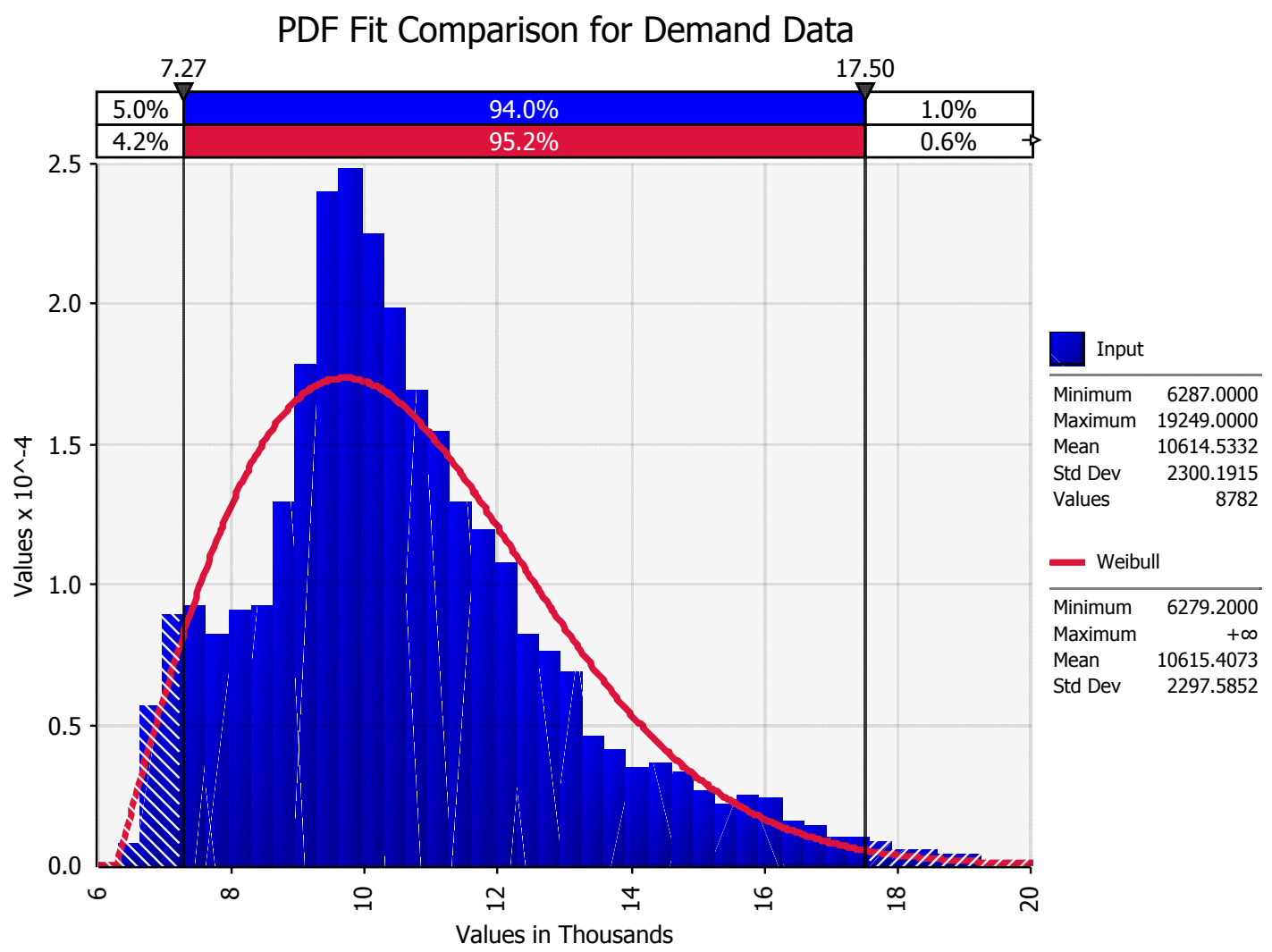

Figure 28- Fitting Weibull distribution to demand data

The demand data appears to have two peaks corresponding to the high consumption (around 10,000 MWh) and low consumption (around $7000 \mathrm{MWh}$ ) periods. While the fitted curve seems unable to fully embrace the high peak of sampled data (none of the distributions considered in this analysis are bimodal), considering the fact that the 
cumulative distribution function (CDF) of demand is engaged in the formulation, Weibull distribution can actually be a good fit for such application.

Figure 29 shows the cumulative distribution functions of the data and the fitted curve. As it can be seen, the two curves do not deviate much from one another and they follow an identical path. Moreover, in most cases where there is a discrepancy, the blue curve (actual demand) is above the red curve. This means that the fitted curve tends to slightly overestimate the demand volume, which works towards increased reliability in our solution. Furthermore, in almost any power network, the objective is to maintain a high level of reliability at all times. Therefore, throughout the mathematical analysis, the right portion of the CDF curve in Figure 29 comes to play, which has a negligible discrepancy from the actual data.

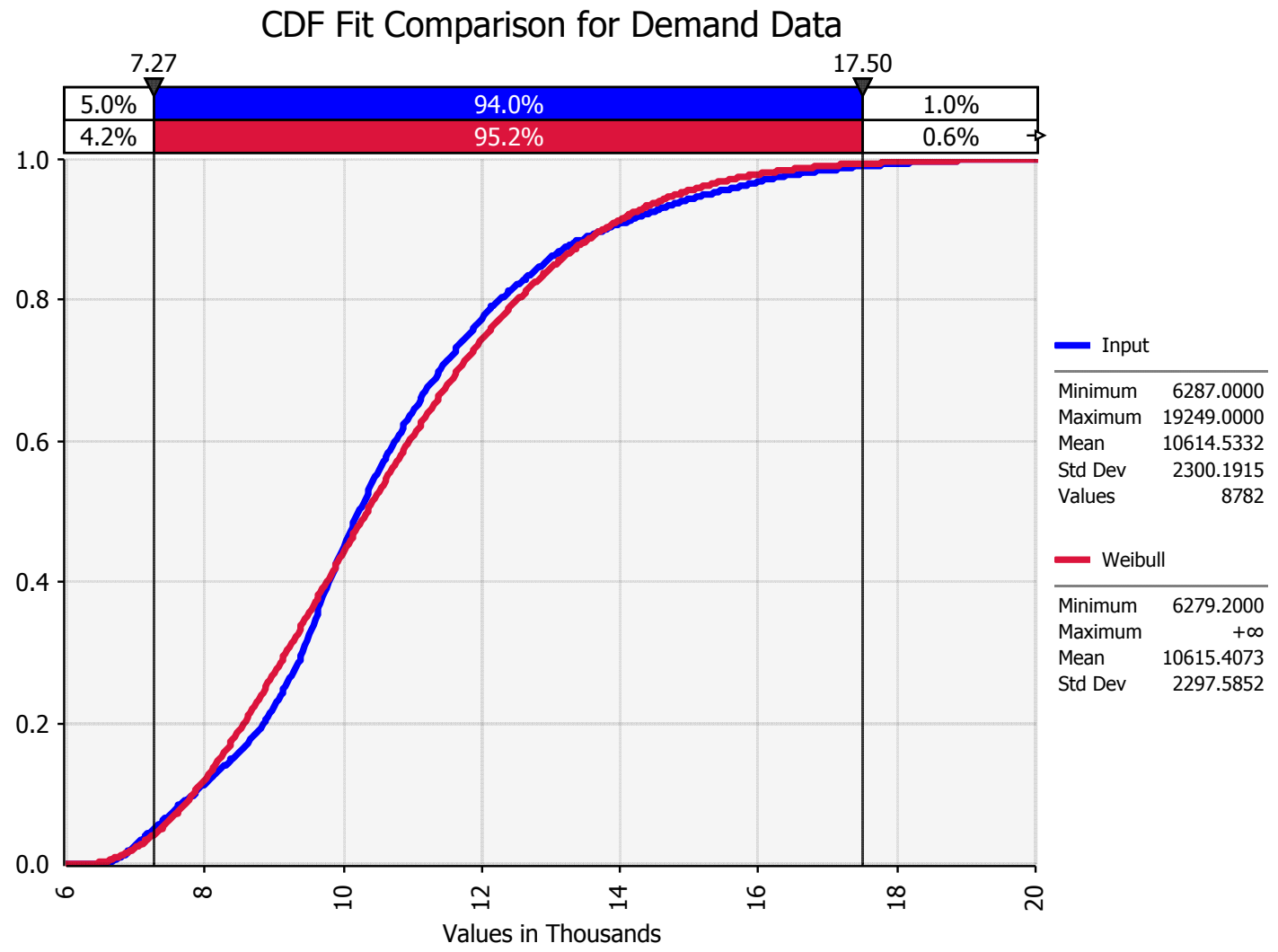

Figure 29- Cumulative distribution function for fitted curve and input data 
Additionally, there is another concern in the formulation which mandates a minimum on the reliability level. As discussed in chapter 3 , in order to be able to solve this nonlinear optimization problem, we need to have a convex program. For this purpose, the concave portion of the CDF curve should be binding as a constraint. According to Figure 29 , this segment roughly corresponds to reliabilities above $40 \%$. The exact value can be calculated by finding the inflection point of demand CDF curve which is defined as follows:

$\mathrm{F}(\mathrm{x})=1-\exp \left(-(\mathrm{x} / \lambda)^{\mathrm{k}}\right)$

Where $\lambda$ is the scale parameter and $\mathrm{k}$ is the shape factor. At the inflection point we have:

$F^{\prime \prime}(x)=0$

So:

$\mathrm{x}^{\mathrm{k}-2}\left(\mathrm{k}(\mathrm{k}-1) / \lambda^{\mathrm{k}}-\mathrm{k}^{2} \mathrm{x}^{\mathrm{k}} / \lambda^{2 \mathrm{k}}\right)=0$

One solution for equation 5.3 is $\mathrm{x}=0$, which is not the inflection point. The other solution is:

$\mathrm{x}=\lambda(1-1 / \mathrm{k})^{1 / \mathrm{k}}$

Or:

$(\mathrm{x} / \lambda)^{\mathrm{k}}=1-1 / \mathrm{k}$

Replacing in 5.1 we have:

$\mathrm{F}($ inflection point $)=1-\mathrm{e}^{1 / \mathrm{k}-1}$

The upper limit for equation 5.6 is obtained when $\mathrm{k}$ is increased toward infinity. So, the highest reliability beyond which concavity of the CDF function is guaranteed is equal to: 
$\mathrm{F}($ inflection point $)<1-1 / \mathrm{e} \approx 63.2 \%$

For our fitted Weibull distribution, $\mathrm{k}$ is equal to 1.97 and so the reliability at the inflection point is about $38.9 \%$ which is way below the values we will be considering. Furthermore, it should be noted that we can always add a constraint set mandating the total supply to be greater than the inflection point value which is not necessary for high reliabilities as discussed.

Finally, it should be noted that since the upper section of the curve is important to us, the best fit for the whole curve might not be the best fit for the segment we are interested in. So, we can adjust the parameters of the fitted distribution to obtain a better fit for the upper segment. For example, using a shape factor (k) of 1.81 gives us a tighter fit for reliabilities above $92 \%$. So, we can use this shape factor when solving the problem in that range of numbers. Alternatively, we can add a fixed amount to demand values as safety factor to make sure that the reliability will never drop below the designated level. This is equivalent to shifting the fitted curve further to the right so that it falls slightly below the actual demand curve. Depending on the situation, one or both of these approaches can be used to obtain a better fit if necessary. The parameters of the Weibull distribution we have used are as follows:

$\mathrm{k}=1.97$

$\lambda=4891.4 \mathrm{MWh}$

Shift $=6279.2 \mathrm{MWh}$

The standard Weibull distribution starts at zero. Since the minimum demand value is much higher than zero, we should shift the standard function to the right so that it roughly starts at minimum demand. This is done by replacing $\mathrm{x}$ with $(\mathrm{x}-$ shift $)$. 


\subsubsection{Wind Speed}

As discussed earlier, Weibull distribution with a shape parameter of 2 has been widely used in the literature for modeling the wind speed distribution in North America. The same approach has been used in this work. In order to define the scale parameter $(\lambda)$, we just need to measure the average wind speed $\left(V_{\text {mean }}\right)$ at the wind farm site. Then, the scale parameter can be easily calculated as follows:

$\lambda=2 \mathrm{~V}_{\text {mean }} / \pi^{1 / 2}$

Figure 30 shows the map of annual average wind speeds at the height of 80 meters for the United States. As it can be seen, the central parts of the country get the highest winds with average speeds above $9 \mathrm{~m} / \mathrm{s}$. Since we have adopted our demand database from PJM, we will assume that the wind farm site is located in the North East.

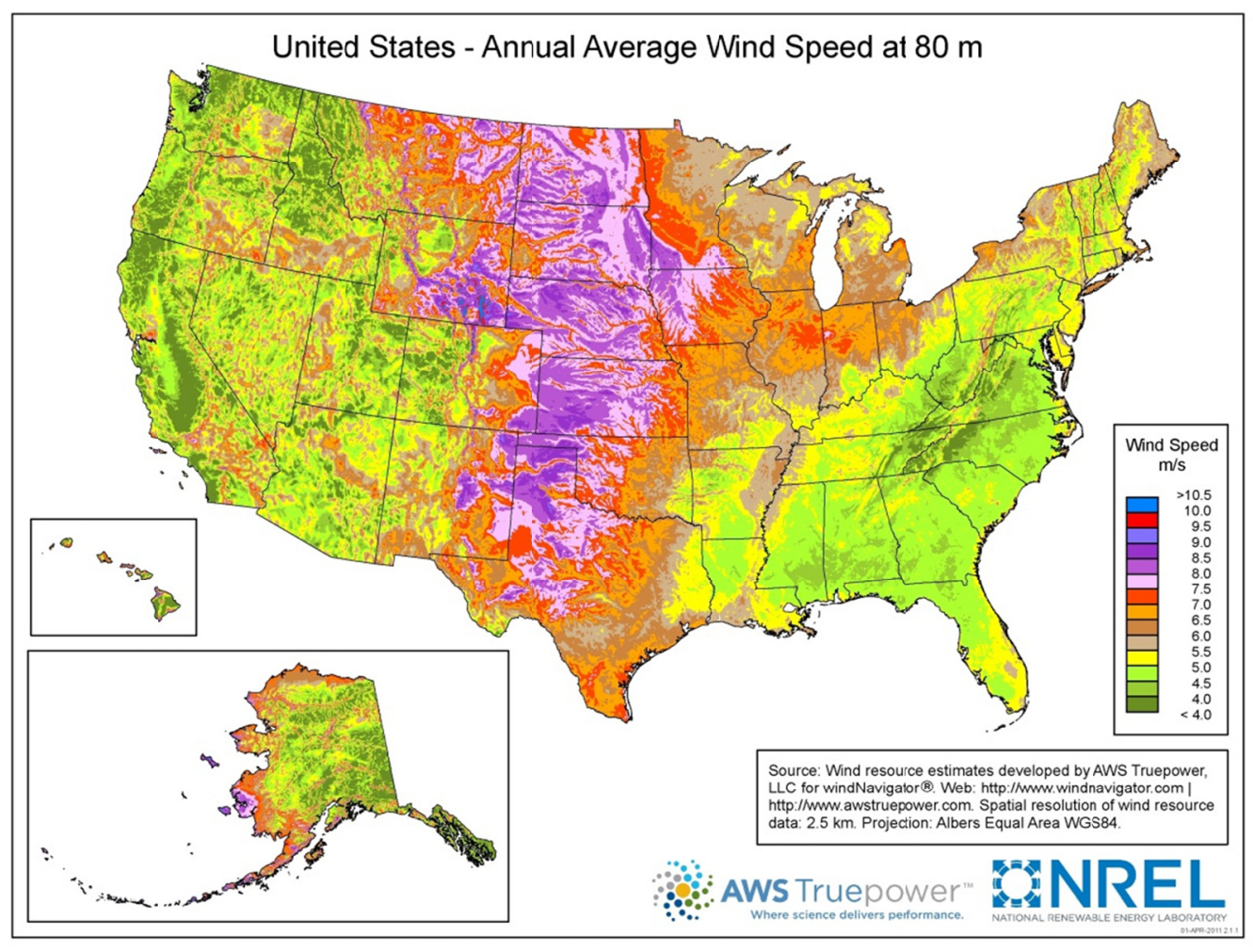

Figure 30- Annual average wind speeds at $80 \mathrm{~m}$ across the US (NREL, 2012) 
While locations with stronger winds might exist as well, the highest average wind speeds visible in that area of the map at this resolution are in the vicinity of $6 \mathrm{~m} / \mathrm{s}$. Furthermore, it should be noted that offshore wind speeds in this area are much higher, as depicted in Figure 31. However, the cost of construction and installation for an offshore wind turbine is several times greater compared to an onshore unit. Accordingly, for this problem, we will consider an onshore wind farm with an average wind speed of $6 \mathrm{~m} / \mathrm{s}$ at 80 meters. The reason for taking the wind speed at such height is that most of the modern grid-scale wind power generators have hub heights of 80 meters and above. So, the scale parameter is equal to:

$\lambda=2 \times 6 / \pi^{1 / 2} \approx 6.77 \mathrm{~m} / \mathrm{s}$

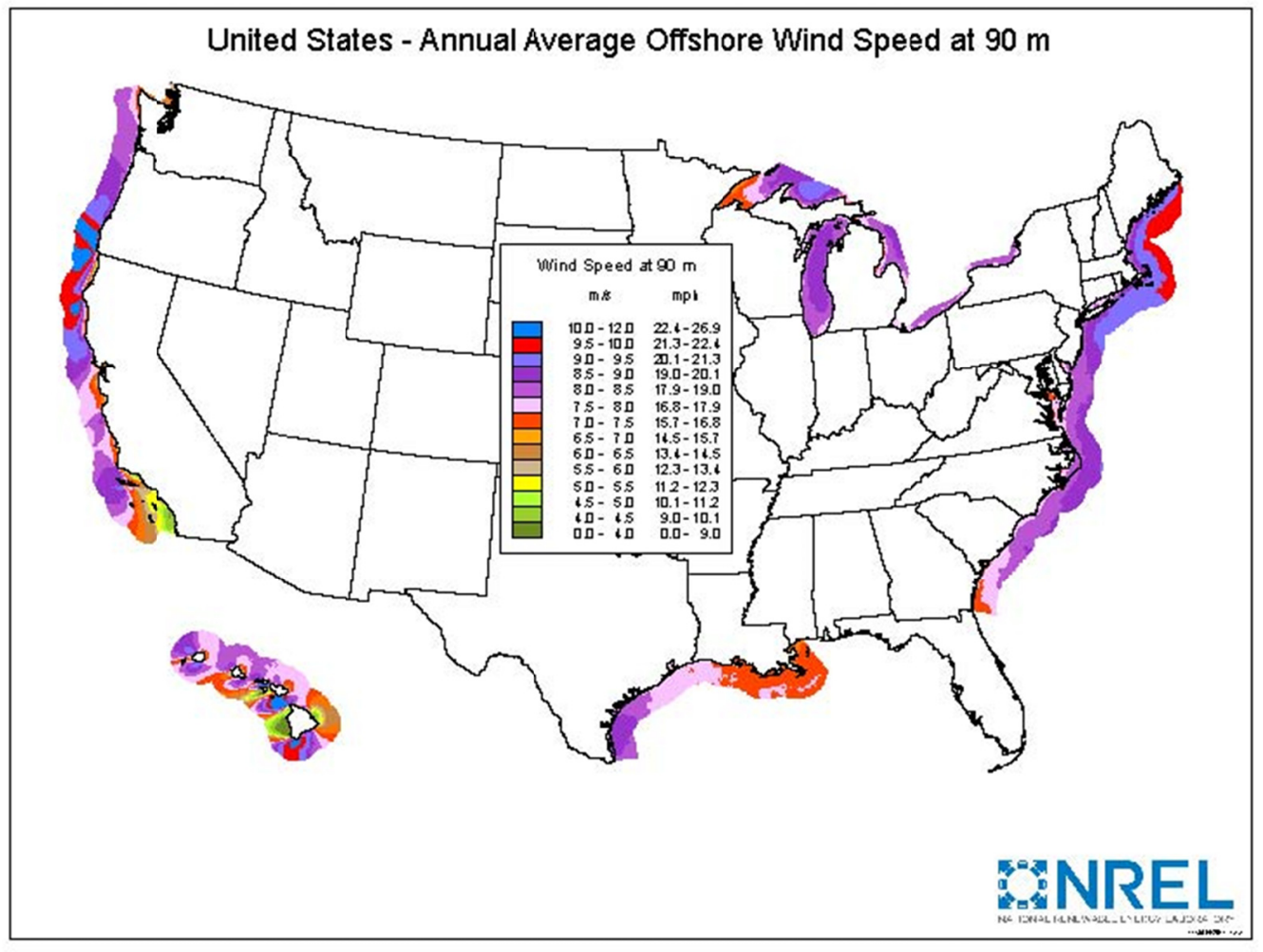

Figure 31- Annual average offshore wind speeds at 90m for US (NREL, 2012) 


\subsubsection{Wind Turbine Specifications}

In order to generate power production scenarios for wind energy, we need to assign a specific type of wind turbine to our wind farm. Since the average wind speed we have assumed for our wind farm is on the lower range, we need a wind turbine which can generate enough power at lower wind speeds. The rated speed $\left(\mathrm{V}_{\mathrm{r}}\right)$ for common wind turbines varies between $11 \mathrm{~m} / \mathrm{s}$ and $16 \mathrm{~m} / \mathrm{s}$. This is the wind speed at which the nominal rated power is produced by the turbine. So, we should pick a wind turbine from the lower end of the rated power spectrum. Considering these provisions, Avantis AV 928 has been selected for the wind farm. This is a German made wind turbine with the following specifications (The Wind Power, 2013):

Wind turbine brand: Avantis

Wind turbine name: AV 928

Nominal power: $2500 \mathrm{~kW}$

Hub height: $80 \mathrm{~m}$

Rotor diameter: $93.2 \mathrm{~m}$

Swept area: $6822.2 \mathrm{~m}^{2}$

Power density: $0.03 \mathrm{~m}^{2} / \mathrm{kW}$

Number of blades: 3

Minimum rotor speed: $16 \mathrm{rad} / \mathrm{min}$

Maximum rotor speed: $18 \mathrm{rad} / \mathrm{min}$

Cut-in wind speed: $3 \mathrm{~m} / \mathrm{s}$

Nominal wind speed: $11.3 \mathrm{~m} / \mathrm{s}$

Cut-out wind speed: $25 \mathrm{~m} / \mathrm{s}$ 


\subsubsection{Wind power generation scenarios}

Now that a type of wind turbine has been specified for the wind farm, we can generate the power production scenarios. In order to do so, we have to start with wind speed distribution and make wind speed scenarios, and then convert them to power generation scenarios using equation 3.18.

For this purpose, we have to discretize wind speed distribution first. Figure 32 shows how the wind speed range between 0 and $25 \mathrm{~m} / \mathrm{s}$ has been divided in to 25 scenarios. Each scenario covers an interval of $1 \mathrm{~m} / \mathrm{s}$ starting from zero. The midpoint of each interval has been selected as the representative wind speed for that scenario. For instance, the first scenario covers the probability of wind speed being between 0 and $1 \mathrm{~m} / \mathrm{s}$ and it is considered as a scenario with a wind speed of $0.5 \mathrm{~m} / \mathrm{s}$. Since the cutout speed for AV 928 wind turbine is $25 \mathrm{~m} / \mathrm{s}$, we can use this discretized and truncated distribution for wind speed scenarios.

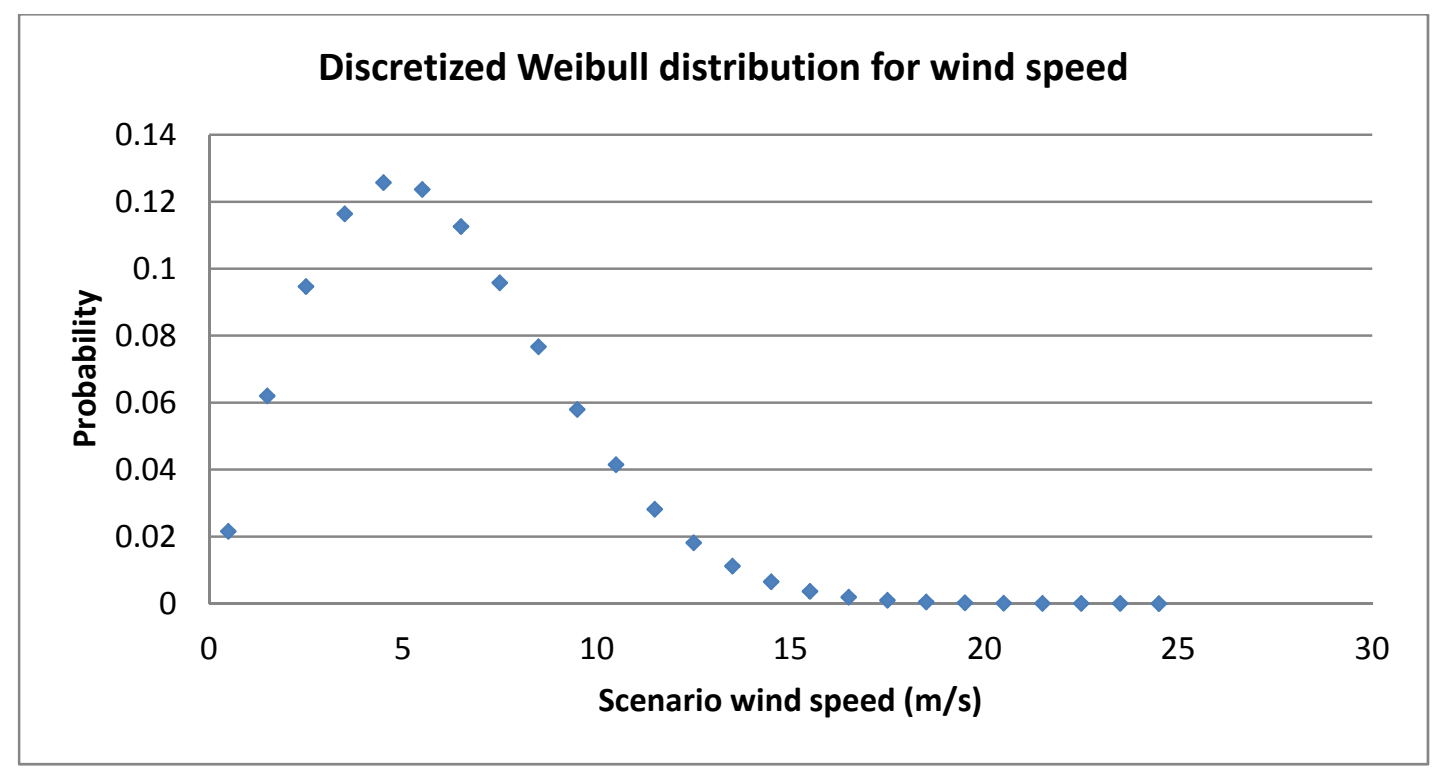

Figure 32- Probability mass function for wind speed scenarios 
Subsequently, we can build power generation scenarios based on wind speed scenarios using equation 3.18. While we can simply plug the representative wind speed values in the wind turbine power curve to get the generated power quantities for each scenario, a smarter approach can be used to reduce the number of scenarios and at the same time increase the accuracy of the solution.

Looking at equation 3.18, we realize that we can group wide ranges of wind speed scenarios under two power production realizations. In other words, for all wind speeds below turbine's cut-in value or above its cut-out value, there is no power generation. Also, for wind speeds ranging from the rated speed up to the cut-out speed, the power production is equal to the rated (nominal) power $\left(\mathrm{P}_{\mathrm{r}}\right)$.

We can easily calculate the probabilities of these two cases and incorporate them as reserved scenarios in our model. For other scenarios (wind speeds varying from the cut-in speed up to the rated speed), the procedure depicted in Figure 32 is required. If the original continuous Weibull wind speed CDF is denoted with G, the probabilities for reserved scenarios can be calculated as follows:

$$
\begin{aligned}
& P(\text { Production }=0)=G\left(V_{\text {cut-in }}\right)+\left(1-G\left(V_{\text {cut-out }}\right)\right) \\
& =1-\exp \left(-\left(\mathrm{V}_{\text {cut-in }} / \lambda\right)^{2}+\exp \left(-\left(\mathrm{V}_{\text {cut-out }} / \lambda\right)^{2}\right.\right.
\end{aligned}
$$

$\mathrm{P}\left(\right.$ Production $\left.=\mathrm{P}_{\mathrm{r}}\right)=\mathrm{G}\left(\mathrm{V}_{\text {cut-out }}\right)-\mathrm{G}\left(\mathrm{V}_{\mathrm{r}}\right)=\exp \left(-\left(\mathrm{V}_{\mathrm{r}} / \lambda\right)^{2}-\exp \left(-\left(\mathrm{V}_{\text {cut-out }} / \lambda\right)^{2}\right.\right.$

Replacing the values for our numerical example we have:

$\mathrm{P}($ Production $=0)=17.8 \%$

$\mathrm{P}\left(\right.$ Production $\left.=\mathrm{P}_{\mathrm{r}}\right)=6.2 \%$ 


\subsubsection{Other Parameters}

The remaining input parameters mainly constitute cost, efficiency and carbon emission information plus capacity caps for power generation facilities. There are two sources of carbon emission in our model: Coal and gas combustion. Based on US EPA (Environmental Protection Agency) estimates, the average emission rate for these sources are (US EPA, 2012):

$\mathrm{Co} 2 \mathrm{c}=1.02$ ton $/ \mathrm{MWh}$

$\mathrm{Co} 2 \mathrm{~g}=0.51$ ton $/ \mathrm{MWh}$

Also, we presume the carbon cap is equal to 12,750 tons:

CCap $=12,750$ ton

In the basic case, no energy exchange or storage is allowed (The impact of adding these options to the model is studied in the sensitivity analysis section):

$\mathrm{U}_{\mathrm{st}}=0$

$\mathrm{U}_{\mathrm{im}}=\mathrm{U}_{\mathrm{ex}}=0$

For other sources, we assume the following caps in order to roughly replicate the average energy source combination for the US according to Figure 27:

$\mathrm{U}_{\mathrm{c}}=10,000 \mathrm{MW}$

$\mathrm{U}_{\mathrm{g}}=5,000 \mathrm{MW}$

$\mathrm{U}_{\mathrm{n}}=5,000 \mathrm{MW}$

$\mathrm{U}_{\mathrm{r}}=2,000 \mathrm{MW}$

$\mathrm{U}_{\mathrm{w}}=2,000$ Units

For assigning cost and efficiency to different sources of energy, we can use the valuable data from Table 1 provided by U.S. Energy Information Administration. 
Table 1- U.S. average levelized costs (2010 \$/MWh) for Plants Entering Service in 2017 (US EIA, 2012)

\begin{tabular}{|c|c|c|c|c|c|c|}
\hline & & & & Variable & & \\
\hline & & Levelized & & O\&M & & Total System \\
\hline & Capacity & Capital & Fixed & (including & Transmission & Levelized \\
\hline Plant Type & Factor (\%) & Cost & O\&M & fuel) & Investment & Cost \\
\hline Dispatchable Tecl & ogies & & & & & \\
\hline Conventional Coal & 85 & 64.9 & 4.0 & 27.5 & 1.2 & 97.7 \\
\hline Advanced Coal & 85 & 74.1 & 6.6 & 29.1 & 1.2 & 110.9 \\
\hline $\begin{array}{l}\text { Advanced Coal } \\
\text { with CCS }\end{array}$ & 85 & 91.8 & 9.3 & 36.4 & 1.2 & 138.8 \\
\hline Natural Gas-fired & & & & & & \\
\hline Conventional & 87 & 17.2 & 1.9 & 45.8 & 1.2 & 66.1 \\
\hline Combined Cycle & & & & & & \\
\hline Advanced & 87 & 17.5 & 1.9 & 42.4 & 1.2 & 63.1 \\
\hline Combined Cycle & & & & & & \\
\hline $\begin{array}{l}\text { Advanced CC } \\
\text { with CCS }\end{array}$ & 87 & 34.3 & 4.0 & 50.6 & 1.2 & 90.1 \\
\hline Conventional & 30 & 45.3 & 2.7 & 76.4 & 3.6 & 127.9 \\
\hline Combustion & & & & & & \\
\hline Turbine & & & & & & \\
\hline Advanced & 30 & 31.0 & 2.6 & 64.7 & 3.6 & 101.8 \\
\hline Combustion & & & & & & \\
\hline Turbine & & & & & & \\
\hline Advanced Nuclear & 90 & 87.5 & 11.3 & 11.6 & 1.1 & 111.4 \\
\hline Geothermal & 91 & 75.1 & 11.9 & 9.6 & 1.5 & 98.2 \\
\hline Biomass & 83 & 56.0 & 13.8 & 44.3 & 1.3 & 115.4 \\
\hline Non-Dispatchable & chnologies & & & & & \\
\hline Wind & 33 & 82.5 & 9.8 & 0.0 & 3.8 & 96.0 \\
\hline Solar PV ${ }^{1}$ & 25 & 140.7 & 7.7 & 0.0 & 4.3 & 152.7 \\
\hline Solar Thermal & 20 & 195.6 & 40.1 & 0.0 & 6.3 & 242.0 \\
\hline Hydro $^{2}$ & 53 & 76.9 & 4.0 & 6.0 & 2.1 & 88.9 \\
\hline
\end{tabular}


Using Table 1, the following values are assigned to our input parameters:

$\mathrm{C}_{\mathrm{c}}=\$ 100 / \mathrm{MWh}$

$\mathrm{E}_{\mathrm{c}}=0.85$

$\mathrm{C}_{\mathrm{g}}=\$ 70 / \mathrm{MWh}$

$E_{g}=0.87$

$\mathrm{C}_{\mathrm{n}}=\$ 110 / \mathrm{MWh}$

$E_{n}=0.90$

For residual power generation capacity, we will assign a higher cost so that it will only be used if the other three sources are fully utilized. This is because the focus of the model is on major sources of energy generation and wind power:

$\mathrm{C}_{\mathrm{r}}=\$ 130 / \mathrm{MWh}$

Additionally, we will start with a high cost for energy import and low price for energy export so that in the next stage we can study the effect of favorable import/export prices on wind power capacity planning:

$\mathrm{C}_{\mathrm{im}}=\$ 140 / \mathrm{MWh}$

$\mathrm{P}_{\mathrm{ex}}=\$ 100 / \mathrm{MWh}$

For wind power generators, manufacturers claim that Forced Outage Rate (FOR) values are less than $4 \%$ while other sources report values around $10 \%$ (Giorsetto \& Utsurogi, 1983). We take the outage probability of $7 \%$ for our model which is somewhere in between:

$\mathrm{E}_{\mathrm{w}}=0.93$

The cost of wind generated power is estimated at $\$ 96 / \mathrm{MWh}$ in Table 1 . Since considering the direct capital cost and maintenance is more realistic and 
straightforward in the model, we will scale the total cost down to hourly values to be consistent with other parameters in our model. The capacity factor reported in Table 1 is 0.33 , so the hourly unit cost of wind power capacity is:

$\mathrm{C}_{\mathrm{w}}=96 \times 0.33=\$ 31.68 / \mathrm{MWh}$

This means that $1 \mathrm{MW}$ of installed wind power generator costs $\$ 31.68$ per hour throughout the life of the wind turbine.

Energy storage parameters depend on the type of technology being utilized. The most commonly used grid storage technology in the world is pumped hydro-electricity. It is also one of the least expensive options available. Therefore, storage parameters of the model are assigned based on this technology. The typical capacity for this type of facility is in the range of $200 \mathrm{MW}$ to $400 \mathrm{MW}$. Storage cost varies between $\$ 50 / \mathrm{MWh}$ and $\$ 150 / \mathrm{MWh}$ and efficiency is in the range of 0.7 to 0.8 (IEA-ETSAP \& IRENA, 2012). Based on these facts, the following values have been set for storage parameters:

$\mathrm{C}_{\mathrm{st}}=\$ 50 / \mathrm{MWh}$

$\mathrm{E}_{\mathrm{st}}=0.8$

And finally, the reliability is initially set to $96 \%$.

$\alpha=0.96$

With all the input parameters in place, we can proceed to solve the problem.

\section{2. $\quad$ Solution and Results}

5.2.1. Transforming the Chance Constraint

At this point, we have all the input data required to define the model including the demand function. In the final step before solving the formulation, we need to 
substitute the designated probability distribution function in constraint 4.2 and rewrite it in the deterministic format of equation 4.15. Accordingly, equation 4.2 can be written as:

$\sum_{i=0}^{I} P_{i} \cdot\left(1-e^{-\left(\frac{E_{C} X_{C}+E_{g} X_{g}+E_{n} X_{n}+E_{r} X_{r}+E_{w} R_{i} X_{w}+\text { Xim }_{i}-\text { Xex }_{i}+\text { Xrel }_{i}-X t_{i}-6279}{4891}\right)^{1.97}}\right) \geq \alpha$

\subsubsection{Solver}

At this stage, the formulation is ready for being processed by a computer solver. It can be coded into any optimization software package capable of solving NLP (NonLinear Programming) problems. The optimization package we have selected for this purpose is GAMS (General Algebraic Modeling System). GAMS is a very powerful optimization program which can employ a variety of solvers for dealing with different types of problems. It is best suited for solving large-scale problems as the language compiler is able to directly operate on indexed expressions. Some of the problem types GAMS is capable of solving include LP (Linear Program), IP (Integer Program), MIP (Mixed Integer Program), NLP, etc. The NLP solver used for this model is known as CONOPT.

\subsubsection{Solution}

Now, we can run the model to obtain a solution. Before we proceed, however, there is one last parameter to set: We need to assign the number of scenarios for wind speed realizations. Since we have initially considered a single wind farm location, there is hardly any computational restriction on the number of scenarios we can consider. So, the model runs are completed within seconds even for unnecessarily large numbers of 
scenarios. For multiple independent wind farms, as we will see, this is not the case since the size of the problem grows exponentially with the number of wind farms.

Table 2 shows the solution for several scenario counts. It should be noted that while the same problem is being solved conceptually, we are dealing with an altered numerical problem when the number of scenarios changes. As it can be seen, the objective function value is fairly accurate even for as few as three scenarios considered. This is mainly caused by the fact that the scenario-dependent decision variable (wind turbine count) does not constitute a major share of supply in the solution. This fact is reflected more conspicuously in the huge variance in the number of wind turbines. Nonetheless, the solution converges rapidly as more scenarios are considered. At 10 scenarios, there is not much difference in the results compared to 500 scenarios. This quick converges is also caused by the scarcity of scenario-based decision variables in the basic case. The convergence rate will drop as different types of energy exchange (importing, exporting and storage) are made available.

Table 2- Basic case solution considering varying number of scenarios

\begin{tabular}{|c|c|c|c|c|c|c|}
\hline $\begin{array}{c}\text { Number of } \\
\text { Scenarios }\end{array}$ & Cost $(\$ / \mathbf{h r})$ & $\mathbf{X}_{\mathbf{c}}(\mathbf{M W})$ & $\mathbf{X}_{\mathbf{g}}$ (MW) & $\mathbf{X}_{\mathbf{n}}(\mathbf{M W})$ & $\mathbf{X}_{\mathrm{r}}$ (MW) & $\mathbf{X}_{\mathrm{w}}$ (Units) \\
\hline 3 & $\$ 1,622,618$ & 10,000 & 5,000 & 1,841 & 0 & 885 \\
\hline 4 & $\$ 1,628,352$ & 10,000 & 5,000 & 2,394 & 0 & 190 \\
\hline 5 & $\$ 1,628,587$ & 10,000 & 5,000 & 2,427 & 0 & 147 \\
\hline 6 & $\$ 1,628,656$ & 10,000 & 5,000 & 2,437 & 0 & 133 \\
\hline 10 & $\$ 1,628,709$ & 10,000 & 5,000 & 2,447 & 0 & 121 \\
\hline 50 & $\$ 1,628,728$ & 10,000 & 5,000 & 2,450 & 0 & 117 \\
\hline 500 & $\$ 1,628,728$ & 10,000 & 5,000 & 2,450 & 0 & 117 \\
\hline
\end{tabular}


According to this solution, for a reliability level of $96 \%$, we need to have $10,000 \mathrm{MW}$ of coal, 5,000 MW of natural gas and 2,450 MW of nuclear power capacity available. Additionally, 117 wind turbine units are also required. Therefore, fossil fueled power stations should be utilized at maximum capacity and the rest of the load is supplied with nuclear power and wind energy. This outcome is commensurate with the cost structure of the problem.

An explanation is deemed necessary here regarding the type of decision variables. Logically, all of the variables can be real valued numbers with the exception of the variable denoting the number of wind turbines. While defining this variable as integer is the natural way of formulating the problem, it will add another order of complexity to this NLP model without almost any merits. In other words, this provision will turn the formulation into a Mixed Integer Non-Linear Program (MINLP) only to avoid the optimality gap created from rounding up a real valued solution which is less than the unit cost of a wind turbine, or $\$ 32 /$ hour. This is roughly around $0.002 \%$ of the objective function value whereas it is very likely for the approximations in input parameters, formulation and even the NLP solving algorithm to exceed that threshold. So, we can confidently avoid the extra complexity of dealing with an MINLP and solve the problem for real valued decision variables.

Returning to the analysis of the solution, it is observed that the share of wind power in power generation is very low. One hundred and seventeen units of Avantis AV 928 turbines add up to $292.5 \mathrm{MW}$ of nameplate capacity, which is less than $2 \%$ of the total capacity provided by other sources combined $(10,000+5,000+2,450=17,450$ MW). 
The amount of carbon emission for this combination of sources is equal to 12,750 tons, which is equals the maximum limit (CCap). So, further restrictions on carbon emission are required to push for utilizing other sources of energy.

In order to see how much conventional capacity can be replaced by wind power in the basic case, we have to solve the problem assuming wind power generation is not allowed. This provision will lead to the following solution:

Table 3- Solution for the base case without wind power

\begin{tabular}{|c|c|c|c|c|c|}
\hline Cost $\mathbf{( \$ / \mathbf { h r } )}$ & $\mathbf{X}_{\mathbf{c}} \mathbf{( M W )}$ & $\mathbf{X}_{\mathbf{g}} \mathbf{( M W )}$ & $\mathbf{X}_{\mathbf{n}} \mathbf{( M W )}$ & $\mathbf{X}_{\mathbf{r}} \mathbf{( M W )}$ & $\mathbf{X}_{\mathbf{w}}$ (Units) \\
\hline $1,628,974$ & 10,000 & 5,000 & 2,536 & 0 & 0 \\
\hline
\end{tabular}

As the solution indicates, $86 \mathrm{MW}$ of extra conventional capacity $(2,536-2,450=86)$ is required to cover for wind energy. So, the capacity credit for wind power generation is:

Capacity Credit $=86 / 292.5 \approx 30 \%$

Which is typical for wind turbines. In the next section, we will study how variation of different parameters in the model can affect the energy supply combination. 


\section{Model Testing and Sensitivity Analysis}

In order to figure out the dynamics of the model and verify its functionality, we have carried out a series of sensitivity analyses. More than eighty instances of the model with different input parameters have been solved to ensure that the model responds rationally when there is a change in circumstances.

\section{1. $\quad$ Reliability level}

In this analysis, the problem is solved for a set of reliability values from $80 \%$ to $99 \%$. The results for seven instances are summarized in Table 4. As expected, the total cost of meeting demand grows monotonically with increased reliability levels. The marginal increase in cost is also greater at higher reliability values, as Figure 33 demonstrates.

Furthermore, share of wind power in power supply decreases at higher reliability levels. This behavior is illustrated in Figure 34 .

Table 4- Sensitivity analysis with respect to reliability level

\begin{tabular}{|c|c|c|c|c|c|c|}
\hline Reliability & Cost $(\$ / \mathbf{h r})$ & $\mathbf{X}_{\mathrm{c}}(\mathbf{M W})$ & $\left.\mathbf{X}_{\mathrm{g}} \mathbf{( M W}\right)$ & $\left.\mathbf{X}_{\mathrm{n}} \mathbf{( M W}\right)$ & $\left.\mathbf{X}_{\mathrm{r}} \mathbf{( M W}\right)$ & $\mathbf{X}_{\mathrm{w}}$ (Units) \\
\hline 0.99 & $\$ 1,844,525$ & 10,000 & 5,000 & 4,430 & 0 & 92 \\
\hline 0.98 & $\$ 1,741,367$ & 10,000 & 5,000 & 3,485 & 0 & 102 \\
\hline 0.97 & $\$ 1,676,804$ & 10,000 & 5,000 & 2,893 & 0 & 109 \\
\hline 0.96 & $\$ 1,628,728$ & 10,000 & 5,000 & 2,450 & 0 & 117 \\
\hline 0.90 & $\$ 1,459,454$ & 10,000 & 5,000 & 890 & 0 & 146 \\
\hline 0.85 & $\$ 1,373,918$ & 10,000 & 5,000 & 96 & 0 & 170 \\
\hline 0.80 & $\$ 1,309,551$ & 9,555 & 5,000 & 0 & 0 & 52 \\
\hline
\end{tabular}




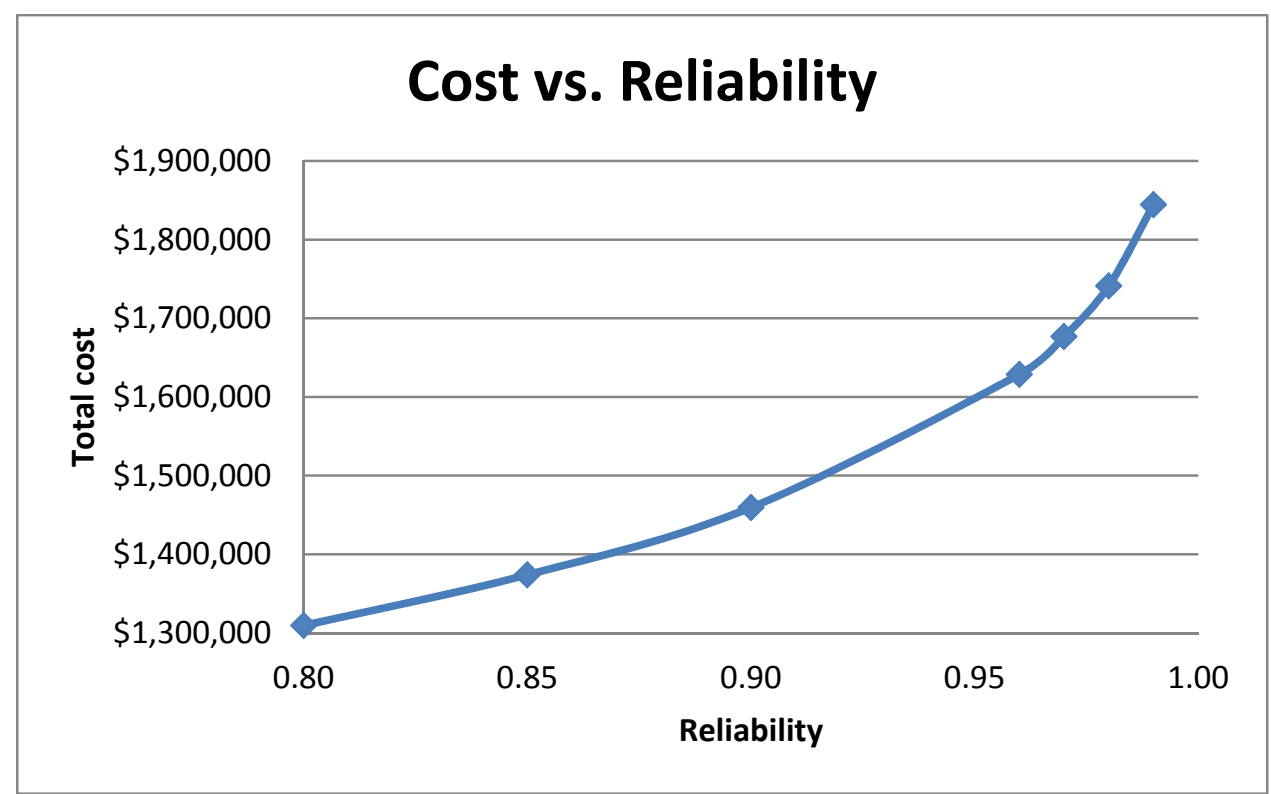

Figure 33- Cost increase at higher reliability levels

While one might initially expect the number of wind turbines to increase as the reliability is reduced, Figure 34 shows a sudden decrease at reliability of $85 \%$ compared to higher values. This is resulting from the fact that the more expensive nuclear power is no longer needed at this reliability level and the wind power has to compete with the less expensive coal generated electricity. If we slightly reduce the cost of wind power, the previous trend will be recovered.

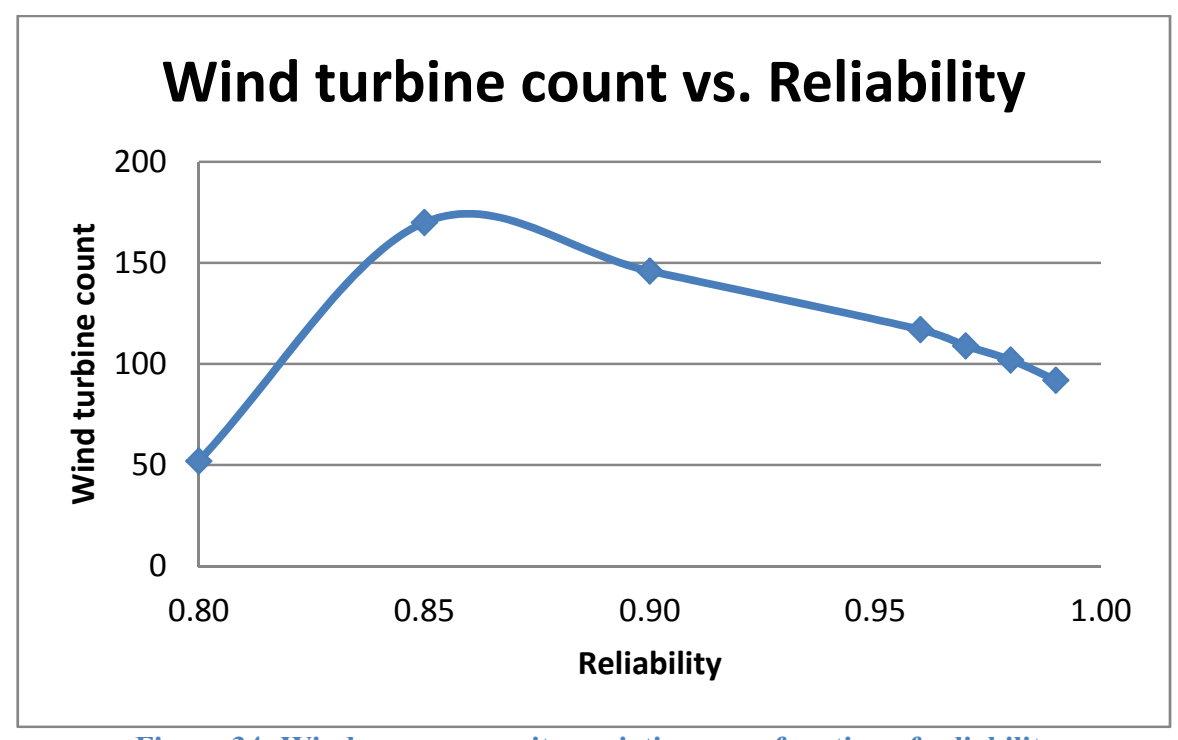

Figure 34- Wind power capacity variations as a function of reliability 


\section{2. $\quad$ Carbon Cap}

In this section, we will investigate the effect of carbon emission restriction on the model. Table 5 summarizes nine solutions covering a wide range of carbon cap values. As these calculations show, carbon caps above 12,750 ton/hour will not affect the solution in any fashion. Below this threshold, however, the capacity of coalburning facilities will be reduced in favor of other clean alternatives. At the beginning of this trend, the capacity cut resulting from carbon emission restriction is compensated for by utilizing additional nuclear power capacity available.

Table 5- Sensitivity analysis with respect to carbon cap limit

\begin{tabular}{|c|c|c|c|c|c|c|}
\hline $\begin{array}{c}\text { Ccap } \\
\text { (ton/hr) }\end{array}$ & Cost $\mathbf{( \$ / h r )}$ & $\mathbf{X}_{\mathbf{c}}(\mathbf{M W})$ & $\mathbf{X}_{\mathbf{g}}(\mathbf{M W})$ & $\mathbf{X}_{\mathbf{n}}(\mathbf{M W})$ & $\mathbf{X}_{\mathbf{r}}(\mathbf{M W})$ & $\mathbf{X w}$ (Units) \\
\hline 6,600 & Infeasible & 3,971 & 5,000 & 5,000 & 2,000 & 2,000 \\
\hline 6,700 & $\$ 1,705,118$ & 4,069 & 5,000 & 5,000 & 2,000 & 1,746 \\
\hline 7,000 & $\$ 1,680,257$ & 4,363 & 5,000 & 5,000 & 2,000 & 1,061 \\
\hline 7,500 & $\$ 1,664,584$ & 4,853 & 5,000 & 5,000 & 1,995 & 253 \\
\hline 8,000 & $\$ 1,659,437$ & 5,343 & 5,000 & 5,000 & 1,578 & 253 \\
\hline 9,000 & $\$ 1,649,143$ & 6,324 & 5,000 & 5,000 & 745 & 253 \\
\hline 10,000 & $\$ 1,639,213$ & 7,304 & 5,000 & 4,996 & 0 & 117 \\
\hline 12,750 & $\$ 1,628,728$ & 10,000 & 5,000 & 2,450 & 0 & 117 \\
\hline 14,000 & $\$ 1,628,728$ & 10,000 & 5,000 & 2,450 & 0 & 117 \\
\hline
\end{tabular}

After nuclear power reaches full capacity, the more costly residual power generation capacity (denoted by $\mathrm{X}_{\mathrm{r}}$ ) is used along with some additional wind power capacity. When the residual capacity is also fully utilized, only the reserve wind power capacity will be left. Therefore, a large hike in the number of wind turbines is observed at this 
point. As the carbon cap is further reduced, more wind turbine units will be deployed until the available wind power capacity is fully installed. This trend is graphically illustrated in Figure 35. Yet if the carbon cap is reduced further, the model will be rendered infeasible.

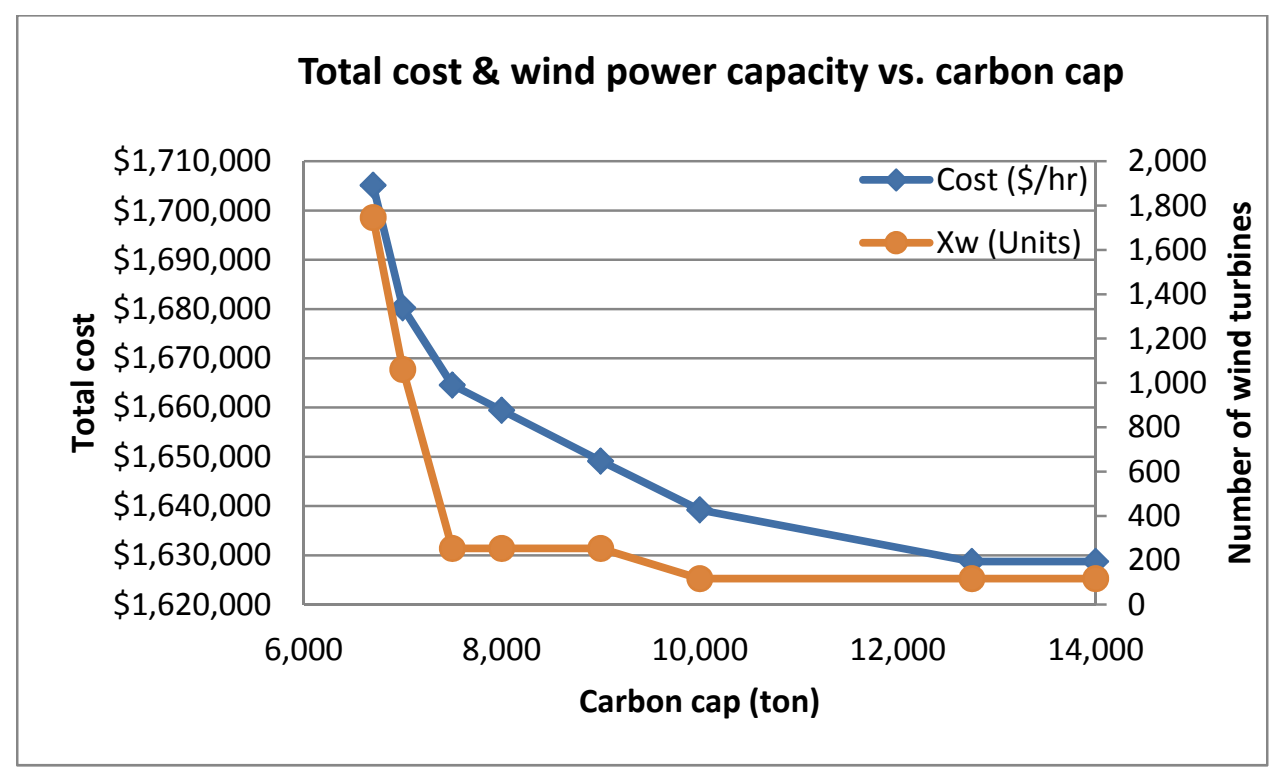

Figure 35- Impact of lowering carbon cap limit

It should be noted that even if the limit on wind power capacity is removed, the ability of wind power to reliably satisfy demand would still be very limited. Table 6 shows the results of six more runs with the wind power capacity cap removed. As the capacity cap is lowered under 6,000 tons, the number of wind turbines increases rapidly to compensate for the lost capacity from coal burning facilities. However, the efficiency of wind power generation drops according to the last column of the table (capacity credit). 
Table 6- Sensitivity analysis on carbon emission limit with wind power capacity removed

\begin{tabular}{|c|c|c|c|c|c|c|c|}
\hline $\begin{array}{c}\begin{array}{c}\text { Ccap } \\
\text { (ton } / \mathrm{hr} \text { ) }\end{array} \\
\text { (1) }\end{array}$ & Cost (\$/hr) & $\mathrm{X}_{\mathrm{c}}(\mathrm{MW})$ & $\mathrm{X}_{\mathrm{g}}(\mathrm{MW})$ & $\mathrm{X}_{\mathrm{n}}(\mathrm{MW})$ & $\mathrm{X}_{\mathrm{r}}(\mathrm{MW})$ & $\begin{array}{c}\text { Xw } \\
\text { (Units) }\end{array}$ & $\begin{array}{c}\text { Capacity } \\
\text { Credit (\%) }\end{array}$ \\
\hline 6,600 & $\$ 1,717,354$ & 3,971 & 5,000 & 5,000 & 2,000 & 2,024 & $26.5 \%$ \\
\hline 6,000 & $\$ 1,858,996$ & 3,382 & 5,000 & 5,000 & 2,000 & 4,556 & $17.0 \%$ \\
\hline 5,500 & $\$ 2,153,679$ & 2,892 & 5,000 & 5,000 & 2,000 & 8,895 & $10.9 \%$ \\
\hline 5,000 & $\$ 2,961,244$ & 2,402 & 5,000 & 5,000 & 2,000 & 19,711 & $5.9 \%$ \\
\hline 4,500 & $\$ 7,514,023$ & 1,912 & 5,000 & 5,000 & 2,000 & 77,814 & $1.7 \%$ \\
\hline 4,000 & Infeasible & 1,422 & 5,000 & 5,000 & 2,000 & Inf & N/A \\
\hline
\end{tabular}

When the carbon cap is lowered below 5,000 tons limit, there will be a sudden increase in the rate of growth for wind power capacity as well as the total cost, as illustrated in Figure 36.

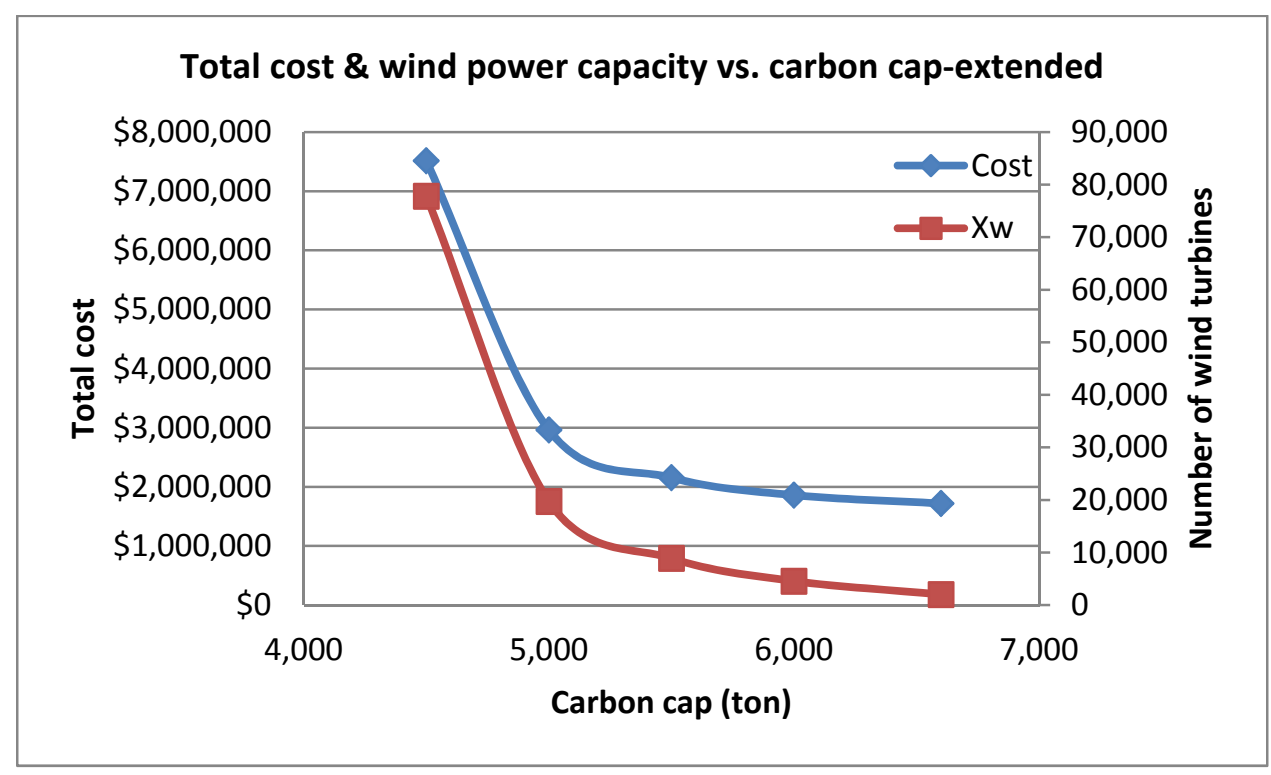

Figure 36- Extended observation of carbon cap impact on wind power capacity and cost 
From this point on, more than 3,000 megawatts of conventional capacity should be replaced with wind power without any loss in system reliability. This is a challenging task to accomplish and requires excessive investment on wind power generation. At a cap limit of 4,500 tons, the total cost and count of wind turbines are extremely high although they are severely underutilized. When the cap is further lowered to 4,000 tons, wind power is unable to effectively replace the lost conventional capacity at any cost and the model becomes infeasible.

\section{3. $\quad$ Average wind speed}

Obviously, stronger winds lead to greater quantities of wind generated power. In this subsection, we will numerically study the effect of high winds on wind power utilization. Table 7 lists fifteen solutions for average wind speed values starting from $5.5 \mathrm{~m} / \mathrm{s}$ up to $14 \mathrm{~m} / \mathrm{s}$. The last column in the table is the ratio of nominal wind power capacity to the total capacity from all other sources.

As calculations show, for average wind speeds below $5.5 \mathrm{~m} / \mathrm{s}$, the quantity of power generated from wind does not justify any investments in wind power considering current cost structure of the problem. At $6 \mathrm{~m} / \mathrm{s}$ however, the share of wind energy rises to near 2\% limit. From this point on, as Figure 37 demonstrates, wind power capacity increases rapidly with a descending slope. At $12 \mathrm{~m} / \mathrm{s}$, wind capacity reaches its maximum which amounts to more than $30 \%$ of the total capacity from other sources. After this threshold, the number of wind turbines in the solution starts to drop slowly. 
Table 7- Solutions for varied values of average wind speed

\begin{tabular}{|c|c|c|c|c|c|c|}
\hline $\mathbf{V}_{\text {mean }}(\mathbf{m} / \mathbf{s})$ & Cost $\mathbf{\$} / \mathbf{h r})$ & $\mathbf{X}_{\mathbf{c}}(\mathbf{M W})$ & $\mathbf{X}_{\mathbf{g}}(\mathbf{M W})$ & $\mathbf{X}_{\mathbf{n}}(\mathbf{M W})$ & $\mathbf{X} \mathbf{w}$ (Units) & $\mathbf{X}_{\mathbf{w}}(\%)$ \\
\hline 5.5 & $\$ 1,628,974$ & 10,000 & 5,000 & 2,536 & 0 & $0.0 \%$ \\
\hline 6.0 & $\$ 1,628,728$ & 10,000 & 5,000 & 2,450 & 117 & $1.7 \%$ \\
\hline 6.5 & $\$ 1,625,167$ & 10,000 & 5,000 & 2,186 & 439 & $6.4 \%$ \\
\hline 7.0 & $\$ 1,618,580$ & 10,000 & 5,000 & 1,937 & 701 & $10.3 \%$ \\
\hline 7.5 & $\$ 1,610,029$ & 10,000 & 5,000 & 1,701 & 921 & $13.8 \%$ \\
\hline 8.0 & $\$ 1,600,219$ & 10,000 & 5,000 & 1,476 & 1,110 & $16.8 \%$ \\
\hline 8.5 & $\$ 1,589,674$ & 10,000 & 5,000 & 1,262 & 1,274 & $19.6 \%$ \\
\hline 9.0 & $\$ 1,578,835$ & 10,000 & 5,000 & 1,060 & 1,418 & $22.1 \%$ \\
\hline 9.5 & $\$ 1,568,116$ & 10,000 & 5,000 & 873 & 1,542 & $24.3 \%$ \\
\hline 10.0 & $\$ 1,557,929$ & 10,000 & 5,000 & 705 & 1,646 & $26.2 \%$ \\
\hline 11.0 & $\$ 1,540,733$ & 10,000 & 5,000 & 443 & 1,793 & $29.0 \%$ \\
\hline 12.0 & $\$ 1,529,847$ & 10,000 & 5,000 & 301 & 1,853 & $30.3 \%$ \\
\hline 13.0 & $\$ 1,526,258$ & 10,000 & 5,000 & 283 & 1,833 & $30.0 \%$ \\
\hline 14.0 & $\$ 1,529,079$ & 10,000 & 5,000 & 364 & 1,756 & $28.6 \%$ \\
\hline 15.0 & $\$ 1,536,323$ & 10,000 & 5,000 & 510 & 1,644 & $26.5 \%$ \\
\hline
\end{tabular}

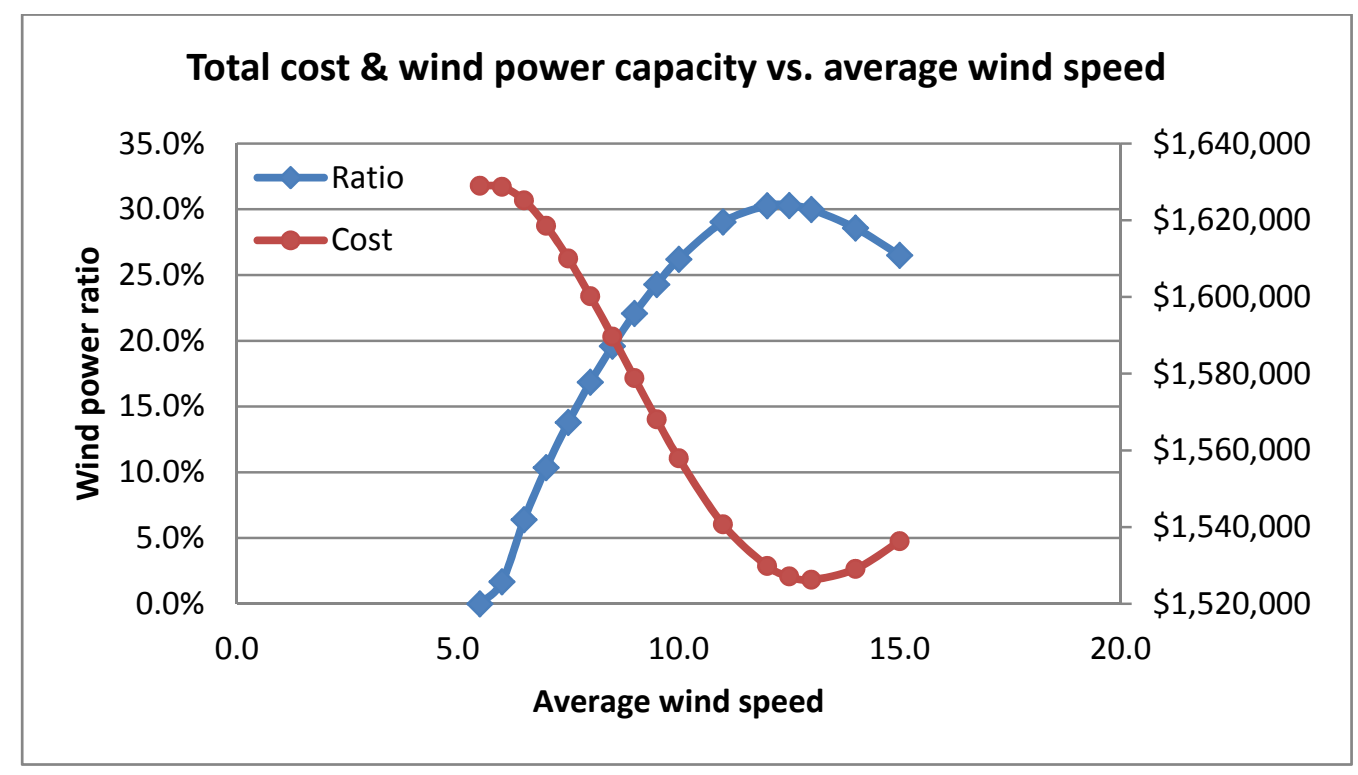

Figure 37- Variation of wind power capacity utilization with average wind speed 
With respect to cost, as the graph illustrates, more wind turbines result in more savings in general. The minimum cost, however, does not correspond exactly with the maximum number of wind turbines deployed. The reason is that the cost savings gained from wind power generation linger briefly after the maximum utilization is reached where slightly fewer wind turbines can produce slightly more electricity at higher wind speeds (e.g. at $13 \mathrm{~m} / \mathrm{s}$, less wind turbines are installed compared to 12 $\mathrm{m} / \mathrm{s}$ but since they produce more power (offset more conventional capacity), the total cost is less.). After this point, further increase of the average wind speed will lead to a reduction in objective function value and wind power utilization, as the turbines must be shut down more frequently to avoid damage from strong winds.

In summary, higher wind speeds favor larger wind power generation capacities which in turn lead to greater cost savings. In the best scenario of the example solved above $\left(\mathrm{V}_{\text {mean }}=12 \mathrm{~m} / \mathrm{s}\right)$, wind turbines have replaced 2,235 MW of non-wind power capacity (compared to the case with no wind turbines installed: $2,536-301=2,235$ ). So, the capacity credit can be calculated as:

Capacity credit $=2,235 /(2.5 \times 1,853) \approx 48 \%$

This figure is on the high end of typical capacity credit ratios. Nonetheless, it should be noted that it is generally very unlikely for wind speed to average $12 \mathrm{~m} / \mathrm{s}$ or above even at a height of 100 meters, especially for onshore locations. In fact, any location on land receiving an average wind speed of $8 \mathrm{~m} / \mathrm{s}$ or greater is potentially considered as a favorable place for wind power generation. For average wind speed of $8 \mathrm{~m} / \mathrm{s}$, the capacity credit would be around $38 \%$ which is a more realistic figure:

Capacity credit $=(2,536-1,476) /(2.5 \times 1,110)=38 \%$ 


\section{4. $\quad \underline{\text { Turbine Specifications }}$}

As discussed earlier, the type of turbine utilized in a wind farm can greatly affect the amount of power production. Equation 3.18 demonstrates how turbine-specific parameters determine the turbine output under different circumstances. Therefore, wind turbine specifications should be compatible with geographical conditions of the wind farm location in order to have optimal operation. As equation 3.18 indicates, the main turbine-specific parameters affecting the output are the rated power, the rated speed, cut-in speed and cut-out speed. In this subsection, we have modified some of these parameters to see how they influence the solution.

The rated power is not altered in this analysis since the hourly wind turbine cost as well the quantity of wind generated power is linearly correlated with this parameter. So, changing the rated power will only change the number of wind turbines proportionally while the total installed wind power capacity and the total cost values are preserved. Obviously, a different cost structure could have been used to account for the economies of scale. Equally, brand-specific pricing can be used in the model. However, since wind power associated expenses such as construction, maintenance, etc. are very location-specific, we have decided to use a generic linear cost model and consequently drop this parameter from the sensitivity analysis.

In order to better understand how turbine specifications interact with the model, it is helpful to keep track of the capacity factor. The capacity factor can be calculated as follows:

$$
\begin{aligned}
& \mathrm{CF}=\int_{V_{c i}}^{V_{c o}} P_{w}(V) \cdot f(V) \cdot d V=\int_{V_{c i}}^{V_{r}} P_{a s c}(V) \cdot f(V) \cdot d V+P_{r} \int_{V_{r}}^{V_{c o}} f(V) \cdot d V \\
& =\int_{V_{c i}}^{V_{r}} P_{a s c}(V) \cdot f(V) \cdot d V+P_{r}\left[F\left(V_{c o}\right)-F\left(V_{r}\right)\right]
\end{aligned}
$$


Table 8 lists six solutions for varying cut-in speed values ranging from 1 to $3.5 \mathrm{~m} / \mathrm{s}$. As this parameter increases, wind turbine output at low wind speeds is reduced. This behavior is reflected in the capacity factor values. Consequently, the number of wind turbines decreases as the capacity factor drops. At cut-in wind speeds below $3.5 \mathrm{~m} / \mathrm{s}$, the amount of wind power production is too low to justify any investments on wind power. This trend is illustrated in Figure 38.

Table 8- Solutions for varying cut-in speeds

\begin{tabular}{|c|c|c|c|c|c|c|}
\hline $\mathbf{V}_{\mathbf{c i}}(\mathbf{m} / \mathbf{s})$ & $\mathbf{C o s t} \mathbf{( \$ / \mathbf { h r } )}$ & $\left.\mathbf{X}_{\mathbf{c}} \mathbf{( M W}\right)$ & $\mathbf{X}_{\mathbf{g}} \mathbf{( M W )}$ & $\mathbf{X}_{\mathbf{n}} \mathbf{( M W )}$ & $\mathbf{X w}$ (Units) & $\mathbf{C F} \mathbf{( \% )}$ \\
\hline 1.0 & $\$ 1,626,865$ & 10,000 & 5,000 & 2,243 & 366 & $33.2 \%$ \\
\hline 1.5 & $\$ 1,627,493$ & 10,000 & 5,000 & 2,297 & 302 & $32.5 \%$ \\
\hline 2.0 & $\$ 1,628,154$ & 10,000 & 5,000 & 2,364 & 220 & $31.7 \%$ \\
\hline 2.5 & $\$ 1,628,690$ & 10,000 & 5,000 & 2,439 & 127 & $30.6 \%$ \\
\hline 3.0 & $\$ 1,628,728$ & 10,000 & 5,000 & 2,450 & 117 & $29.4 \%$ \\
\hline 3.5 & $\$ 1,628,974$ & 10,000 & 5,000 & 2,536 & 0 & $27.9 \%$ \\
\hline
\end{tabular}

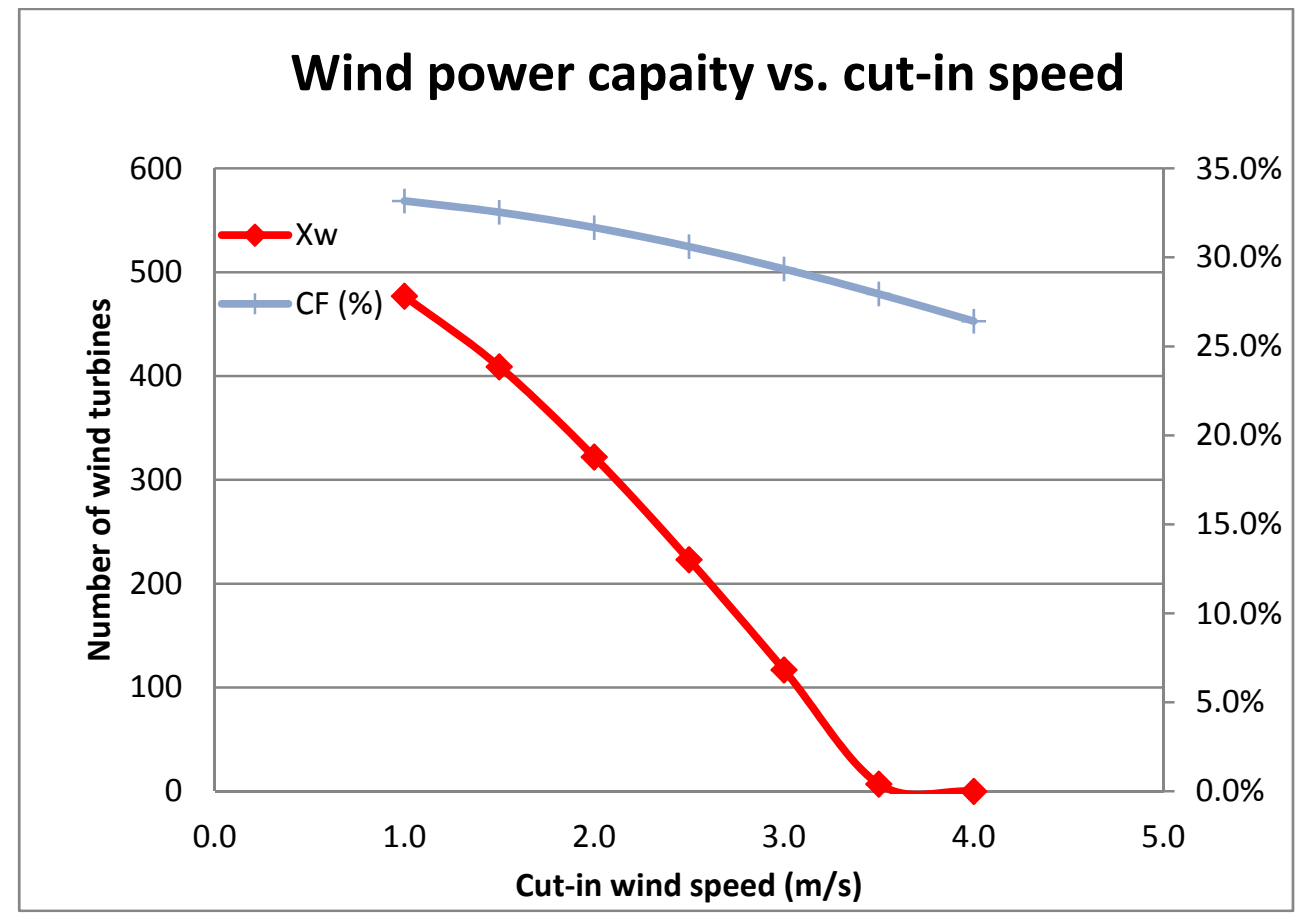

Figure 38- Wind power capacity variation with respect to cut-in speed 
The next parameter investigated in this analysis is the cut-out wind speed. Table 9 denotes three solutions for different cut-out wind speed values. As these numbers demonstrate, the solution is not very sensitive to this parameter. The reason is that the typical cut-out wind speed values generally fall into the ending tail of wind speed distribution curve where the probability densities are the lowest. In other words, although an increased cut-out speed means the wind turbine can operate at higher wind speeds, the probability of such scenarios is very low and it would not affect the capacity factor much, as the last column of Table 9 indicates.

Table 9- Solution for varying wind cut-out speeds

\begin{tabular}{|c|c|c|c|c|c|c|}
\hline $\mathbf{V}_{\mathrm{co}}(\mathbf{m} / \mathbf{s})$ & Cost $(\mathbf{\$} / \mathbf{h r})$ & $\mathbf{X}_{\mathbf{c}}(\mathbf{M W})$ & $\mathbf{X}_{\mathrm{g}}(\mathbf{M W})$ & $\mathbf{X}_{\mathbf{n}}(\mathbf{M W})$ & $\mathbf{X w}($ Units) & $\mathbf{C F}(\%)$ \\
\hline 20.0 & $\$ 1,628,733$ & 10,000 & 5,000 & 2,451 & 116 & $29.3 \%$ \\
\hline 25.0 & $\$ 1,628,728$ & 10,000 & 5,000 & 2,450 & 117 & $29.4 \%$ \\
\hline 40.0 & $\$ 1,628,728$ & 10,000 & 5,000 & 2,450 & 117 & $29.4 \%$ \\
\hline
\end{tabular}

Finally, the impact of the rated speed is analyzed in this subsection. Table 10 lists eight solutions for varying values of the rated speed. As these results indicate, the model is very responsive to this parameter. A slight modification of the rated speed leads to a sizeable variation in the capacity factor which in turn has a strong influence on the total wind power capacity. Lower rated speed can be equated with higher probability of operating the wind turbine at nominal power. Higher values for this parameter, however, reduce the capacity factor and result in a lesser total capacity for wind power. In our numerical example, for instance, wind power generation is no longer economical when the rated speed rises above $12 \mathrm{~m} / \mathrm{s}$. Figure 39 illustrates 
variations of the capacity factor and total wind power capacity as the rated speed is modified.

Table 10- Model solution for varying rated wind speed

\begin{tabular}{|c|c|c|c|c|c|c|c|}
\hline $\mathbf{V}_{\mathbf{r}}(\mathbf{m} / \mathbf{s})$ & Cost $(\mathbf{\$} / \mathbf{h r})$ & $\mathbf{X}_{\mathbf{c}}(\mathbf{M W})$ & $\mathbf{X}_{\mathrm{g}}(\mathbf{M W})$ & $\mathbf{X}_{\mathbf{n}}(\mathbf{M W})$ & $\mathbf{X w}($ Units) & $\mathbf{X}_{\mathbf{w}}(\%)$ & $\mathbf{C F}(\%)$ \\
\hline 9.0 & $\$ 1,614,735$ & 10,000 & 5,000 & 1,854 & 768 & $11.4 \%$ & $41.4 \%$ \\
\hline 9.5 & $\$ 1,619,623$ & 10,000 & 5,000 & 1,989 & 642 & $9.4 \%$ & $38.5 \%$ \\
\hline 10.0 & $\$ 1,623,477$ & 10,000 & 5,000 & 2,121 & 508 & $7.4 \%$ & $35.7 \%$ \\
\hline 10.5 & $\$ 1,626,308$ & 10,000 & 5,000 & 2,250 & 365 & $5.3 \%$ & $33.1 \%$ \\
\hline 11.0 & $\$ 1,628,124$ & 10,000 & 5,000 & 2,376 & 213 & $3.1 \%$ & $30.7 \%$ \\
\hline 11.3 & $\$ 1,628,728$ & 10,000 & 5,000 & 2,450 & 117 & $1.7 \%$ & $29.4 \%$ \\
\hline 11.5 & $\$ 1,628,929$ & 10,000 & 5,000 & 2,500 & 51 & $0.7 \%$ & $28.5 \%$ \\
\hline 12.0 & $\$ 1,628,974$ & 10,000 & 5,000 & 2,536 & 0 & $0.0 \%$ & $26.4 \%$ \\
\hline
\end{tabular}

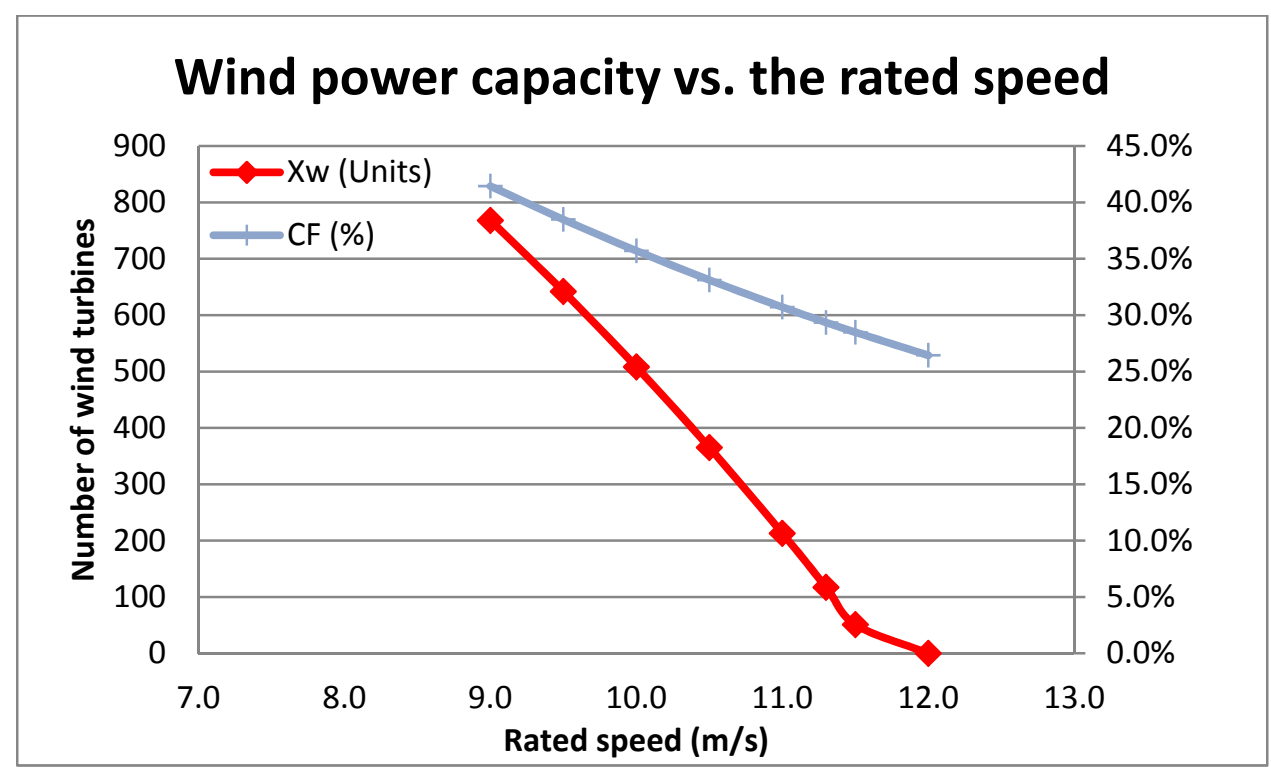

Figure 39- Impact of rated wind speed on wind power capacity

As this analysis shows, the rated wind speed has the greatest impact on the capacity factor among all other wind turbine specifications, followed by cut-in wind speed. 
Therefore, when comparing similar wind turbines, more consideration should be given to those with lower rated speeds since they are likely to generate power in greater quantities on average.

\section{5. $\quad$ Wind Power Cost}

In this section, the influence of wind power cost on wind power utilization is explored. Table 11 lists nine solutions over a wide range of unit cost values for wind generated power. As expected, the total available capacity (2,000 wind turbine units) for wind power generation is utilized when the price is sufficiently low (first row in the table). The capacity credit, on the other hand, is the lowest at this point. As the unit cost rises, wind turbines are used in fewer numbers yet more efficiently (Capacity factor increases but the number of wind turbines drops). When the unit cost exceeds $\$ 105 / \mathrm{MWh}$, wind generated power becomes too expensive to use and the number of wind turbines drops to zero. Figure 40 visually illustrates this trend.

Table 11- Sensitivity analysis with respect to the unit cost of wind power

\begin{tabular}{|c|c|c|c|c|c|c|c|}
\hline $\begin{array}{c}\mathbf{C}_{\mathbf{w}} \\
(\mathbf{M} \mathbf{M W})\end{array}$ & Cost (\$/hr) & $\begin{array}{c}\mathbf{X}_{\mathbf{c}} \\
(\mathbf{M W})\end{array}$ & $\mathbf{X}_{\mathbf{g}} \mathbf{( M W )}$ & $\begin{array}{c}\mathbf{X}_{\mathbf{n}} \\
(\mathbf{M W})\end{array}$ & $\begin{array}{c}\mathbf{X w} \\
(\mathbf{U n i t s})\end{array}$ & $\mathbf{X}_{\mathbf{w}} \mathbf{( \% )}$ & $\begin{array}{c}\text { Capacity } \\
\text { Credit (\%) }\end{array}$ \\
\hline 40 & $\$ 1,584,890$ & 10,000 & 5,000 & 1,535 & 2,000 & $30.2 \%$ & $20.0 \%$ \\
\hline 50 & $\$ 1,600,023$ & 10,000 & 5,000 & 1,681 & 1,579 & $23.7 \%$ & $21.7 \%$ \\
\hline 60 & $\$ 1,611,198$ & 10,000 & 5,000 & 1,857 & 1,150 & $17.1 \%$ & $23.6 \%$ \\
\hline 70 & $\$ 1,619,216$ & 10,000 & 5,000 & 2,024 & 806 & $11.8 \%$ & $25.4 \%$ \\
\hline 80 & $\$ 1,624,634$ & 10,000 & 5,000 & 2,188 & 515 & $7.5 \%$ & $27.0 \%$ \\
\hline 90 & $\$ 1,627,804$ & 10,000 & 5,000 & 2,351 & 259 & $3.7 \%$ & $28.6 \%$ \\
\hline 96 & $\$ 1,628,728$ & 10,000 & 5,000 & 2,450 & 117 & $1.7 \%$ & $29.4 \%$ \\
\hline 100 & $\$ 1,628,961$ & 10,000 & 5,000 & 2,517 & 26 & $0.4 \%$ & $29.2 \%$ \\
\hline 105 & $\$ 1,628,974$ & 10,000 & 5,000 & 2,536 & 0 & $0.0 \%$ & N/A \\
\hline
\end{tabular}


Moreover, the total cost rises when the unit cost of wind generated power is increased as expected. The rate of growth, however, decreases at higher unit costs as the graph shows. This is resulting from the fact that lesser wind turbines are used when they cost more.

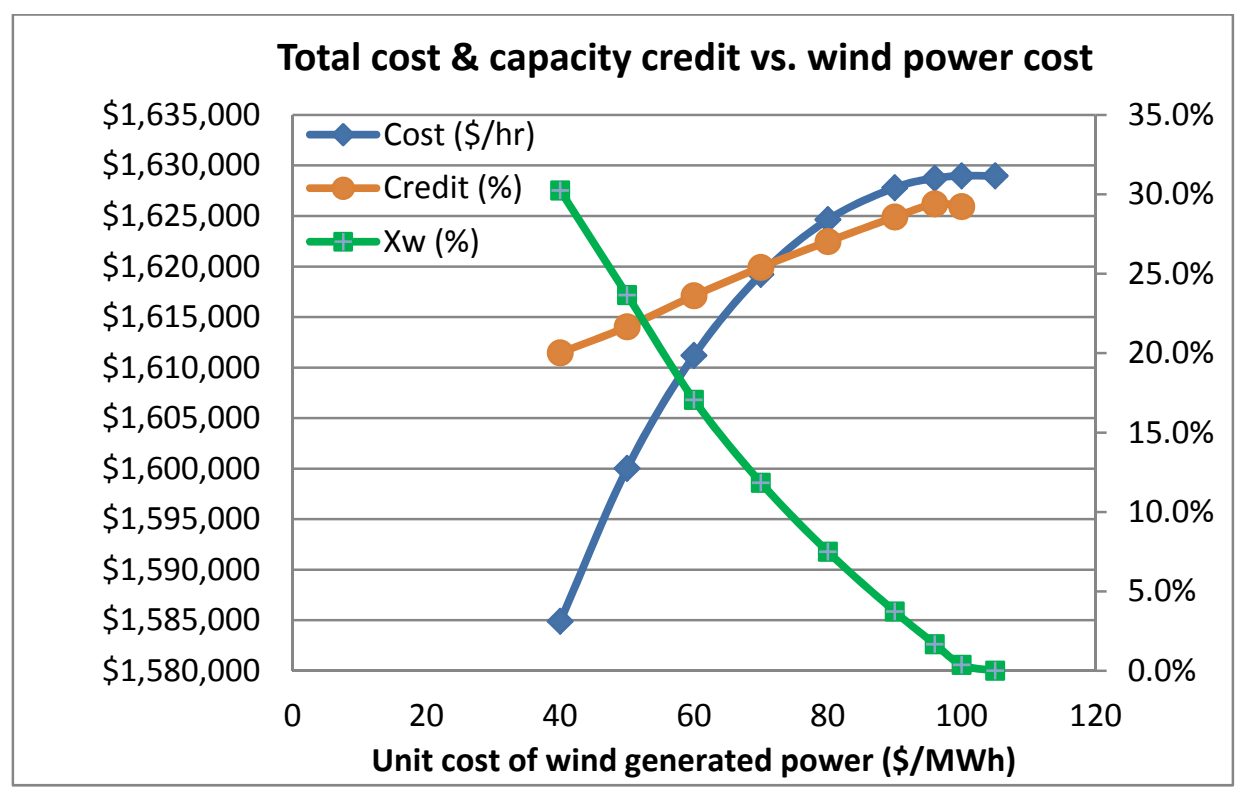

Figure 40- Variation of total cost and wind power utilization with unit cost of wind power

\section{6. $\quad$ Cost of Imported Electricity}

At this point, we will allow electricity exchange in the model by assigning a transmission capacity for energy importation on a scenario basis. This capacity is set at one thousand megawatt-hours:

$\mathrm{U}_{\mathrm{im}}=1,000 \mathrm{MWh}$

Since the decision variables denoting imported power quantities in each scenario are numerous, their expected value is used as a measure for presentation and comparison:

$\mathrm{E}(\mathrm{Xim})=\sum_{I} \operatorname{Xim}_{i} \cdot P_{i}$

The model has been solved for a set of seven unit cost values ranging from $\$ 105$ /MWh to $\$ 140 / \mathrm{MWh}$. Table 12 summarizes the results. According to these 
calculations, when the cost is above $\$ 130 / \mathrm{MWh}$, energy importation is too expensive and the demand is fulfilled using only in-network resources.

As the price falls below this limit, a combination of imported energy and wind generated power partly replaces the nuclear power capacity, which is the most expensive type of power station in the mix. While the expected quantity of imported power increases monotonically as its cost drops, the behavior of wind power capacity is more complex, as Figure 41 illustrates. Initially, a sharp growth is observed in the number of wind turbines as the imported energy cost drops. With further cost reductions, however, the imported energy takes precedence over wind generated power and the number of wind turbines is decreased.

Ultimately, at energy import cost of $\$ 105 / \mathrm{MWh}$, the wind power capacity drops all the way back to its initial level (117 wind turbines) and all of the imported power quantities are used to offset the nuclear power capacity.

A question might arise here regarding capacity combinations in the solution. Comparison of the first row and the last row in the solution table indicates that energy importation has offset greater nuclear power capacity than the quantity of the imported power (Initially, the nuclear power capacity is $2,450 \mathrm{MW}$. When power is imported at full capacity, this value drops down to 1,339 . So the difference is $2,450-$ $1,339=1,111)$. The reason for this apparent disparity is that the imported power has been assumed fully reliable, while a capacity factor of 0.9 is considered for nuclear power stations. Therefore, 1,000 $\mathrm{MW}$ of transmission capacity is equivalent to $1,000 / 0.9=1,111 \mathrm{MW}$ of nuclear power capacity. 
Regarding total cost, the trend is pretty much expectable. Higher prices lead to higher total costs at a decreasing rate.

Table 12- Sensitivity analysis with respect to imported energy cost

\begin{tabular}{|c|c|c|c|c|c|c|}
\hline $\begin{array}{c}\text { Cim } \\
\mathbf{( \$ / M W h})\end{array}$ & Cost $\mathbf{( \$ / h r )}$ & $\mathbf{X}_{\mathbf{c}}(\mathbf{M W})$ & $\mathbf{X}_{\mathbf{g}}(\mathbf{M W})$ & $\mathbf{X}_{\mathbf{n}}(\mathbf{M W})$ & $\begin{array}{c}\mathbf{X w} \\
\text { (Units) }\end{array}$ & $\begin{array}{c}\mathbf{E}(\mathbf{X i m}) \\
\mathbf{( M W h})\end{array}$ \\
\hline 105 & $\$ 1,611,506$ & 10,000 & 5,000 & 1,339 & 117 & 1,000 \\
\hline 110 & $\$ 1,616,504$ & 10,000 & 5,000 & 1,335 & 126 & 997 \\
\hline 115 & $\$ 1,621,357$ & 10,000 & 5,000 & 1,264 & 421 & 861 \\
\hline 120 & $\$ 1,625,173$ & 10,000 & 5,000 & 1,283 & 598 & 723 \\
\hline 125 & $\$ 1,628,554$ & 10,000 & 5,000 & 1,573 & 534 & 506 \\
\hline 130 & $\$ 1,628,728$ & 10,000 & 5,000 & 2,450 & 117 & 0 \\
\hline 140 & $\$ 1,628,728$ & 10,000 & 5,000 & 2,450 & 117 & 0 \\
\hline
\end{tabular}

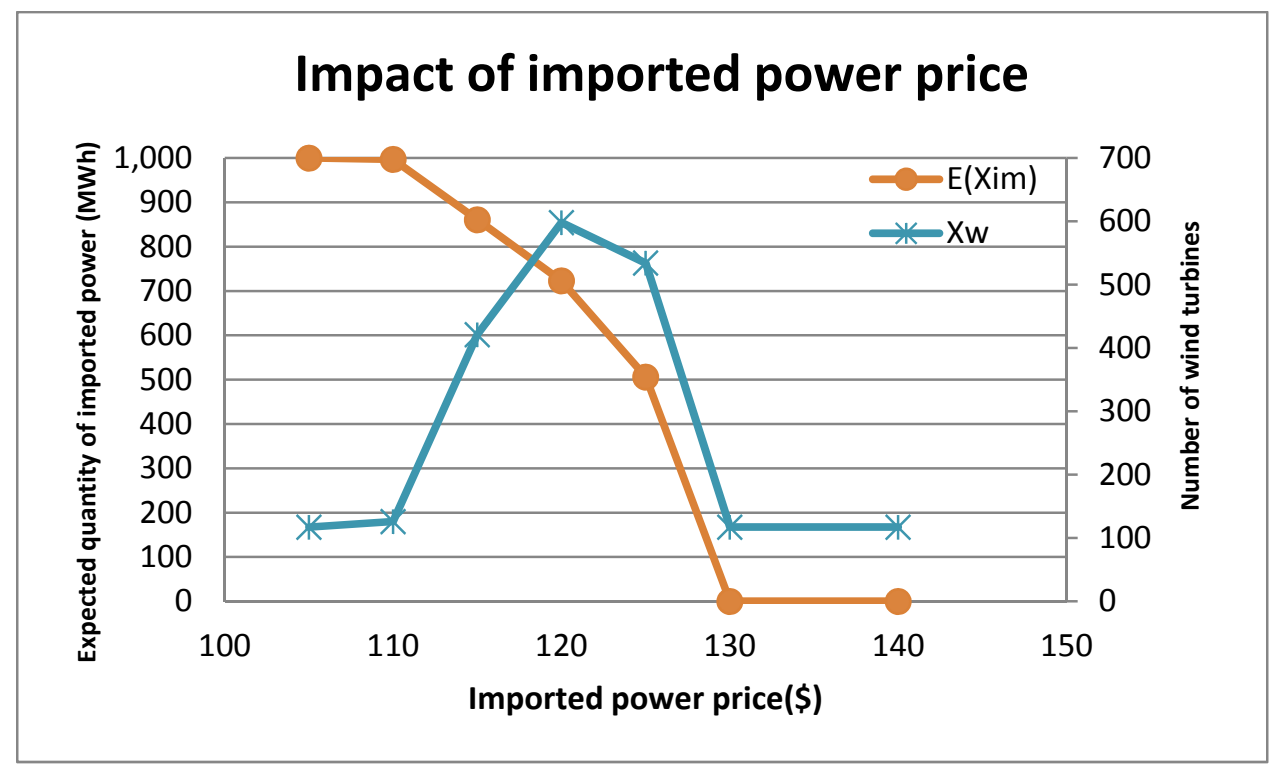

Figure 41- Effect of variations in imported power price

\section{7. $\quad$ Price of Exported Electricity}

By the same token, energy exportation can also be considered in the model. Table 13 lists five solutions with varying values of unit prices for exported power. At the price 
point of $\$ 100 / \mathrm{MWh}$, energy exportation is not profitable and it will not happen. When the price is increased to $\$ 110 / \mathrm{MWh}$, energy trade becomes marginally rewarding. As the price rises further, more power exchange will take place until full transmission capacity is utilized. The total wind power capacity (number of wind turbines) follows a trend similar to the last parameter studied (power importation): It goes up initially and reaches a maximum at around $\$ 120 / \mathrm{MWh}$ and then gradually drops back to its primary level. Figure 42 illustrates this trend.

Table 13- Model solution for varying prices of exported power

\begin{tabular}{|c|c|c|c|c|c|c|}
\hline $\begin{array}{c}\text { Pex } \\
\text { (\$/MWh) }\end{array}$ & Cost (\$/hr) & $\mathbf{X}_{\mathbf{c}}$ (MW) & $\mathbf{X}_{\mathbf{g}}$ (MW) & $\mathbf{X}_{\mathbf{n}}$ (MW) & $\mathbf{X w}$ (Units) & $\begin{array}{c}\mathbf{E}(\mathbf{X e x}) \\
\text { (MWh) }\end{array}$ \\
\hline 100 & $\$ 1,628,728$ & 10,000 & 5,000 & 2,450 & 117 & 0 \\
\hline 110 & $\$ 1,628,726$ & 10,000 & 5,000 & 2,447 & 126 & 3 \\
\hline 120 & $\$ 1,627,395$ & 10,000 & 5,000 & 2,394 & 598 & 277 \\
\hline 125 & $\$ 1,625,777$ & 10,000 & 5,000 & 2,684 & 534 & 494 \\
\hline 130 & $\$ 1,620,950$ & 10,000 & 5,000 & 3,561 & 117 & 1,000 \\
\hline
\end{tabular}

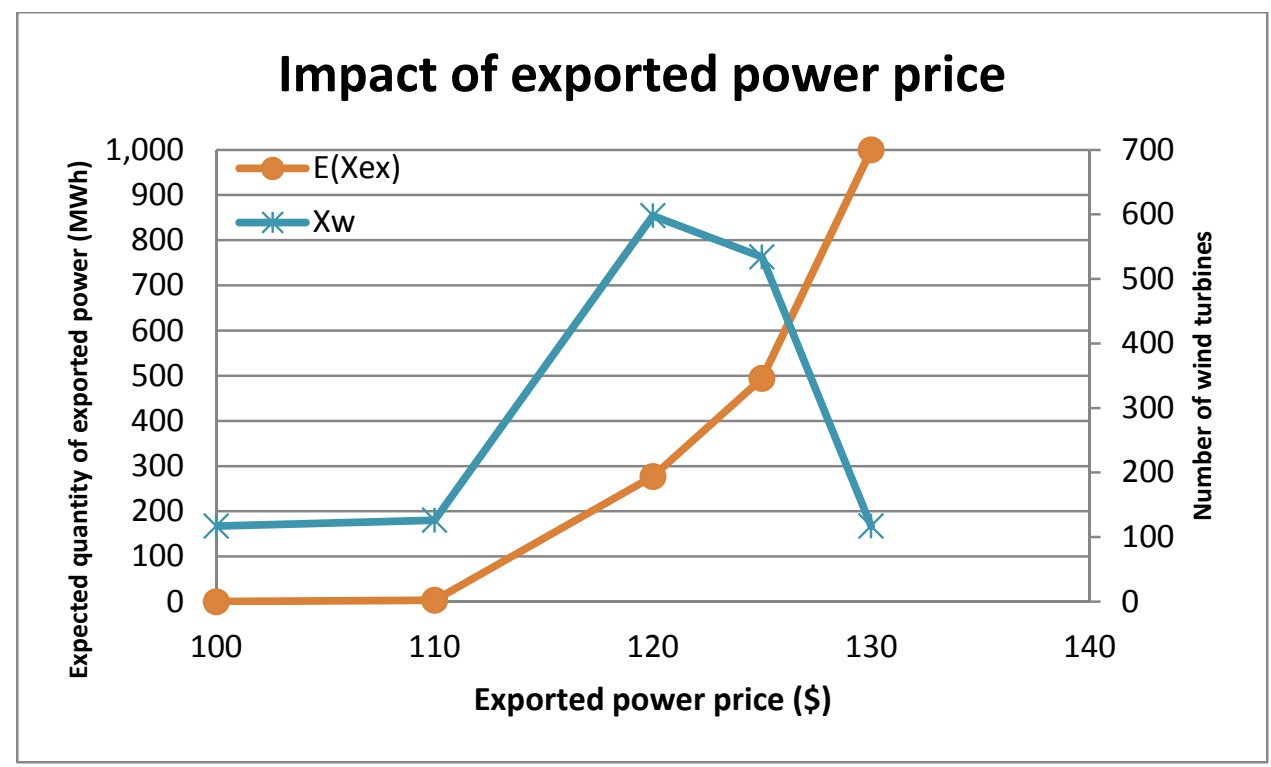

Figure 42- Impact of exported energy price on wind power capacity 
Comparison of the model behavior for energy importation and energy exportation shows that there is some sort of symmetry (or matching) between the solutions. As it can be seen, at any common price, identical capacities have been assigned to wind power in both cases. Furthermore, the imported and exported quantities complement one another. In other words:

$\mathrm{E}(\mathrm{Xim})+\mathrm{E}(\mathrm{Xex})=1,000 \mathrm{MWh}$

This observation is not a coincidence and it can be justified. Assuming that the problem has been solved for an import cap of 1,000 MWh, it can be inferred that the price of imported energy has been fair enough so that it has partially replaced the most expensive conventional power source in the mix. Now if the energy import is disabled and export is allowed instead, there is no need to disturb the structure of the solution. All needed to be done is to increase the capacity of the most expensive source in the mix by an amount equivalent to the maximum quantity imported in a single scenario (so that it satisfies the scenarios with highest demand for imported energy) which is equal to the transmission cap for our example since it is binding as a constraint. Hence, some scenarios will have production surplus which will emerge as the exported power quantities in the solution. Consequently, the solutions for these two cases should be related as such.

In our model, for instance, the expected quantities of exported and imported energy in identical cases add up to 1,000 MWh while the difference between their respective nuclear power capacities is equivalent to this value. For example, at $\$ 120$, the difference is:

$\mathrm{Xn}(\mathrm{ex})-\mathrm{Xn}(\mathrm{im})=2,394-1,283=1,111 \mathrm{MWh}$ 
Which is equal to the transmission cap if the capacity factor is accounted for:

\section{$1,111 \times 0.9=1,000 \mathrm{MWh}$}

\section{8. $\quad$ Cost of Energy Storage}

Another type of recourse action embedded in the model is the energy storage. What makes this feature more interesting is the fact that it allows for a much higher level of interaction among the scenarios. Energy storage differs from other second stage variables (i.e. energy importation and exportation) in the fact that the source and the sink of energy are both scenario-based.

The storage capacity is set at $400 \mathrm{MWh}$. At an average wind speed of $6 \mathrm{~m} / \mathrm{s}$, the amount of surplus energy generated in scenarios is not enough to favor any energy storage. Therefore, the analysis is performed for an average wind speed of $7 \mathrm{~m} / \mathrm{s}$. Table 14 summarizes several solutions for a range of storage costs covering values between 0 and $\$ 75 / \mathrm{MWh}$. As calculations show, lower storage costs lead to installation of more wind turbines and greater quantities of energy being stored. In addition, the total cost of energy procurement is reduced as expected. These observations are visually presented in Figure 43.

Table 14- Model solution for varying energy storage costs

\begin{tabular}{|c|c|c|c|c|c|c|c|}
\hline $\begin{array}{c}\text { Cst } \\
\text { (\$/MWh) }\end{array}$ & Cost $\mathbf{( \$ / h r )}$ & $\mathbf{X}_{\mathbf{c}}(\mathbf{M W})$ & $\mathbf{X}_{\mathbf{g}} \mathbf{( M W )}$ & $\mathbf{X}_{\mathbf{n}} \mathbf{( M W )}$ & $\begin{array}{c}\mathbf{X w} \\
\text { (Units) }\end{array}$ & $\begin{array}{c}\mathbf{E}(\mathbf{X s t}) \\
(\mathbf{M W h})\end{array}$ & $\mathbf{X}_{\mathbf{w}}(\mathbf{\%})$ \\
\hline 0 & $\$ 1,611,132$ & 10,000 & 5,000 & 1,581 & 1,101 & 155 & $16.6 \%$ \\
\hline 25 & $\$ 1,614,627$ & 10,000 & 5,000 & 1,624 & 1,047 & 124 & $15.7 \%$ \\
\hline 50 & $\$ 1,617,240$ & 10,000 & 5,000 & 1,702 & 957 & 85 & $14.3 \%$ \\
\hline 60 & $\$ 1,618,017$ & 10,000 & 5,000 & 1,739 & 916 & 70 & $13.7 \%$ \\
\hline 70 & $\$ 1,618,539$ & 10,000 & 5,000 & 1,881 & 761 & 19 & $11.3 \%$ \\
\hline 75 & $\$ 1,618,580$ & 10,000 & 5,000 & 1,937 & 700 & 0 & $10.3 \%$ \\
\hline
\end{tabular}




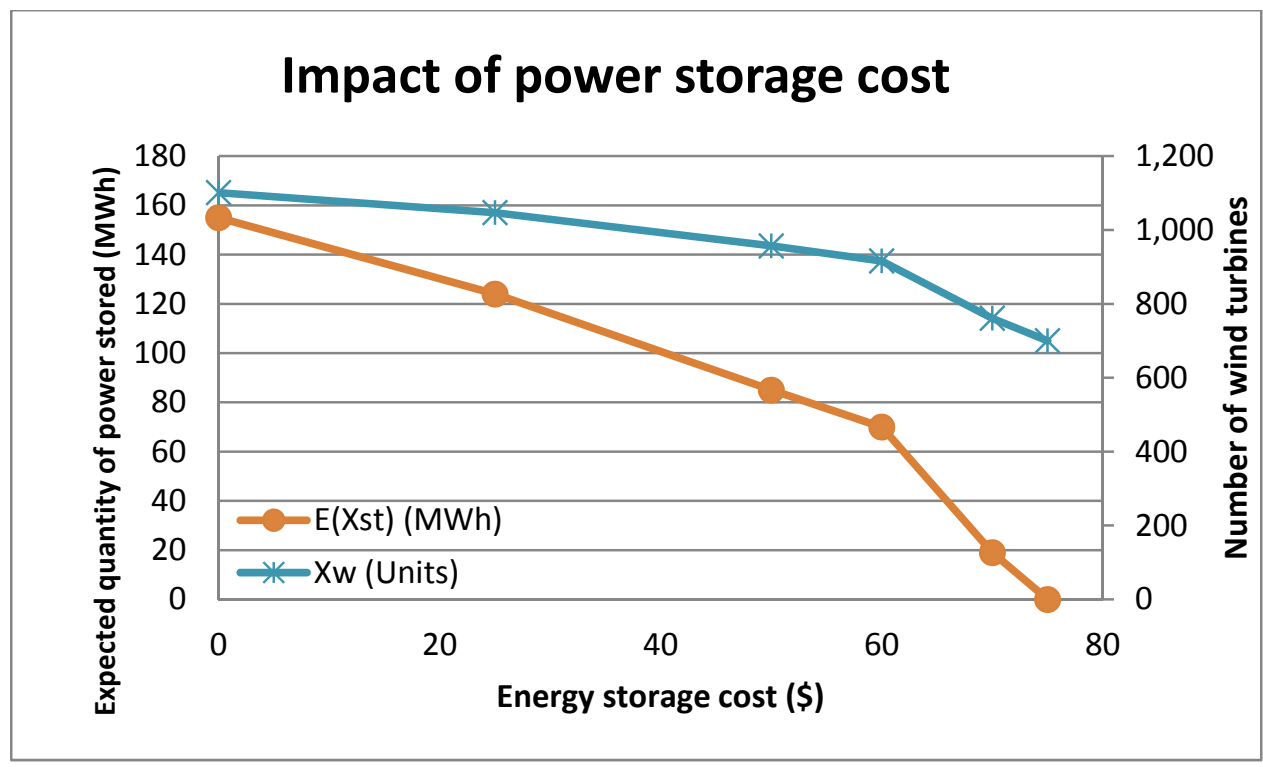

Figure 43- Impact of power storage costs on wind power capacity

\section{9. $\quad$ Multiple Wind Farms}

Finally, we will consider the effect of combining wind power generation from multiple locations. Since the size of the problem grows exponentially as new wind farms are added to the network (For greatest contribution, the wind speed distributions in different locations are assumed independent), efficiency in scenario generation is very critical when dealing with multiple sites.

In light of the comparative information provided in Table 2, we have considered ten scenarios for each location in this analysis since the solution is barely affected at this reduced level of detail yet the problem size is quite manageable. The analysis results for up to four wind farms are summarized in Table 15. 
Table 15- Model solution for multiple wind farms

\begin{tabular}{|c|c|c|c|c|c|}
\hline $\begin{array}{c}\text { Number of } \\
\text { wind farms }\end{array}$ & Cost $\mathbf{\$} / \mathbf{h r})$ & $\mathbf{X}_{\mathbf{c}}(\mathbf{M W})$ & $\mathbf{X}_{\mathbf{g}}(\mathbf{M W})$ & $\mathbf{X}_{\mathbf{n}}(\mathbf{M W})$ & $\mathbf{X w}_{\mathbf{w}}$ Units) \\
\hline 1 & $\$ 1,628,709$ & 10,000 & 5,000 & 2,447 & 121 \\
\hline 2 & $\$ 1,628,445$ & 10,000 & 5,000 & 2,357 & 242 \\
\hline 3 & $\$ 1,628,181$ & 10,000 & 5,000 & 2,268 & 363 \\
\hline 4 & $\$ 1,627,916$ & 10,000 & 5,000 & 2,178 & 484 \\
\hline
\end{tabular}

As the table shows, the number of wind turbines required at each additional wind farm has remained constant (121 units). This result is visually demonstrated in Figure 44. As the graphs illustrate, the number of wind turbines has linearly increased while the total cost has dropped at a constant rate.

The reason for this behavior is quite obvious. Since no recourse action (energy import, export or storage) is allowed in this analysis, the second stage variables are all zero. Therefore, the problem can be decomposed into separate wind farms and solved independently. Consequently, the aggregate result can be obtained by escalating the impact of a single wind farm by a factor equal to the number of wind farms.

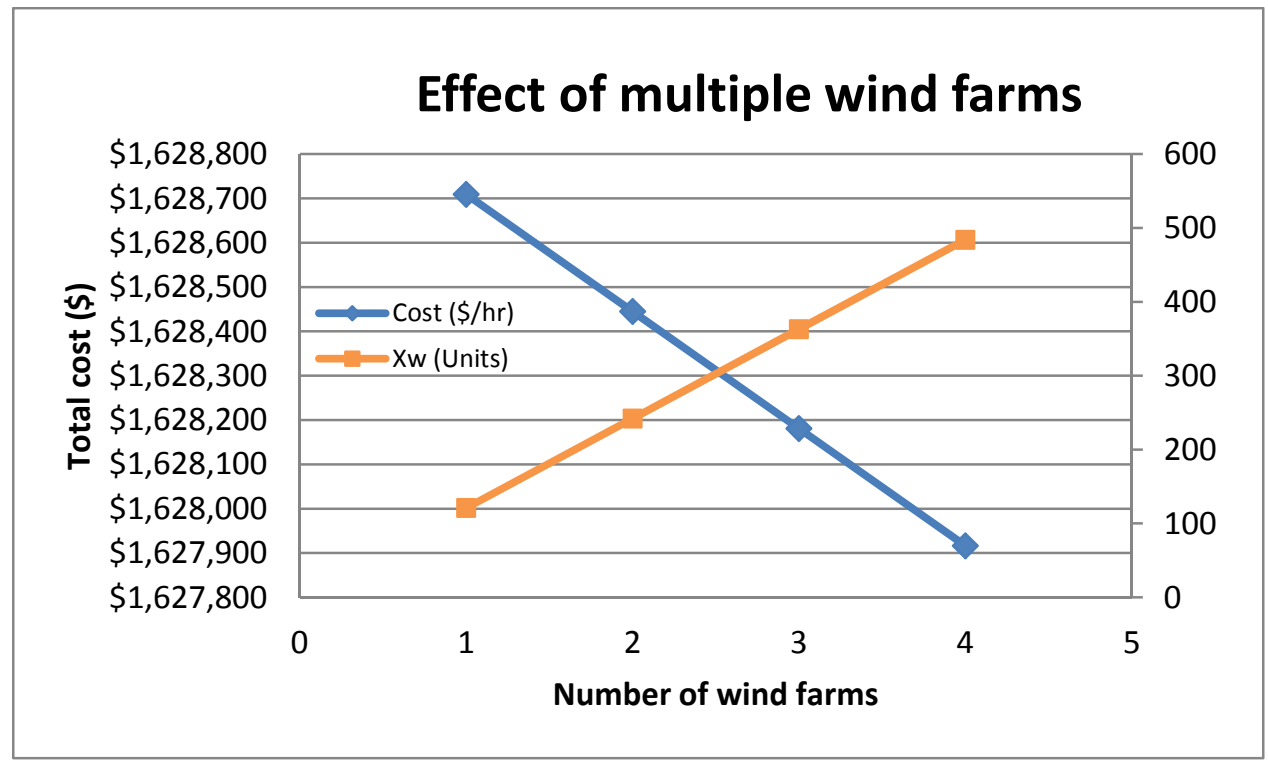

Figure 44- Effect of linking multiple wind farms 
In order to better investigate the model behavior when multiple wind farms are involved, we have repeated the analysis with energy importation and exportation enabled. The solutions for four instances of the problem are summarized in Table 16.

Table 16- Multiple wind farm impact with recourse

\begin{tabular}{|c|c|c|c|c|c|c|c|c|}
\hline $\begin{array}{c}\text { Number of } \\
\text { wind farms }\end{array}$ & Cost $\mathbf{( \$ / h r )}$ & $\begin{array}{c}\mathbf{X}_{\mathbf{c}} \\
(\mathbf{M W})\end{array}$ & $\begin{array}{c}\mathbf{X}_{\mathrm{g}} \\
\mathbf{( M W )}\end{array}$ & $\begin{array}{c}\mathbf{X}_{\mathbf{n}} \\
(\mathbf{M W})\end{array}$ & $\begin{array}{c}\mathbf{E}(\mathbf{X i m}) \\
(\mathbf{M W h})\end{array}$ & $\begin{array}{c}\mathbf{E}(\mathbf{X e x}) \\
(\mathbf{M W h})\end{array}$ & $\begin{array}{c}\mathbf{X w} \\
(\mathbf{s i t e})\end{array}$ & $\begin{array}{c}\mathbf{X w} \\
\text { (total) }\end{array}$ \\
\hline 1 & $\$ 1,623,777$ & 10,000 & 5,000 & 1,257 & 716 & 284 & 1,058 & 1,058 \\
\hline 2 & $\$ 1,622,600$ & 10,000 & 5,000 & 1,031 & 653 & 341 & 769 & 1,538 \\
\hline 3 & $\$ 1,621,334$ & 10,000 & 5,000 & 789 & 434 & 188 & 653 & 1,959 \\
\hline 4 & $\$ 1,620,166$ & 10,000 & 5,000 & 549 & 407 & 207 & 586 & 2,344 \\
\hline
\end{tabular}

As these results show, the number of wind turbines is no longer proportional to the number of locations in this case and the growth rate has decreased. However, the relationship between the total cost (and the total number of turbines) and the number of wind farms is still nearly linear, as Figure 45 illustrates. A probable reason for this observation might be the fact that the wind farms are still largely independent since the available recourses can only induce a limited interrelation.

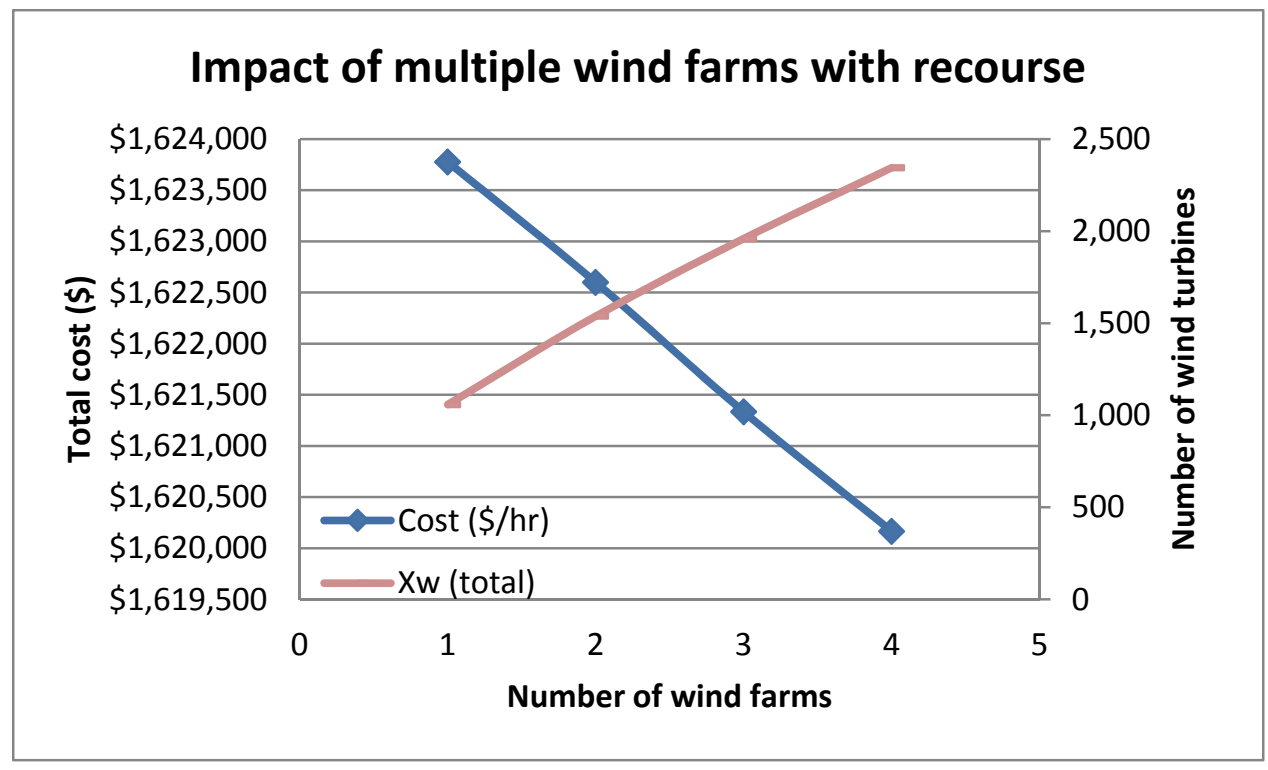

Figure 45- Impact of multiple wind farms with recourse 


\section{Heuristics for Dealing with a Large Problem}

As mentioned earlier, the problem size increases exponentially as more wind farms are connected to the grid. For example, considering a network including ten wind farms and assuming only ten wind speed scenarios for each location will lead to a problem where the number of variables and constraints are in order of $10^{10}$ (ten billions). Therefore, we have to consider a reduced set of scenarios.

The information presented at Table 2 indicates that at least four scenarios are necessary in order to obtain a solution within a reasonable tolerance. In such case, the number of constraints and variables will be of order of $4^{10}$ or approximately a few millions. While this reduction might be sufficient to enable a microcomputer to solve the problem, there might be other ways to solve the problem more efficiently.

\subsection{Standard Scenario Reduction}

Fast forward selection is a well-known method used for scenario reduction. In this approach, starting from an original set, scenarios are picked one by one in a fashion that the probability distance of the selected set is minimized. The selection continues until the reduced set reaches a specified size. Eventually, the probabilities of unselected scenarios are distributed among the selected ones based on their proximity (Conejo, Carrion, \& Morales, 2010).

In order to apply this method to our example, we have to define the initial set of scenarios first. As discussed earlier, ten scenarios are deemed sufficiently accurate according to Table 2. Power production rates $\left(\mathrm{R}_{\mathrm{i}}\right)$ and probabilities $\left(\mathrm{P}_{\mathrm{i}}\right)$ for this initial scenario set are denoted in Table 17 (Efficiency is factored in production values). 
Table 17- Power production rate and probabilities considering ten scenarios

\begin{tabular}{|c|c|c|c|c|c|c|c|c|c|c|}
\hline Scenario & $\mathbf{1}$ & $\mathbf{2}$ & $\mathbf{3}$ & $\mathbf{4}$ & $\mathbf{5}$ & $\mathbf{6}$ & $\mathbf{7}$ & $\mathbf{8}$ & $\mathbf{9}$ & $\mathbf{1 0}$ \\
\hline $\mathbf{P}_{\mathbf{i}}$ & 0.178 & 0.120 & 0.131 & 0.128 & 0.115 & 0.096 & 0.075 & 0.056 & 0.039 & 0.062 \\
\hline $\mathbf{R}_{\mathbf{i}}(\mathbf{k W})$ & 0 & 66 & 230 & 437 & 685 & 976 & 1309 & 1683 & 2101 & 2325 \\
\hline
\end{tabular}

Now we can start the selection process. The probability distance for each element of the initial scenario set is calculated in Table 18. Each row and each column corresponds to a specific scenario. The number in each cell denotes the power production difference between the respective scenarios (column and row). The probability distance for each scenario $\left(\mathrm{D}_{\mathrm{i}}\right)$ is calculated at the bottom of each column using the following formulation:

$\mathrm{D}_{\mathrm{i}}=\sum_{j} P_{j} \cdot\left(R_{j}-R_{i}\right)$

Table 18- Scenario distance calculations at step 1

\begin{tabular}{|c|c|c|c|c|c|c|c|c|c|c|}
\hline Scenarios & $\mathbf{1}$ & $\mathbf{2}$ & $\mathbf{3}$ & $\mathbf{4}$ & $\mathbf{5}$ & $\mathbf{6}$ & $\mathbf{7}$ & $\mathbf{8}$ & $\mathbf{9}$ & $\mathbf{1 0}$ \\
\hline $\mathbf{1}$ & 0 & 66 & 230 & 437 & 685 & 976 & 1309 & 1683 & 2101 & 2325 \\
\hline $\mathbf{2}$ & 66 & 0 & 164 & 371 & 619 & 910 & 1243 & 1617 & 2035 & 2259 \\
\hline $\mathbf{3}$ & 230 & 164 & 0 & 207 & 455 & 746 & 1079 & 1453 & 1871 & 2095 \\
\hline $\mathbf{4}$ & 437 & 371 & 207 & 0 & 248 & 539 & 872 & 1246 & 1664 & 1888 \\
\hline $\mathbf{5}$ & 685 & 619 & 455 & 248 & 0 & 291 & 624 & 998 & 1416 & 1640 \\
\hline $\mathbf{6}$ & 976 & 910 & 746 & 539 & 291 & 0 & 333 & 707 & 1125 & 1349 \\
\hline $\mathbf{7}$ & 1309 & 1243 & 1079 & 872 & 624 & 333 & 0 & 374 & 792 & 1016 \\
\hline $\mathbf{8}$ & 1683 & 1617 & 1453 & 1246 & 998 & 707 & 374 & 0 & 418 & 642 \\
\hline $\mathbf{9}$ & 2101 & 2035 & 1871 & 1664 & 1416 & 1125 & 792 & 418 & 0 & 224 \\
\hline $\mathbf{1 0}$ & 2325 & 2259 & 2095 & 1888 & 1640 & 1349 & 1016 & 642 & 224 & 0 \\
\hline Distance & $\mathbf{6 8 5}$ & $\mathbf{6 4 2}$ & $\mathbf{5 7 6}$ & $\underline{\mathbf{5 4 7}}$ & $\mathbf{5 7 5}$ & $\mathbf{6 7 5}$ & $\mathbf{8 5 4}$ & $\mathbf{1 1 1 0}$ & $\mathbf{1 4 4 4}$ & $\mathbf{1 6 4 0}$ \\
\hline
\end{tabular}

Based on the results, scenario \#4 is selected at this stage since it has the smallest probability distance. This procedure should be repeated to obtain the next element of the reduced scenario set. However, scenario differences need to be updated. First, the values in the row corresponding to scenario $\# 4$ are set to zero since this scenario is already selected. In addition, since the reduced set has a member now (scenario \#4), 
the scenario difference for the reduced set is the minimum of the scenario differences for the new element and the current member. For example, calculating for scenario \#2 as the new element in the reduced set, the distance with scenario \#1 (the number in column 2, row 1 of the difference matrix) would be equal to Min $\left\{\mathrm{R}_{2}-\mathrm{R}_{1}, \mathrm{R}_{4}-\mathrm{R}_{1}\right\}$. Based on these provisions, the updated scenario differences and the new probability distances are calculated in Table 19. According to these calculations, scenario \#8 must be picked as the second member of the reduced scenario set. Continuing with this procedure, scenario \#2 (Table 20) and scenario \#6 (Table 21) will also be selected in the third and fourth step respectively.

Table 19- Scenario distance calculations at step 2

\begin{tabular}{|c|c|c|c|c|c|c|c|c|c|c|}
\hline Scenarios & $\mathbf{1}$ & $\mathbf{2}$ & $\mathbf{3}$ & $\mathbf{4}$ & $\mathbf{5}$ & $\mathbf{6}$ & $\mathbf{7}$ & $\mathbf{8}$ & $\mathbf{9}$ & $\mathbf{1 0}$ \\
\hline $\mathbf{1}$ & 0 & 66 & 230 & 437 & 437 & 437 & 437 & 437 & 437 & 437 \\
\hline $\mathbf{2}$ & 66 & 0 & 164 & 371 & 371 & 371 & 371 & 371 & 371 & 371 \\
\hline $\mathbf{3}$ & 207 & 164 & 0 & 207 & 207 & 207 & 207 & 207 & 207 & 207 \\
\hline $\mathbf{4}$ & 0 & 0 & 0 & 0 & 0 & 0 & 0 & 0 & 0 & 0 \\
\hline $\mathbf{5}$ & 248 & 248 & 248 & 248 & 0 & 248 & 248 & 248 & 248 & 248 \\
\hline $\mathbf{6}$ & 539 & 539 & 539 & 539 & 291 & 0 & 333 & 539 & 539 & 539 \\
\hline $\mathbf{7}$ & 872 & 872 & 872 & 872 & 624 & 333 & 0 & 374 & 792 & 872 \\
\hline $\mathbf{8}$ & 1246 & 1246 & 1246 & 1246 & 998 & 707 & 374 & 0 & 418 & 642 \\
\hline $\mathbf{9}$ & 1664 & 1664 & 1664 & 1664 & 1416 & 1125 & 792 & 418 & 0 & 224 \\
\hline $\mathbf{1 0}$ & 1888 & 1888 & 1888 & 1888 & 1640 & 1349 & 1016 & 642 & $\mathbf{2 2 4}$ & 0 \\
\hline Distance & $\mathbf{4 3 2}$ & $\mathbf{4 3 1}$ & $\mathbf{4 5 8}$ & $\mathbf{5 4 7}$ & $\mathbf{4 3 7}$ & $\mathbf{3 7 0}$ & $\mathbf{3 2 5}$ & $\mathbf{3 1 4}$ & $\mathbf{3 2 6}$ & $\mathbf{3 4 0}$ \\
\hline
\end{tabular}

Table 20- Scenario distance calculations at step 3

\begin{tabular}{|c|c|c|c|c|c|c|c|c|c|c|}
\hline Scenarios & $\mathbf{1}$ & $\mathbf{2}$ & $\mathbf{3}$ & $\mathbf{4}$ & $\mathbf{5}$ & $\mathbf{6}$ & $\mathbf{7}$ & $\mathbf{8}$ & $\mathbf{9}$ & $\mathbf{1 0}$ \\
\hline $\mathbf{1}$ & 0 & 66 & 230 & 437 & 437 & 437 & 437 & 437 & 437 & 437 \\
\hline $\mathbf{2}$ & 66 & 0 & 164 & 371 & 371 & 371 & 371 & 371 & 371 & 371 \\
\hline $\mathbf{3}$ & 207 & 164 & 0 & 207 & 207 & 207 & 207 & 207 & 207 & 207 \\
\hline $\mathbf{4}$ & 0 & 0 & 0 & 0 & 0 & 0 & 0 & 0 & 0 & 0 \\
\hline $\mathbf{5}$ & 248 & 248 & 248 & 248 & 0 & 248 & 248 & 248 & 248 & 248 \\
\hline $\mathbf{6}$ & 539 & 539 & 539 & 539 & 291 & 0 & 333 & 539 & 539 & 539 \\
\hline $\mathbf{7}$ & 374 & 374 & 374 & 374 & 374 & 333 & 0 & 374 & 374 & 374 \\
\hline $\mathbf{8}$ & 0 & 0 & 0 & 0 & 0 & 0 & 0 & 0 & 0 & 0 \\
\hline $\mathbf{9}$ & 418 & 418 & 418 & 418 & 418 & 418 & 418 & 418 & 0 & 224 \\
\hline $\mathbf{1 0}$ & 642 & 642 & 642 & 642 & 642 & 642 & 642 & 642 & 224 & 0 \\
\hline Distance & $\mathbf{1 9 9}$ & $\mathbf{1 9 8}$ & $\mathbf{2 2 5}$ & $\mathbf{3 1 4}$ & $\mathbf{2 6 2}$ & $\mathbf{2 5 9}$ & $\mathbf{2 6 6}$ & $\mathbf{3 1 4}$ & $\mathbf{2 7 2}$ & $\mathbf{2 6 6}$ \\
\hline
\end{tabular}


Table 21- Scenario distance calculations at step 4

\begin{tabular}{|c|c|c|c|c|c|c|c|c|c|c|}
\hline Scenarios & $\mathbf{1}$ & $\mathbf{2}$ & $\mathbf{3}$ & $\mathbf{4}$ & $\mathbf{5}$ & $\mathbf{6}$ & $\mathbf{7}$ & $\mathbf{8}$ & $\mathbf{9}$ & $\mathbf{1 0}$ \\
\hline $\mathbf{1}$ & 0 & 66 & 66 & 66 & 66 & 66 & 66 & 66 & 66 & 66 \\
\hline $\mathbf{2}$ & 0 & 0 & 0 & 0 & 0 & 0 & 0 & 0 & 0 & 0 \\
\hline $\mathbf{3}$ & 164 & 164 & 0 & 164 & 164 & 164 & 164 & 164 & 164 & 164 \\
\hline $\mathbf{4}$ & 0 & 0 & 0 & 0 & 0 & 0 & 0 & 0 & 0 & 0 \\
\hline $\mathbf{5}$ & 248 & 248 & 248 & 248 & 0 & 248 & 248 & 248 & 248 & 248 \\
\hline $\mathbf{6}$ & 539 & 539 & 539 & 539 & 291 & 0 & 333 & 539 & 539 & 539 \\
\hline $\mathbf{7}$ & 374 & 374 & 374 & 374 & 374 & 333 & 0 & 374 & 374 & 374 \\
\hline $\mathbf{8}$ & 0 & 0 & 0 & 0 & 0 & 0 & 0 & 0 & 0 & 0 \\
\hline $\mathbf{9}$ & 418 & 418 & 418 & 418 & 418 & 418 & 418 & 418 & 0 & 224 \\
\hline $\mathbf{1 0}$ & 642 & 642 & 642 & 642 & 642 & 642 & 642 & 642 & 224 & 0 \\
\hline
\end{tabular}

The selection procedure stops here since considering more than four scenarios would limit the computational ability to deal with a large problem. Moreover, the original scenario generation technique of the model seems to be adequate for greater than four scenarios as indicated by Table 2 and there is no need to use reduction techniques on a larger scenario set.

Now, we have to redistribute the probabilities of unselected scenarios among the selected ones based on their differences. This is a very easy process and the results are displayed in Table 22 and Table 23 for three and four selected scenarios respectively. The first row in Table 22, for example, shows that the probability of scenario \#2 in the reduced set $\{2,4,6\}$ is 0.429 which is obtained by adding up the probabilities of scenarios $\# 1$ through $\# 3$ in the original set. The elements of the reduced scenario set in the table are marked with an asterisk to differentiate them from the original scenario set elements (since they might have different probabilities).

Table 22- Probability redistribution for three selected scenarios

\begin{tabular}{|c|c|c|c|}
\hline $\begin{array}{c}\text { Reduced set } \\
\text { scenarios }\end{array}$ & $\begin{array}{c}\text { Production } \\
\text { (kW) }\end{array}$ & Probability & $\begin{array}{c}\text { Scenario probabilities } \\
\text { redistributed }\end{array}$ \\
\hline $2^{*}$ & 66 & 0.429 & $1,2,3$ \\
\hline $4^{*}$ & 437 & 0.339 & $4,5,6$ \\
\hline $8^{*}$ & 1683 & 0.232 & $7,8,9,10$ \\
\hline
\end{tabular}


Table 23- Probability redistribution for four selected scenarios

\begin{tabular}{|c|c|c|c|}
\hline $\begin{array}{c}\text { Reduced set } \\
\text { scenarios }\end{array}$ & $\begin{array}{c}\text { Production } \\
\text { (kW) }\end{array}$ & Probability & $\begin{array}{c}\text { Scenario probabilities } \\
\text { redistributed }\end{array}$ \\
\hline $2^{*}$ & 66 & 0.429 & $1,2,3$ \\
\hline $4^{*}$ & 437 & 0.243 & 4,5 \\
\hline $6^{*}$ & 976 & 0.171 & 6,7 \\
\hline $8^{*}$ & 1683 & 0.157 & $8,9,10$ \\
\hline
\end{tabular}

With the reduced scenario sets defined, we are ready to run tests in order to evaluate the effectiveness of this approach. Table 24 presents the solution for three and four selected scenarios. As the results show, wind power generation is not utilized in any of the cases. In other words, the stochastic aspect of the model has been completely disregarded.

Table 24- Model solution for three and four selected scenarios

\begin{tabular}{|c|c|c|c|c|c|c|}
\hline $\begin{array}{c}\text { Reduced } \\
\text { set }\end{array}$ & $\begin{array}{c}\text { Cost } \\
\text { (\$/ / hr) }\end{array}$ & $\mathrm{X}_{\mathrm{c}}(\mathrm{MW})$ & $\mathrm{X}_{\mathrm{g}}(\mathrm{MW})$ & $\mathrm{X}_{\mathrm{n}}(\mathrm{MW})$ & $\mathrm{X}_{\mathrm{r}}(\mathrm{MW})$ & $\mathbf{X}_{\mathrm{w}}$ (Units) \\
\hline$\{2,4,8\}$ & $1,628,974$ & 10,000 & 5,000 & 2,536 & 0 & 0 \\
\hline$\{2,4,6,8\}$ & $1,628,974$ & 10,000 & 5,000 & 2,536 & 0 & 0 \\
\hline
\end{tabular}

Therefore, the standard scenario reduction is not suitable for our model. The reason for this outcome seems to be the fact that this selection approach favors the average scenarios compared to boundary scenarios (minimum and maximum wind power production). The second stage variables (which constitute the recourse action i.e. energy trade), however, have the greatest influence on the boundary scenarios. Consequently, when the boundary scenarios are eliminated, the recourse action is downplayed and it might totally be neglected in the solution. Therefore, we need to modify this approach accordingly so that we can address these special requirements. 


\section{2. $\quad$ Customized Scenario Reduction}

Pursuant to the discussion above, we decided to start with the boundary scenarios (zero and maximum production) and then add new elements to this set. Again, the underlying reason for this adjustment was the fact that these extreme cases play an important role in dynamics of the model (especially the stochastic part), as observed in several instances throughout the sensitivity analyses (e.g. energy storage).

Application of this adjustment to standard procedure leads to scenario \#5 and scenario \#7 being selected as the third and fourth members of the reduced set. The selection process is summarized in Table 25 and Table 26.

Table 25- Selection of the third scenario

\begin{tabular}{|c|c|c|c|c|c|c|c|c|c|c|}
\hline Scenarios & $\mathbf{1}$ & $\mathbf{2}$ & $\mathbf{3}$ & $\mathbf{4}$ & $\mathbf{5}$ & $\mathbf{6}$ & $\mathbf{7}$ & $\mathbf{8}$ & $\mathbf{9}$ & $\mathbf{1 0}$ \\
\hline $\mathbf{1}$ & 0 & 0 & 0 & 0 & 0 & 0 & 0 & 0 & 0 & 0 \\
\hline $\mathbf{2}$ & 66 & 0 & 66 & 66 & 66 & 66 & 66 & 66 & 66 & 66 \\
\hline $\mathbf{3}$ & 230 & 164 & 0 & 207 & 230 & 230 & 230 & 230 & 230 & 230 \\
\hline $\mathbf{4}$ & 437 & 371 & 207 & 0 & 248 & 437 & 437 & 437 & 437 & 437 \\
\hline $\mathbf{5}$ & 685 & 619 & 455 & 248 & 0 & 291 & 624 & 685 & 685 & 685 \\
\hline $\mathbf{6}$ & 976 & 910 & 746 & 539 & 291 & 0 & 333 & 707 & 976 & 976 \\
\hline $\mathbf{7}$ & 1016 & 1016 & 1016 & 872 & 624 & 333 & 0 & 374 & 792 & 1016 \\
\hline $\mathbf{8}$ & 642 & 642 & 642 & 642 & 642 & 642 & 374 & 0 & 418 & 642 \\
\hline $\mathbf{9}$ & 224 & 224 & 224 & $\mathbf{2 2 4}$ & $\mathbf{2 2 4}$ & 224 & 224 & 224 & 0 & 224 \\
\hline $\mathbf{1 0}$ & 0 & 0 & 0 & 0 & 0 & 0 & 0 & 0 & 0 & 0 \\
\hline Distance & $\mathbf{3 8 7}$ & $\mathbf{3 4 8}$ & $\mathbf{2 7 9}$ & $\mathbf{2 2 5}$ & $\mathbf{1 8 9}$ & $\mathbf{1 9 7}$ & $\mathbf{2 2 7}$ & $\mathbf{2 7 7}$ & $\mathbf{3 4 9}$ & $\mathbf{3 8 7}$ \\
\hline
\end{tabular}

Table 26- Selection of the fourth scenario

\begin{tabular}{|c|c|c|c|c|c|c|c|c|c|c|}
\hline Scenarios & $\mathbf{1}$ & $\mathbf{2}$ & $\mathbf{3}$ & $\mathbf{4}$ & $\mathbf{5}$ & $\mathbf{6}$ & $\mathbf{7}$ & $\mathbf{8}$ & $\mathbf{9}$ & $\mathbf{1 0}$ \\
\hline $\mathbf{1}$ & 0 & 0 & 0 & 0 & 0 & 0 & 0 & 0 & 0 & 0 \\
\hline $\mathbf{2}$ & 66 & 0 & 66 & 66 & 66 & 66 & 66 & 66 & 66 & 66 \\
\hline $\mathbf{3}$ & 230 & 164 & 0 & 207 & 230 & 230 & 230 & 230 & 230 & 230 \\
\hline $\mathbf{4}$ & 248 & 248 & 207 & 0 & 248 & 248 & 248 & 248 & 248 & 248 \\
\hline $\mathbf{5}$ & 0 & 0 & 0 & 0 & 0 & 0 & 0 & 0 & 0 & 0 \\
\hline $\mathbf{6}$ & 291 & 291 & 291 & 291 & 291 & 0 & 291 & 291 & 291 & 291 \\
\hline $\mathbf{7}$ & 624 & 624 & 624 & 624 & 624 & 333 & 0 & 374 & 624 & 624 \\
\hline $\mathbf{8}$ & 642 & 642 & 642 & 642 & 642 & 642 & 374 & 0 & 418 & 642 \\
\hline $\mathbf{9}$ & 224 & 224 & 224 & 224 & 224 & 224 & 224 & 224 & 0 & 224 \\
\hline $\mathbf{1 0}$ & 0 & 0 & 0 & 0 & 0 & 0 & 0 & 0 & 0 & 0 \\
\hline Distance & $\mathbf{1 8 9}$ & $\mathbf{1 7 3}$ & $\mathbf{1 5 4}$ & $\mathbf{1 5 4}$ & $\mathbf{1 8 9}$ & $\mathbf{1 3 9}$ & $\mathbf{1 2 7}$ & $\mathbf{1 3 5}$ & $\mathbf{1 6 8}$ & $\mathbf{1 8 9}$ \\
\hline
\end{tabular}


Probability redistribution can also be done in two ways. We can follow the standard procedure or preserve the boundary scenario probabilities and apply redistribution only to other elements of the reduced set. We have considered both of these cases in order to discover the best approach. Table 27 and Table 28 present the reduced set alternatives for three scenarios (denoted as set 3-1 for standard probability redistribution and set 3-2 for the modified method). Similarly, Table 29 and Table 30 illustrate the reduced sets for four scenarios (set 4-1 and set 4-2).

Table 27- Reduced set for three scenarios using standard redistribution (set 3-1)

\begin{tabular}{|c|c|c|c|}
\hline $\begin{array}{c}\text { Reduced set } \\
\text { scenarios }\end{array}$ & $\begin{array}{c}\text { Production } \\
\text { (kW) }\end{array}$ & Probability & $\begin{array}{c}\text { Scenario probabilities } \\
\text { redistributed }\end{array}$ \\
\hline $1^{*}$ & 0 & 0.429 & $1,2,3$ \\
\hline $5^{*}$ & 685 & 0.414 & $4,5,6,7$ \\
\hline $10^{*}$ & 2325 & 0.157 & $8,9,10$ \\
\hline
\end{tabular}

Table 28- Reduced set for three scenarios using modified redistribution (set 3-2)

\begin{tabular}{|c|c|c|c|}
\hline $\begin{array}{c}\text { Reduced set } \\
\text { scenarios }\end{array}$ & $\begin{array}{c}\text { Production } \\
\text { (kW) }\end{array}$ & Probability & $\begin{array}{c}\text { Scenario probabilities } \\
\text { redistributed }\end{array}$ \\
\hline $1^{*}$ & 0 & 0.178 & 1 \\
\hline $5^{*}$ & 685 & 0.76 & 2 through 9 \\
\hline $10^{*}$ & 2325 & 0.062 & 10 \\
\hline
\end{tabular}

Table 29- Reduced set for four scenarios using standard redistribution (set 4-1)

\begin{tabular}{|c|c|c|c|}
\hline $\begin{array}{c}\text { Reduced set } \\
\text { scenarios }\end{array}$ & $\begin{array}{c}\text { Production } \\
\text { (kW) }\end{array}$ & Probability & $\begin{array}{c}\text { Scenario probabilities } \\
\text { redistributed }\end{array}$ \\
\hline $1^{*}$ & 0 & 0.429 & $1,2,3$ \\
\hline $5^{*}$ & 685 & 0.339 & $4,5,6$ \\
\hline $7^{*}$ & 1309 & 0.131 & 7,8 \\
\hline $10^{*}$ & 2325 & 0.101 & 9,10 \\
\hline
\end{tabular}

Table 30- Reduced set for four scenarios using modified redistribution (set 4-2)

\begin{tabular}{|c|c|c|c|}
\hline $\begin{array}{c}\text { Reduced set } \\
\text { scenarios }\end{array}$ & $\begin{array}{c}\text { Production } \\
\text { (kW) }\end{array}$ & Probability & $\begin{array}{c}\text { Scenario probabilities } \\
\text { redistributed }\end{array}$ \\
\hline $1^{*}$ & 0 & 0.178 & 1 \\
\hline $5^{*}$ & 685 & 0.59 & $2,3,4,5,6$ \\
\hline $7^{*}$ & 1309 & 0.17 & $7,8,9$ \\
\hline $10^{*}$ & 2325 & 0.062 & 10 \\
\hline
\end{tabular}


In order to identify the best alternative, the original model (containing a single wind farm) is solved for each set to compare the solutions. The data obtained from this observation is presented in Table 31. As the results indicate, set 3-2 (three-scenario set with intact boundary scenarios) leads to the most accurate solution.

Table 31- Comparison of reduced sets

\begin{tabular}{|c|c|c|c|c|c|c|}
\hline Case & Cost $\mathbf{\$} / \mathbf{h r})$ & $\mathbf{X}_{\mathrm{c}}(\mathbf{M W})$ & $\left.\mathbf{X}_{\mathrm{g}} \mathbf{( M W}\right)$ & $\mathbf{X}_{\mathrm{n}}(\mathbf{M W})$ & $\mathbf{X}_{\mathrm{r}}(\mathbf{M W})$ & $\mathbf{X}_{\mathrm{w}}$ (Units) \\
\hline $3-1$ & $\$ 1,628,974$ & 10,000 & 5,000 & 2,535 & 0 & 2 \\
\hline $3-2$ & $\$ 1,628,859$ & 10,000 & 5,000 & 2,454 & 0 & 114 \\
\hline $4-1$ & $\$ 1,628,974$ & 10,000 & 5,000 & 2,536 & 0 & 0 \\
\hline $4-2$ & $\$ 1,623,726$ & 10,000 & 5,000 & 1,967 & 0 & 725 \\
\hline $\begin{array}{c}\text { Exact } \\
\text { solution }\end{array}$ & $\$ 1,628,728$ & 10,000 & 5,000 & 2,450 & 0 & 117 \\
\hline
\end{tabular}

Therefore, this reduced scenario set can be used for solving a large problem. As an example, the problem has been solved for ten wind farms with no recourse (energy exchange). While it is not possible to solve this problem considering ten scenarios for each location, a solution is obtained in approximately one hour when scenario set 3-2 is utilized. This solution is presented in Table 32 .

Table 32- Solution for ten wind farms with no recourse

\begin{tabular}{|c|c|c|c|c|c|c|}
\hline $\begin{array}{c}\text { Number of } \\
\text { wind farms }\end{array}$ & Cost (\$/hr) & $\mathbf{X}_{\mathbf{c}}(\mathbf{M W})$ & $\mathbf{X}_{\mathbf{q}}(\mathbf{M W})$ & $\mathbf{X}_{\mathbf{n}}(\mathbf{M W})$ & $\mathbf{X w}$ (per site) & $\mathbf{X w}$ (total) \\
\hline 10 & $\$ 1,627,824$ & 10,000 & 5,000 & 1,710 & 114 & 1,140 \\
\hline
\end{tabular}

Further investigations show that the fitness of reduced scenario set 3-2 can be associated with another parameter as well. The capacity factor of a wind turbine in the original problem is equal to $29.4 \%$ according to Table 8 . If the same turbine is subject to scenario set 3-2, we will have: 
$\mathrm{CF}=(0 \times 0.178+0.76 \times 685+0.062 \times 2325) / 2325=28.6 \%$

This factor is very close to the original value. Therefore, we can directly use this result to reduce the original scenario set down to three members.

It should be noted, however, that the scenario dependent variables were not present in this problem. When considering recourse in the model, the problem is still too large to handle. Therefore, further approximations or assumptions are required to deal with a fully-blown problem.

\section{3. $\quad$ Additional Constraints}

In this section, we are trying to exploit the structure of the problem in order to reduce the solution time. One of the main sources of numerical complication in the model is the excessive number of second stage variables. Investigation of the solution reveals that the matrices corresponding to these variables are sparse. Therefore, we must be able to develop some sort of a prescreening procedure to exclude redundant variables from the optimization process.

As discussed earlier, the second stage variables represent the recourse actions which mainly come to play at boundary and near boundary scenarios. They are less likely to be used in scenarios with average power production. Furthermore, while there are four types of recourse action (import, export, storage and release) available for each realization of power production quantity, at most two and generally only one or none of them will be used in any specific scenario. For instance, in a reasonably priced market, power shall not be imported and exported in the same scenario. Otherwise there will be an arbitrage opportunity (importing at lower cost and exporting at higher price) which is a rare phenomenon in a healthy market. Therefore, according to these 
observations, the number of second stage variables can potentially be reduced by almost half if these logical constraints are enforced.

Based on the above explanation, the idea is to identify the variables which are unlikely to be in the solution basis and preset them to zero. As a result, the variables standing for energy importation and release will be filtered in scenarios with high power production. Similarly, energy exportation and storage are barred in low production scenarios.

Obviously, the thresholds for such classification based on power production quantity can affect the time and accuracy of the solution. It is expected that wider ranges of low or high production scenarios would lead to shorter run times and less accurate solutions. In other words, there is a tradeoff between the solution time and accuracy. The procedure is discussed in detail in the following numerical example.

We will assume the same problem solved in the previous subsection (a network including ten wind farm facilities) but energy exchange and storage will be permitted at the following rates:

$\mathrm{Cst}=\$ 50 / \mathrm{MWh}$ $\mathrm{U}_{\mathrm{st}}=400 \mathrm{MWh}$

$\mathrm{Cim}=\$ 120 / \mathrm{MWh}$ $\mathrm{U}_{\mathrm{im}}=1000 \mathrm{MWh}$

$\mathrm{Pex}=\$ 120 / \mathrm{MWh}$ $\mathrm{U}_{\mathrm{ex}}=1000 \mathrm{MWh}$

Considering the same three scenarios for each location (reduced set 3-2), we will have more than 59,000 $\left(3^{10}\right)$ combined scenarios for the problem. However, many of these realizations are identical in terms of power production quantities. In fact, there are only 66 distinct wind power generation scenarios as Table 33 indicates. The second column in the table denotes the wind generated power quantity in Megawatts and 
column 3 to 5 show what combination of scenarios has led to this output. For instance, in case 7, the power production is equal to $3.01 \mathrm{MW}$ which occurs when 8 wind farms produce no electricity and the remaining two generate $685 \mathrm{~kW}$ and $2,325 \mathrm{~kW}$. This production scenario encompasses 90 combinations considering all the permutations for ten locations (column 6). The next column specifies the probability of this output. The next two columns denote the cumulative count of combinations and the cumulative probability for production values less than or equal to current row output.

Table 33- Scenario analysis for ten wind farms

\begin{tabular}{|c|c|c|c|c|c|c|c|c|}
\hline & Wind & \multicolumn{2}{|c|}{ Combination } & & & Cumulative & Cumulative \\
Case & output(MW) & $\mathbf{0}$ & $\mathbf{0 . 6 8 5}$ & $\mathbf{2 . 3 2 5}$ & Count & Probability & $\begin{array}{c}\text { count } \\
\text { probability }\end{array}$ \\
\hline 1 & 0 & 10 & 0 & 0 & 1 & $3.19 \mathrm{E}-08$ & 1 & 0.000000 \\
\hline 2 & 0.685 & 9 & 1 & 0 & 10 & $1.36 \mathrm{E}-06$ & 11 & 0.000001 \\
\hline 3 & 1.37 & 8 & 2 & 0 & 45 & $2.62 \mathrm{E}-05$ & 56 & 0.000028 \\
\hline 4 & 2.055 & 7 & 3 & 0 & 120 & 0.0003 & 176 & 0.000326 \\
\hline 5 & 2.325 & 9 & 0 & 1 & 10 & $1.11 \mathrm{E}-07$ & 186 & 0.000326 \\
\hline 6 & 2.74 & 6 & 4 & 0 & 210 & 0.0022 & 396 & 0.002554 \\
\hline 7 & 3.01 & 8 & 1 & 1 & 90 & $4.27 \mathrm{E}-06$ & 486 & 0.002559 \\
\hline 8 & 3.425 & 5 & 5 & 0 & 252 & 0.0114 & 738 & 0.013976 \\
\hline 9 & 3.695 & 7 & 2 & 1 & 360 & $7.3 \mathrm{E}-05$ & 1098 & 0.014049 \\
\hline 10 & 4.11 & 4 & 6 & 0 & 210 & 0.0406 & 1308 & 0.054673 \\
\hline 11 & 4.38 & 6 & 3 & 1 & 840 & 0.0007 & 2148 & 0.055400 \\
\hline 12 & 4.65 & 8 & 0 & 2 & 45 & $1.74 \mathrm{E}-07$ & 2193 & 0.055400 \\
\hline 13 & 4.795 & 3 & 7 & 0 & 120 & 0.0991 & 2313 & 0.154515 \\
\hline 14 & 5.065 & 5 & 4 & 1 & 1260 & 0.0047 & 3573 & 0.159172 \\
\hline 15 & 5.335 & 7 & 1 & 2 & 360 & $5.95 \mathrm{E}-06$ & 3933 & 0.159178 \\
\hline 16 & 5.48 & 2 & 8 & 0 & 45 & 0.1587 & 3978 & 0.317872 \\
\hline 17 & 5.75 & 4 & 5 & 1 & 1260 & 0.0199 & 5238 & 0.337756 \\
\hline 18 & 6.02 & 6 & 2 & 2 & 1260 & $8.9 \mathrm{E}-05$ & 6498 & 0.337845 \\
\hline 19 & 6.165 & 1 & 9 & 0 & 10 & 0.1506 & 6508 & 0.488416 \\
\hline 20 & 6.435 & 3 & 6 & 1 & 840 & 0.0566 & 7348 & 0.545016 \\
\hline 21 & 6.705 & 5 & 3 & 2 & 2520 & 0.0008 & 9868 & 0.545776 \\
\hline 22 & 6.85 & 0 & 10 & 0 & 1 & 0.0643 & 9869 & 0.610065 \\
\hline 23 & 6.975 & 7 & 0 & 3 & 120 & $1.62 \mathrm{E}-07$ & 9989 & 0.610065 \\
\hline 24 & 7.12 & 2 & 7 & 1 & 360 & 0.1036 & 10349 & 0.713634 \\
\hline 25 & 7.39 & 4 & 4 & 2 & 3150 & 0.0041 & 13499 & 0.717689 \\
\hline 26 & 7.66 & 6 & 1 & 3 & 840 & $4.84 \mathrm{E}-06$ & 14339 & 0.717694 \\
\hline 27 & 7.805 & 1 & 8 & 1 & 90 & 0.1106 & 14429 & 0.828245 \\
\hline 28 & 8.075 & 3 & 5 & 2 & 2520 & 0.0139 & 16949 & 0.842097 \\
\hline & & & & & & & & \\
\hline 12 & & & & & & & & \\
\hline
\end{tabular}




\begin{tabular}{|c|c|c|c|c|c|c|c|c|}
\hline \multirow[b]{2}{*}{ Case } & \multirow{2}{*}{$\begin{array}{c}\text { Wind } \\
\text { output(MW) }\end{array}$} & \multicolumn{3}{|c|}{ Combination } & \multirow[b]{2}{*}{ Count } & \multirow[b]{2}{*}{ Probability } & \multirow{2}{*}{$\begin{array}{c}\text { Cumulative } \\
\text { count }\end{array}$} & \multirow{2}{*}{$\begin{array}{l}\text { Cumulative } \\
\text { probability }\end{array}$} \\
\hline & & 0 & 0.685 & 2.325 & & & & \\
\hline 29 & 8.345 & 5 & 2 & 3 & 2520 & $6.2 \mathrm{E}-05$ & 19469 & 0.842159 \\
\hline 30 & 8.49 & 0 & 9 & 1 & 10 & 0.0524 & 19479 & 0.894605 \\
\hline 31 & 8.76 & 2 & 6 & 2 & 1260 & 0.0296 & 20739 & 0.924177 \\
\hline 32 & 9.03 & 4 & 3 & 3 & 4200 & 0.0004 & 24939 & 0.924618 \\
\hline 33 & 9.3 & 6 & 0 & 4 & 210 & 9.87E-08 & 25149 & 0.924618 \\
\hline 34 & 9.445 & 1 & 7 & 2 & 360 & 0.0361 & 25509 & 0.960693 \\
\hline 35 & 9.715 & 3 & 4 & 3 & 4200 & 0.0019 & 29709 & 0.962576 \\
\hline 36 & 9.985 & 5 & 1 & 4 & 1260 & 2.53E-06 & 30969 & 0.962579 \\
\hline 37 & 10.13 & 0 & 8 & 2 & 45 & 0.0193 & 31014 & 0.981832 \\
\hline 38 & 10.4 & 2 & 5 & 3 & 2520 & 0.0048 & 33534 & 0.986657 \\
\hline 39 & 10.67 & 4 & 2 & 4 & 3150 & 2.7E-05 & 36684 & 0.986684 \\
\hline 40 & 11.085 & 1 & 6 & 3 & 840 & 0.0069 & 37524 & 0.993550 \\
\hline 41 & 11.355 & 3 & 3 & 4 & 4200 & 0.0002 & 41724 & 0.993704 \\
\hline 42 & 11.625 & 5 & 0 & 5 & 252 & 4.13E-08 & 41976 & 0.993704 \\
\hline 43 & 11.77 & 0 & 7 & 3 & 120 & 0.0042 & 42096 & 0.997893 \\
\hline 44 & 12.04 & 2 & 4 & 4 & 3150 & 0.0005 & 45246 & 0.998385 \\
\hline 45 & 12.31 & 4 & 1 & 5 & 1260 & 8.81E-07 & 46506 & 0.998385 \\
\hline 46 & 12.725 & 1 & 5 & 4 & 1260 & 0.0008 & 47766 & 0.999226 \\
\hline 47 & 12.995 & 3 & 2 & 5 & 2520 & 7.52E-06 & 50286 & 0.999233 \\
\hline 48 & 13.41 & 0 & 6 & 4 & 210 & 0.0006 & 50496 & 0.999831 \\
\hline 49 & 13.68 & 2 & 3 & 5 & 2520 & 3.21E-05 & 53016 & 0.999863 \\
\hline 50 & 13.95 & 4 & 0 & 6 & 210 & 1.2E-08 & 53226 & 0.999863 \\
\hline 51 & 14.365 & 1 & 4 & 5 & 1260 & 6.85E-05 & 54486 & 0.999932 \\
\hline 52 & 14.635 & 3 & 1 & 6 & 840 & 2.05E-07 & 55326 & 0.999932 \\
\hline 53 & 15.05 & 0 & 5 & 5 & 252 & 5.85E-05 & 55578 & 0.999991 \\
\hline 54 & 15.32 & 2 & 2 & 6 & 1260 & 1.31E-06 & 56838 & 0.999992 \\
\hline 55 & 16.005 & 1 & 3 & 6 & 840 & 3.73E-06 & 57678 & 0.999996 \\
\hline 56 & 16.275 & 3 & 0 & 7 & 120 & 2.38E-09 & 57798 & 0.999996 \\
\hline 57 & 16.69 & 0 & 4 & 6 & 210 & $3.98 \mathrm{E}-06$ & 58008 & 1.000000 \\
\hline 58 & 16.96 & 2 & 1 & 7 & 360 & 3.05E-08 & 58368 & 1.000000 \\
\hline 59 & 17.645 & 1 & 2 & 7 & 360 & 1.3E-07 & 58728 & 1.000000 \\
\hline 60 & 18.33 & 0 & 3 & 7 & 120 & 1.86E-07 & 58848 & 1.000000 \\
\hline 61 & 18.6 & 2 & 0 & 8 & 45 & $3.11 \mathrm{E}-10$ & 58893 & 1.000000 \\
\hline 62 & 19.285 & 1 & 1 & 8 & 90 & $2.66 \mathrm{E}-09$ & 58983 & 1.000000 \\
\hline 63 & 19.97 & 0 & 2 & 8 & 45 & 5.68E-09 & 59028 & 1.000000 \\
\hline 64 & 20.925 & 1 & 0 & 9 & 10 & $2.41 \mathrm{E}-11$ & 59038 & 1.000000 \\
\hline 65 & 21.61 & 0 & 1 & 9 & 10 & 1.03E-10 & 59048 & 1.000000 \\
\hline 66 & 23.25 & 0 & 0 & 10 & 1 & 8.39E-13 & 59049 & 1.000000 \\
\hline
\end{tabular}

The cumulative scenario count provides us with an insight into the number of variables being filtered at any given threshold. For example, assuming a low production threshold of $7 \mathrm{MW}$ (corresponding to case 23), we already know that 
9,989 energy export variables and an equal number of energy storage variables will be eliminated from the model. Or for a high production threshold of $16 \mathrm{MW}$ (corresponding to case 55), 1,371 energy import variables (and same number of energy release variables) are preset to zero $(59,049-57,678=1,371)$. The cumulative probability distribution function of the power output is another visual indicator of the same parameter which is presented in Figure 46. With all of this information available, we can proceed with our heuristics to solve the problem.

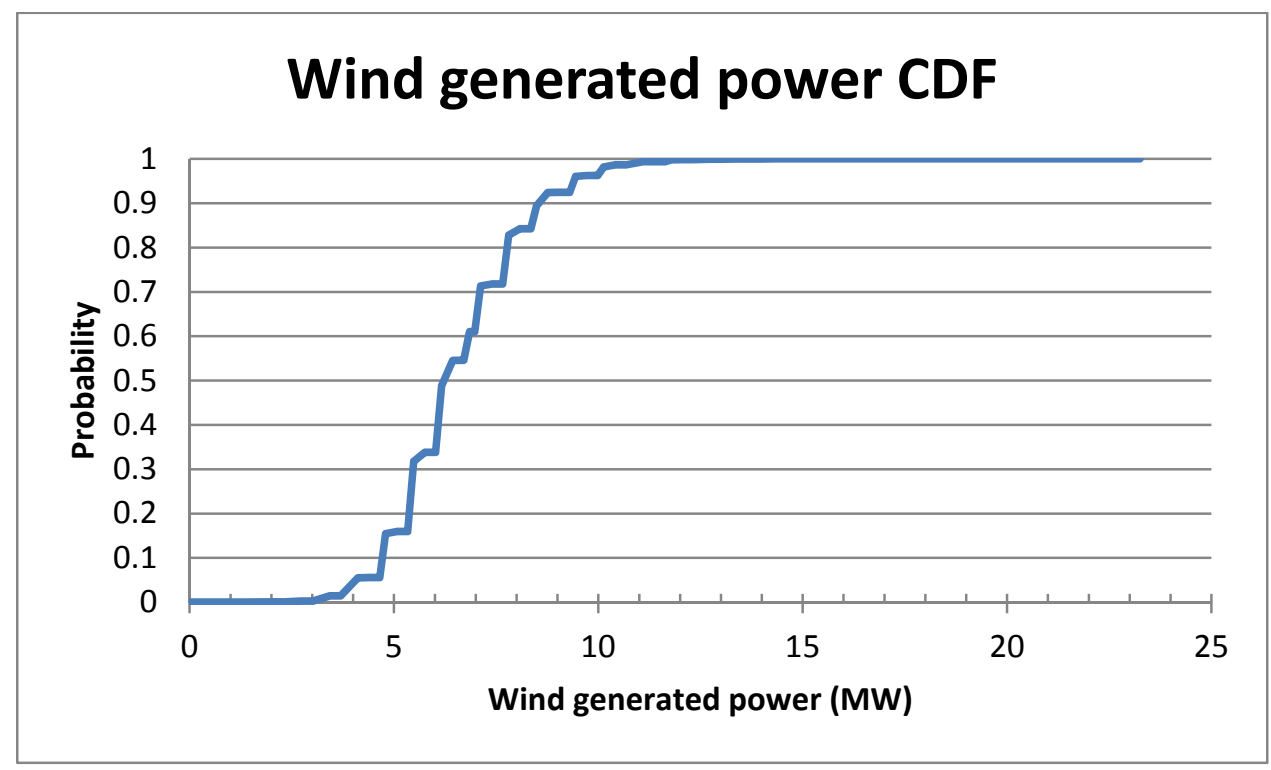

Figure 46- Cumulative distribution function for wind generated power

Based on the above discussion, the following four sets of constraints will be added to the formulation:

If $\left(\mathrm{R}_{\mathrm{i}}+\mathrm{R}_{\mathrm{j}}+\mathrm{R}_{\mathrm{k}}+\mathrm{R}_{\mathrm{l}}+\mathrm{R}_{\mathrm{m}}+\mathrm{R}_{\mathrm{n}}+\mathrm{R}_{\mathrm{o}}+\mathrm{R}_{\mathrm{p}}+\mathrm{R}_{\mathrm{q}}+\mathrm{R}_{\mathrm{r}}\right) \leq \mathrm{TL}$ then

$\mathrm{XeX}_{\mathrm{ijk} \text { lmnopqr }}=0$

If $\left(R_{i}+R_{j}+R_{k}+R_{1}+R_{m}+R_{n}+R_{o}+R_{p}+R_{q}+R_{r}\right) \leq T L$ then

$\mathrm{Xst}_{\mathrm{ijk} \text { mmopqr }}=0$ 
If $\left(R_{i}+R_{j}+R_{k}+R_{1}+R_{m}+R_{n}+R_{o}+R_{p}+R_{q}+R_{r}\right) \geq T H$ then

$\mathrm{Xim}_{\mathrm{ijk} 1 \mathrm{mnopqr}}=0$

If $\left(R_{i}+R_{j}+R_{k}+R_{1}+R_{m}+R_{n}+R_{o}+R_{p}+R_{q}+R_{r}\right) \geq T H$ then

$\mathrm{Xrel}_{\mathrm{ijk} 1 \mathrm{mnopqr}}=0$

Where

- $\quad R_{i}$ to $R_{r}$ are wind generated power amount at each of the ten wind farms.

- $\quad \mathrm{i}, \mathrm{j}, \mathrm{k}, \mathrm{l}, \mathrm{m}, \mathrm{n}, \mathrm{o}, \mathrm{p}, \mathrm{q}, \mathrm{r}$ are the scenario indices at each wind farm. Each one can have three states $(\mathrm{R}=0, \mathrm{R}=685 \mathrm{~kW}$ and $\mathrm{R}=2,325 \mathrm{~kW})$.

- $\quad$ TL and TH are low and high power production thresholds.

- Xim, Xex, Xst and Xrel are scenario dependent variables for energy import, energy export, storage and release amounts.

Investigation of the previous solutions reveals that the upper and lower third of wind power output range are good approximations of high and low production scenarios respectively. The reason is that within these intervals, one or two types of the second stage variables are seldom utilized. So, we regard this observation as a guideline for setting the threshold values.

Table 34 presents the solution for several instances of threshold values. The first run specifies the solution without any filtering. The completion time for this run is about seven hours. In the second run, the above rule of thumb has been applied (TL $=23.25$ $/ 3=7.75 \& \mathrm{TH}=2 \mathrm{TL}=15.5)$. The solver stops after almost two hours in this case with only a feasible solution, since no change is obtained in the objective function after several iterations. This solution, however, is very close to the unfiltered solution 
(Row 1). For the next run, the thresholds are rounded up (to 8 and 16). In this case, an optimal solution is obtained after almost 6 hours which is not as good as the feasible solution we got in the previous case, but still acceptable. In the next three steps, the filtering bands are narrowed so that better solutions are obtained. As the calculations demonstrate, tighter thresholds do not necessarily lead to lower runtimes, although such a trend is loosely observed. Specifically, the thresholds in the last row of the table are less restricting than most of other cases, but they provide the fastest runtime for an optimal solution in approximately five hours.

Table 34- Solution for different threshold values

\begin{tabular}{|c|c|c|c|c|c|c|c|c|c|c|c|}
\hline Run & TL & TH & Cost (\$/hr) & $\begin{array}{c}\mathbf{X}_{\mathrm{c}} \\
(\mathrm{MW})\end{array}$ & $\begin{array}{c}X_{g} \\
(M W)\end{array}$ & $\begin{array}{c}X_{n} \\
(M W)\end{array}$ & $\begin{array}{l}\text { Xw } \\
\text { (per } \\
\text { site) }\end{array}$ & $\begin{array}{l}E(X i m) \\
\text { (MWh) }\end{array}$ & $\begin{array}{l}E(X e x) \\
\text { (MWh) }\end{array}$ & $\begin{array}{l}E(X s t) \\
\text { (MWh) }\end{array}$ & Time \\
\hline 1 & 0 & 24 & $\$ 1,622,198$ & 10,000 & 5,000 & 0 & 329 & 266 & 168 & 0.40 & $6: 55: 10$ \\
\hline 2 & 7.75 & 15.5 & $\$ 1,622,407$ & 10,000 & 5,000 & 0 & 323 & 280 & 137 & 0.33 & $1: 50: 07$ \\
\hline 3 & 8 & 16 & $\$ 1,622,479$ & 10,000 & 5,000 & 0 & 301 & 364 & 81 & 0.17 & $5: 42: 27$ \\
\hline 4 & 7 & 17 & $\$ 1,622,398$ & 10,000 & 5,000 & 0 & 327 & 264 & 152 & 0.39 & $6: 17: 52$ \\
\hline 5 & 6 & 18 & $\$ 1,622,398$ & 10,000 & 5,000 & 0 & 327 & 264 & 152 & 0.39 & $6: 31: 17$ \\
\hline 6 & 5 & 19 & $\$ 1,622,398$ & 10,000 & 5,000 & 0 & 327 & 279 & 168 & 0.39 & 6:08:56 \\
\hline 7 & 5 & 18 & $\$ 1,622,398$ & 10,000 & 5,000 & 0 & 327 & 265 & 153 & 0.39 & $5: 09: 13$ \\
\hline
\end{tabular}

Furthermore, it should be noted that this heuristics generally provides a more conservative solution since it limits utilization of available recourses (through reducing the number of scenarios and filtering). Therefore, in reality, costs will be lower (compared to heuristics solution of course) and system will operate with a higher reliability. This behavior is demonstrated in Table 35 for four wind farms. The first row indicates the original solution (last row from Table 16). In the second run, the scenario reduction approach is used which provides an instant solution in less than 
a second. Except for the nuclear power plant capacity, which has a very low value even in the original solution, other variables are reasonably accurate considering the lightning fast runtime. The objective function, on the other hand, is only about $0.2 \%$ off. Better yet, when we plug this solution (for plant capacity variables only) in the original formulation, the objective function gap falls below $0.1 \%$. This result is shown in the third row of the table.

Table 35- Comparison of original solution with heuristics for four wind farms

\begin{tabular}{|l|c|c|c|c|c|c|c|c|}
\hline Case & Cost $(\$ / \mathbf{h r})$ & $\begin{array}{c}\mathbf{X}_{\mathbf{c}} \\
(\mathbf{M W})\end{array}$ & $\begin{array}{c}\mathbf{X}_{\mathbf{g}} \\
(\mathbf{M W})\end{array}$ & $\begin{array}{c}\mathbf{X}_{\mathbf{n}} \\
(\mathbf{M W})\end{array}$ & $\begin{array}{c}\mathbf{X w} \\
(\text { per site) }\end{array}$ & $\begin{array}{c}\mathbf{E}(\mathbf{X i m}) \\
(\mathbf{M W h})\end{array}$ & $\begin{array}{c}\mathbf{E}(\mathbf{X e x}) \\
(\mathbf{M W h})\end{array}$ & Time \\
\hline Original & $\$ 1,620,166$ & 10,000 & 5,000 & 549 & 586 & 451 & 250 & $0: 47: 48$ \\
\hline $\begin{array}{l}\text { Scenario } \\
\text { reduction }\end{array}$ & $\$ 1,623,776$ & 10,000 & 5,000 & 168 & 674 & 673 & 324 & $0: 00: 01$ \\
\hline $\begin{array}{l}\text { Original with } \\
\text { SR variables }\end{array}$ & $\$ 1,621,137$ & 10,000 & 5,000 & 168 & 674 & 515 & 187 & $0: 39: 30$ \\
\hline
\end{tabular}

\section{4. $\quad$ Heuristics Summary}

The proposed heuristics is composed of two components. The first component is the scenario reduction module where the scenario set size for each wind farm is reduced to only three members. Two scenarios are immediately defined: Zero production and production at the rated power. Consequently, the probability of the third scenario is known as well (since they should add up to 1). The generation rate for the third scenario should be assigned in such a way that the solution for a single wind farm is sufficiently accurate. This is generally accomplished when the original capacity factor is not greatly disturbed.

The second component of this heuristics is the variable reduction module which filters the second stage variables with no or little effect. In other words, this process 
eliminates those recourse variables that are less likely to be used. The filtering is based on the power generation rates of corresponding scenarios and can be adjusted to cover greater or smaller number of variables. Generally, wider filtering results in faster solutions at the expense of accuracy.

In brief, the heuristic algorithm for solving a larger problem can be described as follows:

1- Replace the reduced scenario set in the model:

a. Scenario 1: $\quad \mathrm{P}_{1}=\mathrm{P}\left(\mathrm{V} \leq \mathrm{V}_{\mathrm{ci}}\right)$

$$
\mathrm{R}_{1}=0
$$

b. Scenario 2: $\quad P_{2}=P\left(V \geq V_{r}\right)$

$$
\mathrm{R}_{2}=\mathrm{P}_{\mathrm{r}}
$$

c. Scenario 3: $\quad \mathrm{P}_{3}=1-\mathrm{P}_{2}-\mathrm{P}_{1}$

$$
\mathrm{R}_{3}=\left(\mathrm{CF}-\mathrm{P}_{2}\right) / \mathrm{P}_{3} * \mathrm{P}_{\mathrm{r}}
$$

2- For verification, run the model for a single wind farm and make adjustment to $\mathrm{R}_{3}$ if necessary.

3- Add the filtering constraints 7.2, 7.3, 7.4 and 7.5 and assign low production and high production threshold values (TL \& TH). The lower third and the upper third of power generation spectrum generally work well for this classification. If higher precision is required or a greater computational capacity is available, the filtering bands shall be narrowed (e.g. to lower and upper quarters).

As demonstrated in the previous section, the two components work well together and expand the computational capability of the model when dealing with larger problems. 


\section{Concluding Remarks}

\subsection{Conclusions}

The solutions and sensitivity analysis results confirm that the model is behaving rationally in a variety of circumstances. Some of the observations made through this model are summarized below:

1- Maintaining very high levels of reliability (close to $100 \%$ ) involves incurring huge additional costs and minimal use of stochastic power generation sources.

2- Enactment of policies for protection of the environment such as carbon emission limitations can play an important role in promoting eco-friendly technologies for power generation.

3- As a general conclusion, it can be stated that the ability of stochastic supply resources in satisfying demand at high reliability levels is limited. In other words, insisting on utilization of stochastic resources under such circumstances will result in very high procurement costs or problem infeasibility.

4- The average wind speed is a very important factor in determining the optimal wind power capacity for a location. Based on our model, a difference of $1 \mathrm{~m} / \mathrm{s}$ in this parameter could justify installation of more than $1 \mathrm{GW}$ of wind power capacity in a location and result in exclusion of wind power generation in another site.

5- Turbine specifications also play an important role in wind power generation economics by modifying the capacity factor. The rated speed has the greatest 
influence on this parameter followed by cut-in wind speed. The impact of cutout wind speed was found to be the smallest.

6- Unit cost of wind generated electricity is another factor which influences the optimal capacity of a wind farm. Since wind is not a reliable source of energy, it should be more affordable than other reliable alternatives in order to earn a share in energy procurement. Fortunately, as a result of recent developments in this technology as well as acknowledgement and awareness of environmental costs, wind power is becoming economically competitive in many parts of the world.

7- We observed that the existence of a recourse action (second stage variable) even at a high price, generally provides a more efficient and economical way for dealing with uncertainty compared to first stage decision variables.

8- Additionally, availability of energy transmission and energy storage capabilities at reasonable prices will favor higher capacities of wind power generation in the network. As logically expected, energy importation is more frequently utilized at lower prices whereas energy exportation generally happens at higher prices.

9- Energy storage has a narrow utilization margin with respect to its price since it is an expense incurred on top of production costs. Furthermore, it is mainly utilized when there is an abundance of power production surplus and most of the energy exportation capacity has already been used. In other words, energy transmission is generally a more economical approach for dealing with power production surplus compared to energy storage at the current cost structure. 
10- Addition of multiple wind farms with independent wind speed distributions can increase the share of wind power capacity in power production and result in cost savings.

\section{2. $\quad$ Future Work}

Some ideas for continuation and extension of this work can be summarized as follows:

1- As discussed in the literature review, wind energy and solar power can complement one another. Concurrent use of these two renewable sources of energy has attracted a lot of attention in recent years. This model can be extended to include solar power generation by considering sun radiation scenarios. The correlation between sun radiation and wind speeds can also be considered in these scenarios (A negative correlation is expected since sunny days are generally less windy compared to cloudy days.).

2- Additional network constraints can be added to the model. For example, a lower bound on the expected quantity of satisfied demand could be introduced in the formulation. This constraint would ensure that supply deficits remain localized and major outages affecting large number of customers are restricted (In current form of formulation, the margin by which the reliability constraint is violated in a scenario is of no significance.)

3- The formulation can be extended to model the interaction among multiple utility networks. This would allow for a more realistic simulation of energy exchange among separate grid systems considering local demand distributions, generation capacities and network constraints at each location. 


\section{References}

[1] Akdağ, S., \& Güler, Ö. (2010). Comparison of wind turbine power curve models. Sousse, Tunisia: International Renewable Energy Congress.

Albadi, M. H., \& El-Saadany, L. F. (2010). Optimum turbine-site matching. Energy, 35(9), 3593-3602.

American Solar Energy Society. (2007). Tackling Climate Change in the U.S. Boulder: American Solar Energy Society.

Archer, C. L., \& Jacobson, M. Z. (2005). Evaluation of global wind power. Journal of Geophysical Research, D12110, doi:10.1029/2004JD005462.

Archer, C. L., \& Jacobson, M. Z. (2007). Supplying Baseload Power and Reducing Transmission Requirements by Interconnecting Wind Farms. Journal of Applied Meteorology and Climatology, Vol 46,DOI: 10.1175/2007JAMC1538.1.

BBC. (2013). Standard grade Bitesize Physics- Generation of electricity. Retrieved January 31, 2013, from http://www.bbc.co.uk/bitesize/standard/physics/energy_matters/generation_of electricity/revision/3/

Betz, A. (1966). Introduction to the Theory of Flow Machines. Oxford: Pergamon Press.

Billinton, R., \& Bai, G. (2004). Generating Capacity Adequacy Associated With Wind Energy. IEEE TRANSACTIONS ON ENERGY CONVERSION, 19(3), 641-.

Billinton, R., \& Karki, R. (2001). Maintaining supply reliability of small isolated power systems using renewable energy. IEE Proceedings- Generation, Transmission and Distribution, 148(6), 530-534.

Birge, J. R., \& Louveaux, F. (1997). Introduction to Stochastic Programming (1st ed.). New York: Springer.

Bonsor, K. (2001). How hydropower plants work. Retrieved January 31, 2013, from http://science.howstuffworks.com/environmental/energy/hydropowerplant1.htm

BP. (2006). Statistical Review of World Energy.

California Energy Commission. (2012). Chapter16: Wind Energy. Retrieved January 31, 2013, from http://www.energyquest.ca.gov/story/chapter16.html

Conejo, A. J., Carrion, M., \& Morales, J. M. (2010). Decision making under uncertainty in electricity markets. New York: Springer.

Cramton, P., \& Ockenfels, A. (2011). Economics and design of capacity markets for the power sector. Zeitschrift für Energiewirtschaft, 1-22.

Creti, A., \& Fabra, N. (2003). Capacity markets for electricity.

Davies, M., \& Paterson, R. (1962). Phase unbalance in low-voltage distribution systems. Proceedings of the IEE - Part A: Power Engineering, 109, 535-541.

Dialynas, E. N., \& Machias, A. V. (1989). Dialynas, E. N., and A. V. Machias. "Reliability modelling interactive techniques of power systems including wind generating units." Electrical Engineering (Archiv fur Elektrotechnik) 72, no. 1 (1989): 33-41. Electrical Engineering (Archiv fur Elektrotechnik), 72(1), 3341. 
Dialynas, E. N., \& Machias, A. V. (1989). Reliability modelling interactive techniques of power systems including wind generating units. Electrical Engineering (Archiv fur Elektrotechnik), 72(1), 33-41.

Enerdata. (2011). World energy use in 2010: over 5\% growth. Enerdata Publication.

EWEA. (2009). Wind Energy - The Facts. London: Routledge .

$\mathrm{Fu}$, M. C. (2002). Optimization for Simulation:Theory vs. Practice. INFORMS Journal on Computing, 14(3), 192-215.

Giorsetto, P., \& Utsurogi, K. F. (1983). Development of a new procedure for reliability modeling of wind turbine generators. IEEE Transactions on Power Apparatus and Systems, PAS-102(1), 134-143.

Herman, R., \& Kritzinger, J. (1993). The statistical description of grouped domestic electrical load currents. Electric Power Systems Research, 27(1), 43-48.

IEA Renewable Energy Working Party. (2002). Renewable Energy in to the Mainstream. SITTARD: IEA Renewable Energy Working Party.

IEA-ETSAP \& IRENA. (2012). Energy Storage. IEA-ETSAP \& IRENA.

Karki, R. (2004). Wind power in power generation planning. Canadian Conference on Electrical and Computer Engineering, 1511-1514.

Karki, R., Hu, P., \& Billinton, R. (2006). A Simplified Wind Power Generation Model for Reliability Evaluation. IEEE TRANSACTIONS ON ENERGY CONVERSION, 21(2), 533-540.

Karki, R., \& Billinton, R. (2004). Cost-Effective Wind Energy Utilization for Reliable Power Supply. IEEE TRANSACTIONS ON ENERGY CONVERSION, 19(2), 435-440.

Levitan, D. (2010). Rising Hopes that Electric Cars Can Play a Key Role on the Grid. Retrieved December 12, 2012, from http://e360.yale.edu/feature/rising_hopes_that_electric_cars_can_play_a_key_ role_on_the_grid/2328/

Lu, L., Yang, H., \& Burnett, J. (2002). Investigation on wind power potential on Hong Kong islands - an analysis of wind power and wind turbine characteristics. Renewable Energy, 27(1), 1-12.

Lu, X., McElroy, M. B., \& Kiviluoma, J. (2009). Global potential for wind-generated electricity. Proceedings of the National Academy of Sciences of the United States of America, 106(27), 10933-10938.

Marland, G. T. (2007). Global, Regional, and National CO2 Emissions. In Trends: A Compendium of Data on Global Change. Oak Ridge: Carbon Dioxide Information Analysis Center, Oak Ridge National Laboratory, United States Department of Energy.

McQueen, D., Hyland, P. R., \& Watson, S. (2004). Monte Carlo simulation of residential electricity demand for forecasting maximum demand on distribution networks. IEEE Transactions on Power Systems, 19(3), 16851689.

NREL. (2012). Wind maps. Retrieved February 2, 2013, from http://www.nrel.gov/gis/wind.html

Omegatron. (2007). World energy consumption. Retrieved Jan 2012, from Wikimedia:

http://en.wikipedia.org/wiki/File:World_energy_usage_width_chart.svg 
PelaFlow Consulting. (n.d.). Wind turbine power curves. Retrieved January 17, 2013, from http://www.wind-power-program.com/turbine_characteristics.htm

PJM. (2013). Historical metered load data. Retrieved February 2, 2013, from http://www.pjm.com/markets-and-operations/ops-analysis/historical-loaddata.aspx

Swedish Energy Agency. (2010). Energy in Sweden 2010, Facts and Figures. Swedish Energy Agency.

The Wind Power. (2013). Technical data about Avantis AV 928 wind turbine. Retrieved February 03, 2013, from http://www.thewindpower.net/turbine_technical_en_75_avantis_av-928.php

U.S. DOE. (2011). Power Tower Systems for Concentrating Solar Power. Retrieved January 31, 2013, from http://www.eere.energy.gov/basics/renewable_energy/power_tower.html

U.S. DOE. (2012). Geothermal technologies office. Retrieved January 31, 2013, from http://www1.eere.energy.gov/geothermal/powerplants.html

U.S. Energy Information Administration. (2013). Annual energy outlook 2013 early release. Retrieved January 31, 2013, from http://www.eia.gov/forecasts/aeo/er/early_elecgen.cfm

UN. (2009). World Population Prospects: The 2008 Revision, Highlights. New York: United Nations, Department of Economic and Social Affairs, Population Division (2009).

US EIA. (2012). Annual Energy Outlook 2012. Washington, D.C.: U.S. Department of Energy.

US EPA. (2012). Air emissions. Retrieved February 1, 2013, from http://www.epa.gov/cleanenergy/energy-and-you/affect/air-emissions.html

USEIA. (2011). Energy Explained. Retrieved January 30, 2013, from http://www.eia.gov/energyexplained/

USEIA. (2012). Monthly Energy Review (March 2012). Washington, D.C.: US Energy Information Administration.

Wachter, B. D. (2006, 10 9). Wind farm with battery storage in Ireland. Retrieved 10 5, 2011, from Leonardo Energy: http://www.leonardoenergy.org/drupal/node/959

Wiik, J., Gjerde, J. O., Gjengedal, T., \& Gustafsson, M. (2002). Wiik, J., Gjerde, J. O., GjenSteady state power system issues when planning large wind farms. Power Engineering Society Winter Meeting, 1, 366-371.

Wu, J., Li, G., Cheng, L., \& Sun, Y. (2006). Calculation of maximum injection power of large-scale wind farms connected to power systems. International Conference on Power System Technology, 1-4.

WWEA. (2011). World Wind Energy Report 2010. Bonn: WWEA Head Office.

Xiaoqing, H., \& Yong, Y. (2009). Wind power penetration limit calculation based on power system reliability. International Conference on Sustainable Power Generation and Supply, 1-4.

Zhao, M., Chen, Z., \& Blaabjerg, F. (2006). Probabilistic capacity of a grid connected wind farm based on optimization method. Renewable energy, 31(13), 21712187. 